\title{
Psychosocial interventions for reducing fatigue during cancer treatment in adults (Review)
}

Goedendorp MM, Gielissen MFM, Verhagen CAHHVM, Bleijenberg G

Goedendorp MM, Gielissen MFM, Verhagen CAHHVM, Bleijenberg G.

Psychosocial interventions for reducing fatigue during cancer treatment in adults.

Cochrane Database of Systematic Reviews 2009, Issue 1. Art. No.: CD006953.

DOI: 10.1002/14651858.CD006953.pub2.

www.cochranelibrary.com 
HEADER

ABSTRACT

PLAIN LANGUAGE SUMMARY

SUMMARY OF FINDINGS

BACKGROUND

OBJECTIVES

METHODS

RESULTS

DISCUSSION

AUTHORS' CONCLUSIONS

ACKNOWLEDGEMENTS

REFERENCES

CHARACTERISTICS OF STUDIES

ADDITIONAL TABLES

APPENDICES

WHAT'S NEW

CONTRIBUTIONS OF AUTHORS

DECLARATIONS OF INTEREST

SOURCES OF SUPPORT

INDEX TERMS

\section{TABLE OF CONTENTS}

1

1

2

3

7

7

8

10

15

16

17

18

24

48

55

55

56

56

56

56 
[Intervention Review]

\section{Psychosocial interventions for reducing fatigue during cancer treatment in adults}

Martine Margaretha Goedendorp1, Marieke FM Gielissen²,3, Constantijn AHHVM Verhagen4, Gijs Bleijenberg2

1Department of Health Psychology, University Medical Center Groningen, University of Groningen, Groningen, Netherlands. 2Expert Center for Chronic Fatigue, Radboud University Medical Center, Nijmegen, Netherlands. ${ }^{3}$ Department of Medical Psychology, Radboud University Medical Centre, Nijmegen, Netherlands. ${ }^{4}$ Department of Medical Oncology, Radboud University Medical Center, Nijmegen, Netherlands

Contact address: Martine Margaretha Goedendorp, Department of Health Psychology, University Medical Center Groningen, University of Groningen, Groningen, Netherlands. m.m.goedendorp@umcg.nl.

Editorial group: Cochrane Pain, Palliative and Supportive Care Group.

Publication status and date: Stable (no update expected for reasons given in 'What's new'), published in Issue 3, 2015.

Citation: Goedendorp MM, Gielissen MFM, Verhagen CAHHVM, Bleijenberg G. Psychosocial interventions for reducing fatigue during cancer treatment in adults. Cochrane Database of Systematic Reviews 2009, Issue 1. Art. No.: CD006953. DOI: 10.1002/14651858.CD006953.pub2.

Copyright ( 2015 The Cochrane Collaboration. Published by John Wiley \& Sons, Ltd.

\section{A B S T R A C T}

\section{Background}

Fatigue is a common symptom in cancer patients receiving active treatment. There are a limited number of reviews evaluating interventions for fatigue during active treatment, and they are restricted to patients with advanced cancer, or to patients during radiotherapy. To date there is no systematic review on psychosocial interventions for fatigue during cancer treatment.

\section{Objectives}

To evaluate if psychosocial interventions are effective in reducing fatigue in cancer patients receiving active treatment for cancer, and which types of psychosocial interventions are the most effective.

\section{Search methods}

In September 2008 we searched the Cochrane Central Register of Controlled Trials (CENTRAL) (The Cochrane Library), PUBMED, MEDLINE, EMBASE, CINAHL and PsycINFO, and checked the reference lists.

\section{Selection criteria}

Randomised controlled trials (RCTs) were included which evaluated psychosocial interventions in adult cancer patients during treatment, with fatigue as an outcome measure.

\section{Data collection and analysis}

Three review authors independently extracted data from the selected studies, and assessed the methodological quality using several quality rating scales and additional criteria.

\section{Main results}

Twenty-seven studies met the inclusion criteria with a total of 3324 participants, and seven studies reported significant effects of the psychosocial intervention on fatigue. In three studies the effect was maintained at follow-up. The quality of the studies was generally moderate. Effect sizes varied between 0.17 to 1.07. 
The effectiveness of interventions specific for fatigue was significantly higher (80\%) compared to interventions not specific for fatigue (14\%). In five studies the interventions were specifically focused on fatigue, with four being effective. The five interventions were brief, consisting of three individual sessions, provided by (oncology) nurses. In general, during these interventions participants were educated about fatigue, were taught in self-care or coping techniques, and learned activity management.

Of the remaining 22 studies only three were effective in reducing fatigue, and these interventions had a more general approach. These interventions were aimed at psychological distress, mood and physical symptoms, and varied strongly in duration and content.

\section{Authors' conclusions}

There is limited evidence that psychosocial interventions during cancer treatment are effective in reducing fatigue. At present, psychosocial interventions specifically for fatigue are a promising type of intervention. However, there is no solid evidence for the effectiveness of interventions not specific for fatigue. Most aspects of the included studies were heterogeneous, and therefore it could not be established which other types of interventions, or elements were essential in reducing fatigue.

\section{PLAIN LANGUAGE SUMMARY}

\section{The effect of psychosocial interventions on fatigue during cancer treatment in adults}

There is limited evidence that psychosocial interventions are effective in reducing fatigue during active treatment in cancer patients. Most promising are psychosocial interventions specifically designed to treat fatigue. In general, during these interventions patients were educated about fatigue, were taught in self-care or coping techniques, and learned to manage their activity. Interventions that did not focus on fatigue were rarely effective in reducing fatigue. 


\section{SUMMARY OF FINDINGS}

Summary of findings for the main comparison. Effective studies

\begin{tabular}{|c|c|c|c|c|c|c|c|c|c|}
\hline $\begin{array}{l}\text { At Intervention } \\
\text { th }\end{array}$ & Duration & Patients & $\begin{array}{l}\text { QufResults } \\
\text { i-(to- } \\
\text { tytal) } \\
(0-25)\end{array}$ & $\begin{array}{l}\text { In- } \\
\text { stru- } \\
\text { ments }\end{array}$ & $\begin{array}{l}\text { Fatigue } \\
\text { scores } \\
\text { stmean } \\
\text { (s.d.) To }\end{array}$ & $\begin{array}{l}\text { Fatigue } \\
\text { scores } \\
\text { mean } \\
\text { (s.d.) T1 }\end{array}$ & $\begin{array}{l}\text { Fa- } \\
\text { tigue } \\
\text { scores } \\
\text { mean } \\
\text { (s.d.) } \\
\text { T2 }\end{array}$ & $\begin{array}{l}\text { Fatf- } \\
\text { tigendt } \\
\text { s scaizes } \\
\text { mpeast- } \\
\text { (sid=) } \\
\text { T3er- } \\
\text { ven- } \\
\text { tion } \\
\text { (T1) }\end{array}$ & $\begin{array}{l}\text { Ef- Ef- } \\
\text { fect fect } \\
\text { s size size } \\
\text {-fol- fol- } \\
\text { low-upw-up } \\
\text { (T2) (T3) }\end{array}$ \\
\hline $\begin{array}{l}\text { Ar A brief behaviorally ori- } \\
2 C \text { ented intervention for } \\
\text { cancer-related fatigue, } \\
\text { given by one nurse (the } \\
\text { first author). }\end{array}$ & $\begin{array}{l}\text { Three individual, face-to- } \\
\text { face, } 60 \text { minute sessions at } \\
3 \text { to } 4 \text { weekly intervals (coin- } \\
\text { ciding with chemotherapy). }\end{array}$ & $\begin{array}{l}\text { Cancer pa- } \\
\text { tients who } \\
\text { were at- } \\
\text { tending for } \\
\text { chemothera- } \\
\text { py treatment. }\end{array}$ & $\begin{array}{l}160 \mathrm{An} \text { interaction between group } \\
\text { and time for MFI-fatigue, }(\mathrm{P}= \\
\text { 0.03). }\end{array}$ & $\begin{array}{l}\text { MFI } \\
\text { phys- } \\
\text { ical } \\
\text { fa- } \\
\text { tigue. }\end{array}$ & $\begin{array}{l}\text { EG } 15,4 \\
(3,7) C G \\
15,2(3,7) \\
(N A)\end{array}$ & $\begin{array}{l}\text { EG } 14,3 \\
(4,6) \text { CG } \\
14,6(3,6)\end{array}$ & $\begin{array}{l}E G \\
12,3 \\
(4,5) \\
C G \\
14,7 \\
(3,3)\end{array}$ & $\begin{array}{l}E G 1 \\
10,2 \\
(40,6) \\
C G \\
13,5 \\
(4,2)\end{array}$ & $\begin{array}{l}\text { T2=0,63=0,7 } \\
\text { (MFI (MFI } \\
\text { phys-phys- } \\
\text { i- i- } \\
\text { cal cal } \\
\text { fa- fa- } \\
\text { tiguetigue) } \\
\text { (fol- (fol- } \\
\text { low-upw-up } \\
\text { pe- pe- } \\
\text { ri- ri- } \\
\text { od od } \\
4 \quad 9 \\
\text { weeks).onth } \\
\quad \text { af- } \\
\quad \text { ter } \\
\text { re- } \\
\text { cruit- } \\
\text { ment) }\end{array}$ \\
\hline $\begin{array}{l}\mathrm{B} \text { : ECAM intervention for } \\
\text { se cancer related fatigue. } \\
\text { vi } \\
2 \mathrm{C}\end{array}$ & $\begin{array}{l}\text { Three } 3 \text { telephone sessions } \\
\text { with an oncology nurse, } \\
\text { during the first } 3-5 \text { weeks } \\
\text { of treatment. Duration of } \\
\text { the first two sessions was } 30 \\
\text { minutes, the third session } \\
15 \text { minutes. }\end{array}$ & $\begin{array}{l}\text { Cancer pa- } \\
\text { tients current- } \\
\text { ly beginning } \\
\text { chemothera- } \\
\text { py, radiother- } \\
\text { apy, or both, } \\
\text { intended for } \\
\text { cure. }\end{array}$ & $\begin{array}{l}\text { 1896group-by-time interaction } \\
\text { i.t.t effect was found on GFS ( } P \\
<0.01), \text { SCFS }(P<0.05) \text { and } \\
\text { POMS-F }(<0.05) \text {, examined in } \\
\text { a separate repeated-measures } \\
\text { ANOVA, with cancer treatment } \\
\text { as covariate. After bonferroni } \\
\text { correction }{ }^{+} \text {only GFS was signif- } \\
\text { icant. }\end{array}$ & GFS & $\begin{array}{l}\text { EG 3,3 } \\
(1,8) \text { CG } \\
3,3(1,8)\end{array}$ & $\begin{array}{l}\text { EG } 4,6 \\
(2,2) C G \\
4,6(2,0)\end{array}$ & $\begin{array}{l}E G \\
4,1 \\
(2,2) \\
C G \\
4,7 \\
(2,1)\end{array}$ & $\begin{array}{l}-\mathrm{T} 1 \\
= \\
0\end{array}$ & $\begin{array}{l}\text { T2=0,-28 } \\
\text { (fol- } \\
\text { low-up } \\
\text { pe- } \\
\text { ri- } \\
\text { od } \\
\text { up } \\
\text { to } \\
4 \\
\text { weeks) }\end{array}$ \\
\hline
\end{tabular}




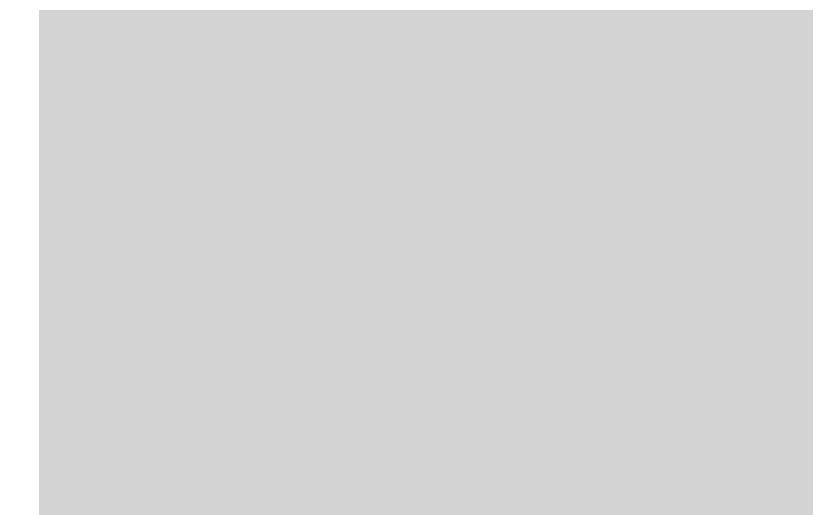

The interventions were conducted by a senior social

tions: cognitive-behav-

iour group, and RGI group. Goal decreasing psychological distress and physical symptoms worker (the first author). Each group of 6-8 participants met weekly, for nine (general approach).

90-minute sessions.

Fc Unstructured individ-

1c ually supportive psychotherapy provided by a psychiatrist (first author), focusing on emotions and physical symptoms (general ap proach)

The 30 minute sessions were given weekly, for 10 weeks ( 4 weeks beyond completion of radiotherapy).

Breast cancer patients,

stages I and II, receiving chemotherapy or radiotherapy.

Cancer patients before they received 6 weeks of ra diotherapy.

Patients with abdominal cancer were excluded.
$(0,72)$ CG

$1,9(0,76)$

$2,5(1,1)$;

2,4

0,17

CG

2,6

$(1,1)$.

\begin{tabular}{llllcl}
\hline SCFS & EG 1,8 & EG 2,4 & EG & - T1 & T2= - \\
& $(0,70)$ CG & $(0,95)$ CG & 2,3 & $=$ & 0,20 \\
$1,8(0,73)$ & $2,4(0,94)$ & $(0,99)$ & 0 &
\end{tabular}

$(1,0)$
131 Rlepeated measures MANOVA

( 3 group $\times 3$ times $\times 6$ variables)

revealed significant group $x$

time effects. For fatigue $\mathrm{P}<$

0.001 . Only the reduction in the

tervention was significant.
RGI group from pre-to post-in-

\begin{tabular}{|c|c|c|c|c|c|}
\hline FSI & $\begin{array}{l}\text { RGI 4,89 } \\
(0,96) \text { CG } \\
4,50(1,30)\end{array}$ & $\begin{array}{l}\text { RGI 3,01 } \\
(1,13) \\
\text { CG 4,32 } \\
(1,31)\end{array}$ & $\begin{array}{l}\text { RGI } \\
2,86 \\
(0,89) \\
\text { CG } \\
3,72 \\
(1,19)\end{array}$ & $\begin{array}{cl}- & \text { RGI } \\
\text { T1 } & \text { T } \\
= & 0 \\
1,07 & \end{array}$ & $\begin{array}{l}\mathrm{RGI} \\
\mathrm{T} 2= \\
0,82\end{array}$ \\
\hline SADS & $\begin{array}{l}\text { EG 3,8 CG } \\
4,0 \text { (s.d. } \\
\text { not report- } \\
\text { ed) }\end{array}$ & $\begin{array}{l}\text { EG } 2,3 \\
\text { CG } 3,3\end{array}$ & $\begin{array}{l}E G \\
3,1 \\
C G \\
3,5\end{array}$ & $\begin{array}{l}-? \quad n \\
\text { (un- } \\
\text { known } \\
\text { s.d.) }\end{array}$ & n.s. - \\
\hline
\end{tabular}

11For fatigue a significant effect was found at $\mathrm{T} 1(\mathrm{P}=<0.01)$ found with repeated measures, analysis of variance. No significant effect was found at $\mathrm{T} 2$.

\begin{tabular}{|c|c|c|c|c|c|c|c|c|c|c|}
\hline \multirow{2}{*}{\multicolumn{2}{|c|}{$\begin{array}{l}\text { Re The supportive interven- } \\
2 C \text { tion for fatigue was pro- } \\
\text { vided by a cancer nurse } \\
\text { who visited individual } \\
\text { patients at home. }\end{array}$}} & \multirow[t]{2}{*}{$\begin{array}{l}\text { Three sessions, over the first } \\
3 \text { treatment cycles, duration } \\
\text { not described. }\end{array}$} & \multirow[t]{2}{*}{$\begin{array}{l}\text { Cancer pa- } \\
\text { tients during } \\
\text { chemothera- } \\
\text { py. }\end{array}$} & \multirow[t]{2}{*}{$\begin{array}{l}\text { 140 os gnificant results on t-test for } \\
\text { between-group differences } \\
\text { post intervention. VAS P }=0.04 \text {, } \\
\text { SF36 } \mathrm{P}=<0.05 \text {. }\end{array}$} & VAS & $\begin{array}{l}E G 38,8 \\
(28,9) C G \\
42,6(28,8) \\
P=0.51\end{array}$ & $\begin{array}{l}\text { EG } 30,6 \\
(27,7) \\
\text { CG } 41,6 \\
(29,4)\end{array}$ & - & $\begin{array}{l}-\mathrm{T} 1 \\
= \\
0,39\end{array}$ & - \\
\hline & & & & & $\begin{array}{l}\text { SF36 } \\
\text { vi- } \\
\text { tal- } \\
\text { ity }\end{array}$ & $\begin{array}{l}\text { Mean rank } \\
\text { EG } 46,3 \text { CG } \\
42,6 \mathrm{P}= \\
0.53\end{array}$ & $\begin{array}{l}\text { EG } 47,1 \\
\text { CG } 38,2\end{array}$ & - & $\begin{array}{l}-? \\
\text { (un- } \\
\text { known } \\
\text { s.d.) }\end{array}$ & - \\
\hline $\begin{array}{l}\text { SF } \\
1 \mathrm{C}\end{array}$ & $\begin{array}{l}\text { Psychological support } \\
\text { groups ( } 3 \text { groups). Each } \\
\text { group had two leaders, }\end{array}$ & $\begin{array}{l}\text { The groups met weekly for } \\
11 / 2 \text { hours, during at least } \\
\text { one year. }\end{array}$ & $\begin{array}{l}\text { Patients with } \\
\text { metastatic } \\
\text { breast cancer }\end{array}$ & $\begin{array}{l}98 \text { 8ศor fatigue a significant effect } \\
\text { was found after one year (com- } \\
\text { pleters) } P<0.05 \text {. Additional }\end{array}$ & POMS & $\begin{array}{l}\text { Slopes: EG: } \\
0,34) \text { CG } 1,5 \\
0,45)\end{array}$ & $\begin{array}{l}\text { 1,06 (s.e.m } \\
\text { (s.e.m. }\end{array}$ & - & $\begin{array}{l}-? \\
\text { (no } \\
\text { mean }\end{array}$ & - \\
\hline
\end{tabular}




\begin{tabular}{|c|c|c|c|c|c|c|c|c|c|}
\hline & $\begin{array}{l}\text { a psychiatrist or a social } \\
\text { worker and a counsellor. } \\
\text { (general approach). }\end{array}$ & & & $\begin{array}{l}\text { slope analysis of patients who } \\
\text { completed two assessments, } \\
\text { showed a significant effect }(\mathrm{P}< \\
0.01) \text {. }\end{array}$ & & & & & $\begin{array}{l}\text { and } \\
\text { s.d. } \\
\text { de- } \\
\text { scribed) }\end{array}$ \\
\hline \multirow[t]{4}{*}{$\begin{array}{l}\text { Ya } \\
2 C\end{array}$} & \multirow[t]{4}{*}{$\begin{array}{l}\text { An individual psycho ed- } \\
\text { ucational intervention } \\
\text { for fatigue, given by an } \\
\text { oncology nurse. }\end{array}$} & \multirow[t]{4}{*}{$\begin{array}{l}\text { Three sessions. The first ses- } \\
\text { sion, was a face to face con- } \\
\text { tact of } 20 \text { minutes, the sec- } \\
\text { ond and third session was } \\
\text { a telephone call of } 10 \text { min- } \\
\text { utes. The intervention was } \\
\text { given at the start of the sec- } \\
\text { ond cycle of chemothera- } \\
\text { py with one week between } \\
\text { each session. }\end{array}$} & \multirow[t]{4}{*}{$\begin{array}{l}\text { Women } \\
\text { receiving } \\
\text { adjuvant } \\
\text { chemother- } \\
\text { apy for early } \\
\text { stage breast } \\
\text { cancer (stage } \\
\text { I \& II). }\end{array}$} & \multirow[t]{4}{*}{$\begin{array}{l}1710 \mathrm{n} 4 \text { of the } 6 \text { fatigue measures } \\
\text { a significant effect was found } \\
\text { at T1. (Analysis of covariance of } \\
\text { the change scores controlling } \\
\text { for baseline values). Follow-up } \\
\text { measures were not significant. }\end{array}$} & $\begin{array}{l}\text { NFRS } \\
\text { fa- } \\
\text { tigue } \\
\text { at } \\
\text { worst } \\
\text { in } \\
\text { the } \\
\text { past } \\
\text { week. }\end{array}$ & $\begin{array}{l}\text { EG } 2,6 \\
(3,0) C G \\
1,8(2,5)\end{array}$ & $\begin{array}{l}\text { EG 3,5 } \\
(3,2) \text { CG } \\
4,5(3,1)\end{array}$ & - & $\begin{array}{l}-\mathrm{T} 1 \quad \text { n.s. }- \\
= \\
0,32\end{array}$ \\
\hline & & & & & $\begin{array}{l}\text { NFRS } \\
\text { av- } \\
\text { er- } \\
\text { age } \\
\text { fa- } \\
\text { tigue } \\
\text { in } \\
\text { the } \\
\text { past } \\
\text { week. }\end{array}$ & $\begin{array}{l}\text { EG } 2,0 \\
(2,5) C G \\
1,2(1,7)\end{array}$ & $\begin{array}{l}\text { EG 2,9 } \\
(2,8) \text { CG } \\
3,5(2,5)\end{array}$ & - & $\begin{array}{l}-\mathrm{T} 1 \quad \text { n.s. - } \\
= \\
0,22\end{array}$ \\
\hline & & & & & $\begin{array}{l}\text { PFS } \\
\text { sub- } \\
\text { scale } \\
\text { fa- } \\
\text { tigue } \\
\text { sever- } \\
\text { ity. }\end{array}$ & $\begin{array}{l}\text { EG } 1,8 \\
(2,6) \text { CG } \\
0,9(1,4)\end{array}$ & $\begin{array}{l}\text { EG 2,7 } \\
(3,0) \text { CG } \\
3,6(3,0)\end{array}$ & - & $\begin{array}{l}-\mathrm{T} 1 \\
= \\
0,30\end{array}$ \\
\hline & & & & & $\begin{array}{l}\text { FACT- } \\
F\end{array}$ & $\begin{array}{l}\text { EG } 1,1 \\
(0,3) C G \\
1,0(0,4)\end{array}$ & $\begin{array}{l}\text { EG } 1,1 \\
(0,4) C G \\
1,3(0,6)\end{array}$ & - & $\begin{array}{c}-\mathrm{T} 1=\text { n.s. } \\
0,39\end{array}$ \\
\hline
\end{tabular}

* = the instruments and abbreviations are explained in Table 1: Outcomes

Bonferroni correction ${ }^{+}=$This correction is applied for multiple testing. In this study three separate ANOVA's were preformed. Results on all three outcomes significant on a 0.05 level.

After Bonferroni correction (0.05/3) only the result on GFS was significant.

$\mathrm{T} 0$ = pre-intervention, $\mathrm{T} 1$ = post-intervention, $\mathrm{T} 2$ = follow-up, $\mathrm{T} 3=$ second follow-up.

$-=$ not assessed, n.s. = not significant, n.a. = not applicable, S.E.M. = Standard error of the mean.

$\mathrm{EG}=$ experimental group, $\mathrm{CG}=$ control group. 

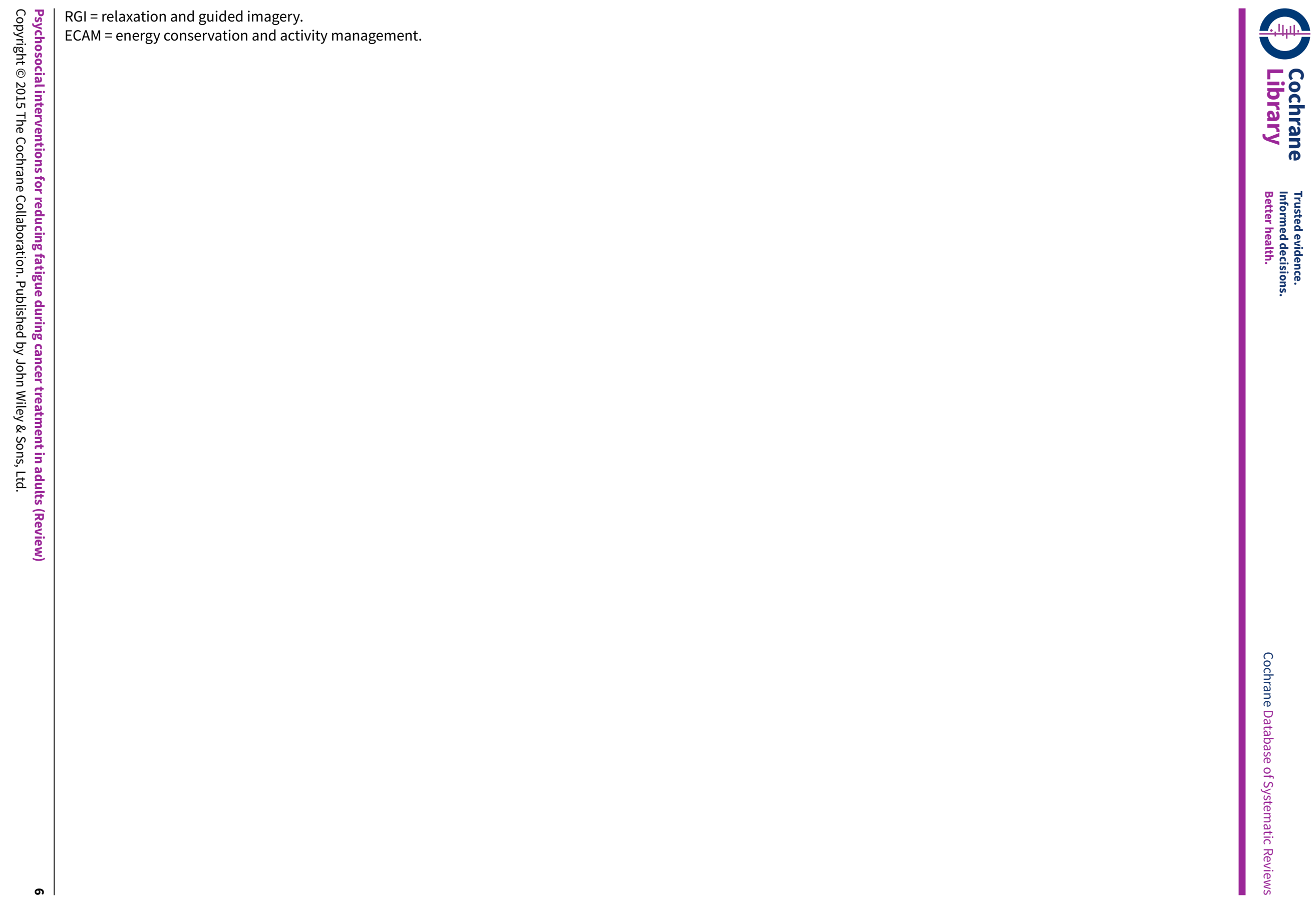


\section{B A C K G R O U N D}

In recent years the treatment of cancer has changed, as more people are treated and an increasing number survive the disease. The primary focus of treatment for cancer is survival, but alongside this the management of symptoms and quality of life of patients are also becoming important. Fatigue is one of the symptoms most commonly reported by cancer patients and is gaining more recognition by oncologists. In addition to this scientific knowledge about fatigue in cancer patients is growing. Fatigue can be described in terms of perceived energy, mental capacity and psychological status (Cella 1998; Portenoy 1999) and is therefore a multidimensional concept. Fatigue is sometimes seen as a continuum, ranging from tiredness to exhaustion (Ahlberg 2003).

Cancer-related fatigue (CRF) is a term that is frequently used. The National Comprehensive Cancer Network (NCCN) defines CRF as a distressing, persistent, subjective sense of physical, emotional and/or cognitive tiredness or exhaustion, related to cancer or cancer treatment that is not proportional to recent activity and interferes with usual functioning (NCCN 2008). Cancer patients can experience fatigue at different stages, for example, during cancer treatment or shortly after finishing treatment. Disease-free cancer patients can also experience fatigue. The prevalence of fatigue during cancer treatment ranges from $25 \%$ to $99 \%$ depending on the sample and on the type of instrument used to measure fatigue (Servaes 2002). After successful cancer treatment, fatigue can still be a problem in up to $38 \%$ of cancer survivors and can persist for many years (Servaes 2002a). It is important to note that the term CRF does not make a distinction between fatigue during cancer treatment, and fatigue after finishing treatment, but covers the whole period.

Efforts to manage fatigue should first focus on identifying and treating the comorbidities that may cause it, for example, anaemia or hypothyroidism. However, often no specific cause for fatigue can be identified in patients during cancer treatment, other than the cancer or the treatment itself. In these situations the management of fatigue usually involves multiple strategies. The strategies are often divided into pharmacological and non-pharmacological interventions.

Minton 2008 reviewed drug therapy for the management of CRF and concluded that erythropoietin and darbopoetin, drugs that improve anaemia, are effective in managing CRF in patients who are anaemic as a result of chemotherapy. However, currently concerns are raised about the safety of these drugs as a series of recent, randomised placebo-controlled clinical trials reported adverse effects including enhanced tumour progression and increased mortality (Bennett 2008; Khuri 2007). Methylphenidate was also effective, but more research is needed to confirm this. No data currently supports the use of paroxetine or progestational steroids for treatment of CRF (Minton 2008). This review included studies that recruited participants at any point of the cancer treatment spectrum. A Cochrane review is also in progress evaluating drugs for the treatment of fatigue in palliative care (Radbruch 2007).

There are an increasing number of studies with exercise as a non-pharmacological intervention for cancer patients. Current literature suggests that exercise is likely to be beneficial, but the latest reviews draw conflicting conclusions about the role of exercise on managing fatigue (Stone 2008). Some reviews concluded that exercise had a positive effect on fatigue (Conn
2006; McNeely 2006) while others found no effect of exercise on fatigue (Jacobsen 2007; Knols 2005; Stevinson 2004). In addition a Cochrane review investigating exercise for fatigue in cancer patients is also now published (Cramp 2008).

All reviews mentioned above were based on studies that included cancer patients during active treatment and disease-free survivors. In the review of Ahlberg 2003 a distinction was made between studies evaluating exercise during cancer treatment and after treatment, and concluded that in all studies the exercise groups had lower levels of fatigue. Contrary to this, the Cochrane review of Markes 2006 concluded that exercise had no effect on fatigue in breast cancer patients during adjuvant therapy.

In recent years more studies have evaluated psychosocial interventions for the management of fatigue. The aim of a psychosocial intervention is to influence or change cognitions, emotions, behaviour, the social environment or a combination of these, with the ultimate goal to decrease fatigue.

Some reviews have included psychosocial interventions as a subgroup for managing fatigue in cancer patients and these interventions have been regarded as some of the more promising treatments, but further research was recommended (Lawrence 2004; Mock 2004). A recent meta-analysis is less positive and concluded that there is limited support for the clinical use for psychological interventions for CRF (Jacobsen 2007). However, these reviews were based on studies that included patients during the whole spectrum of cancer treatment, as well as disease-free survivors.

There are only a limited number of reviews that evaluated interventions for fatigue in patients who received active treatment. These reviews were restricted to certain patient groups, for example to patients with advanced cancer (Barnes 2002), metastatic breast cancer (Edwards 2004), or to patients during radiotherapy (Jacobsen 2003; Jereczek-Fossa 2002).

To date, no systematic review has been published evaluating the effectiveness of psychosocial interventions for fatigue during cancer treatment, which was the goal of this review. In this review we identified studies that tested the effectiveness of psychosocial interventions in randomised controlled trials (RCT). First we described which psychosocial interventions were effective in reducing fatigue, and how strong the effects were by using effect sizes. Secondly, the quality of the studies was evaluated. Finally, the more promising psychosocial interventions for reducing fatigue during cancer treatment are discussed.

\section{O B JECT IVES}

The primary objective was to evaluate if psychosocial interventions are effective in reducing fatigue in cancer patients receiving active treatment for cancer.

The secondary objective was to consider which specific types of psychosocial interventions during cancer treatment are the most effective in reducing fatigue. 


\section{METHODS}

\section{Criteria for considering studies for this review}

\section{Types of studies}

Only RCTs were included in this review. In addition, studies with small sample sizes (less than ten participants) were excluded, as this causes a lack of power to demonstrate the effect of an intervention. This means that when no significant effect of an intervention is found, this doesn't necessarily mean that the intervention is not effective at all. Finding no effect of the intervention can be explained by the small sample size of the studies. Thus the results of these studies can be misinterpreted easily.

\section{Types of participants}

Adult (those aged 16 years and above) cancer patients of either sex, receiving active treatment for cancer, with curative or palliative intention. This review focused only on patients receiving active cancer treatment and not on patients who finished cancer treatment. Although some cancer survivors, specifically breast cancer survivors, continue to receive hormone therapy for several years, in this review this group of survivors was considered as a group who finished the active period of receiving cancer treatment.

\section{Types of interventions}

A broad range of interventions were considered, such as psychotherapy, psycho-education and also interventions containing elements such as; education, cognitive restructuring and changing coping strategies. Interventions focusing on behavioural changes were included, for example; behavioural therapy, self-help or self-care. In addition other intervention types such as; support groups, relaxation, energy conservation, or stress management, and interventions combining psychosocial elements with physical activity were included. Both individual and groupfocused interventions were included.

The psychosocial intervention needed to fulfil the following conditions:

- the interventions involved a systematic treatment consisting of a process between the patient and the person giving the intervention;

- the interventions consisted of at least two contacts between the patient and the care provider who gave the intervention;

- during the intervention a care provider gave the patient some kind of personal feedback concerning the changes they were trying to achieve, for example, in the first session a care provider could advise a patient to change their coping behaviour aiming to reduce fatigue, whilst discussing the progress of the patient and giving feedback on their behaviour in later sessions.

\section{Types of outcome measures}

In the included studies, fatigue was at least one of the outcome measures. Studies were included when fatigue was measured with a questionnaire specifically designed to evaluate fatigue, or other instruments used by authors to evaluate fatigue. For example, fatigue was measured as part of a quality of life instrument, with a visual analogue scale (VAS), or as part of a symptom list and scored as 'present' or 'absent'.

\section{Search methods for identification of studies}

\section{1) Electronic databases}

We searched the Cochrane Central Register of Controlled Trials (CENTRAL) (The Cochrane Library, September 2008), PUBMED (1950 to September 2008), MEDLINE (1966 to September 2008), EMBASE (1980 to September 2008), CINAHL (1982 to September 2008) and PsycINFO (1806 to September 2008).

We identified studies for this review using search strategies based on the MEDLINE (via OVID) strategy set out in Appendix 1, which uses a combination of MeSH and free text terms. MeSH terms were exploded. Terms were searched in the title, abstract, summary, heading or keywords. We applied the Cochrane Collaboration filter for the identification of RCTs, as published in the Cochrane Handbook for Systematic Reviews of Interventions (Higgins 2008). We adjusted the search strategy appropriately for each database searched.

\section{2) Reference search}

We checked the reference lists of relevant articles for additional studies, and applied backward and forward searching to the relevant articles.

\section{3) Journals}

When no digital articles are available, we hand searched the journals.

\section{4) Communications}

We contacted authors of several studies to require additional information.

\section{5) Ongoing studies}

We checked The Australian New Zealand Clinical Trials Registry, the ClinicalTrials.gov registry, the ISRCT register, UMIN Clinical Trials Registry, and the Dutch Trial Register, for ongoing studies. We searched each register for the keywords 'cancer' and 'fatigue', and selected studies that were currently recruiting participants.

There was no language restriction on studies.

\section{Data collection and analysis}

\section{Selection of trials}

One review author (MMG) screened titles and abstracts and eliminated those clearly not relevant to this review. When the title and abstract did not provide all the information concerning the criteria, full paper copies were retrieved and screened. Authors of studies were contacted when additional information was required to assess if the studies met the criteria for inclusion. Three review authors (MMG, MG and GB) screened the remaining studies for their eligibility and discussed in accordance with the above defined criteria, if the studies were included or excluded. Disagreement about the selection of a trial was resolved by consensus. The review authors were already familiar with some of the studies, and therefore the relevant studies were not blinded for assessment.

\section{Quality assessment}

Three review authors (MMG, MG and GB) independently assessed the methodological quality of the selected studies. The RCTs were 
evaluated using a Quality Rating Scale. This scale contained all the criteria of the Oxford Quality Scale (Jadad 1996), the Delphi list (Verhagen 1998) and additional criteria listed by van Tulder 1997. The following aspects of the selected studies were scored to evaluate the methodological quality:

- random assignment;

- losses to follow-up;

- blind analysis;

- intention-to-treat analysis;

- participants adherence;

- adverse effects of the intervention;

- eligibility criteria;

- follow-up measurements;

- power calculation;

- possible differences between the treatment group and the control group, and in the timing of the assessments;

- concealed allocation;

- contamination.

Concealment of allocation was evaluated using the criteria defined in The Cochrane Handbook (Higgins 2008). When nothing was described about concealment of allocation in the studies, concealed allocation was evaluated as 'unclear'. To investigate the effectiveness of an intervention it is important to minimize contamination. Contamination means that patients in the control group get informed about the intervention and its content, and subsequently use this information. When this happens the effect of the intervention itself is harder to demonstrate. To minimize contamination it is advisable to avoid contact between patients in the control condition, and care providers giving the intervention, or other staff informed about the intervention.

Additional aspects were scored to evaluate the quality of the intervention:

- how many care providers gave the intervention;

- if care providers were trained;

- if care providers were supervised;

- if an intervention protocol was used;

- if an integrity check was described.

In most quality rating scales blinding is evaluated on several levels, such as blinding of patients and care providers. These scales are often used to test the quality of placebo-controlled medication studies. However, the nature of RCTs testing psychosocial interventions is different. In these trials it is nearly impossible to blind the patients to the intervention they were assigned to. In addition it is also impossible to blind the care providers to the intervention they are giving to the patients. Thus, blinding of patients and care providers were not scored in the Quality Rating Scale.

The three review authors met to discuss all items of the Quality Rating Scale of the studies, and to reach a final quality score by consensus. The total score of the Quality Rating Scale varied between one and 25 and was divided into three categories. When the total score was between one and nine, the quality was rated as poor, when between ten and 17 as moderate, and when between 18 and 25 as good.

\section{Data extraction}

Three review authors (MMG, MG and GB) independently extracted data from the selected studies using data extraction forms. The data extraction form was designed using listed criteria described by van Tulder 1997, and a scale to evaluate RCTs developed by the EBRO-forum (CBO 2002), and was expanded with necessary information on the psychosocial interventions to be evaluated. Any disagreement was resolved through consensus.

From each selected study the following data was extracted:

\section{Patient characteristics:}

- Demographic characteristics such as age and gender.

- Disease characteristics such as type of cancer, stage of cancer, types and duration of treatment.

\section{Intervention characteristics:}

- Duration of the intervention, total number of sessions and duration of each session.

- The nature and content of the psychosocial intervention.

- The number of care providers and the profession.

- Duration and nature of training and supervision given to the care providers.

- Patient compliance and contamination.

\section{Information on statistics:}

- Number of participants in each arm.

- Duration of short-term follow-up and, if available, long-term follow-up.

- Instruments used, key outcomes and description of missing data.

\section{Data synthesis and effect of psychosocial interventions}

A narrative overview of the included RCTs was provided in this review. We assessed which interventions during cancer treatment were effective in reducing fatigue, and described explanations for the effectiveness where possible. To determine the magnitude of the effect, effect sizes were calculated of the studies that were effective in reducing fatigue. The size of the effect is calculated in a standardized way, and therefore the effect sizes across the various studies can be compared. The effect sizes were calculated by using the means and standard deviations of two groups (experimental group and control group) of the post-intervention or follow-up measurement, in the following way:

Effect size $=M_{1}-M_{2} / \sigma_{\text {pooled }}$

where $\sigma_{\text {pooled }}=\sqrt{ }\left[\left(\sigma_{1}^{2}+\sigma_{2}{ }^{2}\right) / 2\right]$

As the characteristics of the included studies, the instruments, and the interventions were very diverse, we concluded that a metaanalysis or a subgroup analysis was not sensible or appropriate. 


\section{RES U L T S}

\section{Description of studies}

\section{Excluded studies}

The search of the electronic databases retrieved 2210 publications. After eliminating the duplicates 1753 publications were identified for further consideration. After screening the titles and electronic available abstracts 1668 publications were excluded. Reasons for excluding publications were the following:

- studies were no intervention studies, for example studies were reviews, or comments;

- studies evaluated no psychosocial interventions, for example medical treatments, exercise, or massage;

- studies were no RCTs, for example studies did not have a control group, or participants were not randomised;

- studies did not focus on cancer patients or only a part of the sample were cancer patients;

- studies evaluated interventions in cancer patients after finishing cancer treatment;

- fatigue was not assessed as an outcome measure.

After this initial screening, the full-text articles were retrieved of the remaining 85 potential studies. From these full-text articles 56 studies were excluded leaving 29 studies to review. These 56 studies were excluded for the following reasons; 15 studies were excluded because the interventions were given to participants after finishing cancer treatment. One study was excluded because most participants did not receive cancer treatment during the intervention. Five studies did not describe if participants received cancer treatment during the intervention. One study focused on participants receiving colorectal surgery and did not only include cancer patients, but also patients with other types of diseases. Six studies were not RCTs. Two studies had less than ten participants in each condition. In four studies fatigue was not measured and three studies did not describe separate results on fatigue. Nineteen studies identified did not include psychosocial interventions. In two studies the intervention was mainly focused on changing exercise behaviour. In three studies nutritional behaviour was the focus of the intervention and one focused on medication. In 13 studies the interventions were not psychosocial interventions according to our definition described in 'Types of intervention'. The interventions did not consist of a systematic process between the patient and the person giving the intervention. The excluded studies are described in more detail in the 'Characteristics of excluded studies' table.

\section{Ongoing studies}

The search for ongoing studies found eight RCTs that are currently recruiting participants. Three of these studies are evaluating different types of yoga intervention (Cohen 2007a; Cohen 2007b; Oh 2008b). Purcell 2008 is evaluating a group education and support intervention, and Savard 2008 a self help treatment for insomnia. Two studies are evaluating two interventions compared to usual care. Cohen 2004a is evaluating mindfulness relaxation, and music relaxation. Goedendorp 2005 is evaluating cognitive behaviour therapy and a nursing intervention. Cohen 2006 is also evaluating a cognitive behaviour intervention. The ongoing studies are described in more detail in the 'Characteristics of ongoing studies'.

\section{Included studies}

Two remarks should be made with regards to the 29 included studies. In the Sandgren 2003 study the immediate effects of the intervention are described whereas the duplicate study Sandgren 2007 includes the follow-up. Goodwin 2001 and it's duplicate study Bordeleau 2003 described the effects of the same intervention, but presented results on different outcome measures. Therefore these 29 publications were evaluated as 27 separate included studies.

\section{Participants}

\section{Disease characteristics}

A majority of the studies, 13 , focused on patients with one type of malignancy, mainly patients with breast cancer. In eleven studies participants were patients with breast cancer, however, with different stages of cancer. Three studies included breast cancer patients with stages I-II (Cohen 2007; Sandgren 2000; Yates 2005). Sandgren 2003 and Moadel 2007 included patients with stages IIII, and Gaston-Johansson 2000 included patients with stages IIIV. Two studies focused on patients with other types of cancer, such as prostate cancer (Berglund 2007), or malignant melanoma (Fawzy 1995). Six studies included only metastatic cancer patients (Classen 2001; de Moor 2002; Edelman 1999; Goodwin 2001; Savard 2006; Spiegel 1981). Five of these studies included patients with metastatic breast cancer (Classen 2001; Edelman 1999; Goodwin 2001; Savard 2006; Spiegel 1981), and one; patients with metastatic renal cell carcinoma (de Moor 2002).

The remaining studies included cancer patients with more than one diagnosis. Two studies focused on patients with two types of cancer. The first study included patients being treated for prostate or bladder cancer (Faithfull 2001). The second study included patients receiving treatment for gastric or colon cancer (Godino 2006). Rawl 2002 included patients with three different types of cancer: breast, colorectal and lung cancer. Ten studies focused on cancer patients in general and included patients with several types of cancer, such as lymphoma's, breast, lung, colorectal, prostate, gynaecologic, testicular cancer, and other solid tumours (Armes 2007; Barsevick 2004; Brown 2006; Cunningham 1989; Decker 1992; de Wit 1997; Given 2002; Oh 2008; Ream 2006), however, one study excluded patients with abdominal cancer (Forester 1985).

One study explicitly described that patients were treated with curative intent (Barsevick 2004), and Brown 2006 focused on patients with advanced cancer. Eleven studies included cancer patients with various stages of cancer, with or without metastasis (Armes 2007; Cunningham 1989; Decker 1992; de Wit 1997; Faithfull 2001; Forester 1985; Given 2002; Godino 2006; Oh 2008; Rawl 2002; Ream 2006).

\section{Cancer treatment}

All 27 included studies described results of interventions given to patients during cancer treatment. In 15 studies all patients were receiving cancer treatment during the intervention (Armes 2007; Barsevick 2004; Brown 2006; Cohen 2007; Decker 1992; de Moor 2002; Faithfull 2001; Forester 1985; Gaston-Johansson 2000; Given 2002; Godino 2006; Sandgren 2003; Rawl 2002; Ream 2006; Yates 2005). In ten studies most, but not all, patients were receiving active cancer treatment during the intervention (Berglund 2007; Classen 2001; Cunningham 1989; de Wit 1997; Edelman 1999; Fawzy 1995; Goodwin 2001; Moadel 2007; Oh 2008; Sandgren 2000). The percentage of patients receiving active treatment during 
the intervention varied from at least $44 \%$ (Sandgren 2000) to 91\% (de Wit 1997). Edelman 1999, Savard 2006 and Spiegel 1981 did not describe how many patients actually received cancer treatment during the intervention. However, these studies focused on patients with metastatic cancer, and therefore it is expected that these patients would have received treatment sometime during the intervention.

In most studies the interventions were given to patients receiving chemotherapy only (Armes 2007; Given 2002; Godino 2006; Rawl 2002; Ream 2006; Yates 2005), or radiotherapy only (Brown 2006; Decker 1992; Faithfull 2001; Forester 1985). Four studies included participants receiving chemotherapy or radiotherapy (Barsevick 2004; Cohen 2007; Sandgren 2000), or chemotherapy or hormone therapy (Classen 2001). Five studies included participants with several treatment regimes. One study included participants who had surgery, radiotherapy or hormone therapy (Berglund 2007). Five studies included participants receiving chemotherapy, radiotherapy or hormone therapy (Cunningham 1989; Goodwin 2001; Sandgren 2003), or additionally surgery or other treatment (de Wit 1997; Moadel 2007). In one study some participants received chemotherapy, but it is unclear if participants also received other types of treatment (Oh 2008). Three studies focused on other treatments (Fawzy 1995; de Moor 2002; Gaston-Johansson 2000). The first study included patients receiving immunotherapy (Fawzy 1995). The second study focused on patients receiving nephrectomy and vaccine treatment (de Moor 2002) and the third study included patients receiving bone marrow transplantation (Gaston-Johansson 2000).

\section{Other criteria for inclusion}

In two studies the participant sample was strikingly different than the other studies. de Wit 1997 included only participants with cancer related pain, and Savard 2006 focused on depressed metastatic breast cancer patients.

Two studies described inclusion criteria for fatigue. Armes 2007 explicitly described that cancer patients with significant fatigue were included, and Given 2002 included patients reporting both fatigue and pain at baseline. As patients were included during chemotherapy, it is expected that the majority of the patients would experience symptoms at time of accrual.

Most studies described additional exclusion criteria. Participants were excluded for several reasons. Some reasons were cancer or treatment related. Three studies excluded cancer patients with previous (Classen 2001; Fawzy 1995) or other cancer (Berglund 2007). Six studies excluded patients who received previous cancer treatment (Godino 2006), such as chemotherapy (de Moor 2002; Ream 2006), radiotherapy (Decker 1992), cytokine treatment (Armes 2007), or immunotherapy (de Moor 2002). One study excluded patients if their treatment plan included stem cell transplantation, interleukins, interferons, or tumour necrosis factor (Barsevick 2004).

Other additional criteria were also described. Most studies excluded cancer patients with other comorbidities (Armes 2007; Barsevick 2004; Berglund 2007; Classen 2001; de Moor 2002; Edelman 1999; Godino 2006; Goodwin 2001; Oh 2008; Sandgren 2003), or current or a history of psychiatric illnesses (Armes 2007; Berglund 2007; Brown 2006; Cohen 2007; Decker 1992; Decker 1992; Fawzy 1995; Godino 2006; Goodwin 2001; Oh 2008; Ream 2006;
Savard 2006). Eight studies excluded cancer patients involved in intervention studies (Barsevick 2004; Brown 2006), or other types of care programs (Savard 2006), such as support groups (Berglund 2007; Goodwin 2001), attending yoga (Moadel 2007) or medical qigong (Oh 2008), or receiving psychotherapy (Armes 2007). Six studies did not describe additional criteria (Cunningham 1989; Faithfull 2001; Ream 2006; Sandgren 2000; Spiegel 1981; Yates 2005).

\section{Interventions}

Studies were only included in this review if participants received the intervention during cancer treatment.

In most studies the intervention was started during cancer treatment, although it often remained unclear at what stage of cancer treatment the interventions ended. Of the studies that evaluated short interventions (four weeks or less) it is likely that participants continued with cancer treatment after the intervention (Barsevick 2004; Brown 2006; de Moor 2002; Yates 2005). When the duration of the intervention was longer it remained unclear how many participants continued with cancer treatment after the intervention. Only four studies described explicitly at what stage of cancer treatment the intervention ended. In Faithfull 2001 the intervention started at the beginning of cancer treatment and ended at the end of the treatment. In three studies the intervention continued after participants finished cancer treatment (Forester 1985; Gaston-Johansson 2000; Godino 2006).

\section{Format}

In most studies the intervention was administered by nurses (Armes 2007; Barsevick 2004; de Wit 1997; Faithfull 2001; Fawzy 1995; Given 2002; Godino 2006; Rawl 2002; Ream 2006; Sandgren 2003; Yates 2005). In the study of Oh 2008 an experienced instructor gave medical qigong. In the study of Moadel 2007 the yoga instructor was also an oncologist. In the remaining studies the intervention was administered by social workers (Cohen 2007; Gaston-Johansson 2000), (psycho)therapists (Edelman 1999; Forester 1985), psychologists (Savard 2006), or graduate students (Cunningham 1989; Decker 1992; Sandgren 2000). In five studies the intervention was multidisciplinary (Berglund 2007; Brown 2006; Classen 2001; Goodwin 2001; Spiegel 1981). In seven studies there was one care provider giving the intervention (Armes 2007; Cohen 2007; Cunningham 1989; Forester 1985; Moadel 2007; Oh 2008; Rawl 2002). In three studies it was unclear how many care providers gave the intervention (Faithfull 2001; Fawzy 1995; Gaston-Johansson 2000), but it may have been only one. In all other studies more than one care provider gave the intervention.

In ten studies the intervention was given in groups (Berglund 2007; Brown 2006; Classen 2001; Cohen 2007; Cunningham 1989; Edelman 1999; Goodwin 2001; Moadel 2007; Oh 2008; Spiegel 1981), in the remaining studies the intervention was given individually. The individual sessions were mostly face-to-face, but seven were exceptions. In the studies of Sandgren (Sandgren 2000; Sandgren 2003) and Barsevick 2004 the participants received only telephone sessions. Three studies combined face-to-face contact and telephone calls in the intervention (de Wit 1997; Given 2002; Yates 2005). In one study participants received individual writing instructions, for several occasions (de Moor 2002). The instructions stimulated participants to write about their thoughts, feelings and consequences on their lives. We decided to include this study 
as change of cognitions and behaviour were the focus of the intervention.

In 14 studies additional information materials were given to the participants (Armes 2007; Brown 2006; Classen 2001; Cohen 2007; Cunningham 1989; de Wit 1997; Decker 1992; Edelman 1999; Faithfull 2001; Gaston-Johansson 2000; Godino 2006; Moadel 2007; Oh 2008; Yates 2005). In eight studies participants received written information (Armes 2007; Brown 2006; de Wit 1997; Edelman 1999; Faithfull 2001; Godino 2006; Oh 2008; Yates 2005). In one study participants received audiotapes (Moadel 2007), and in five studies participants received both written information and audiotapes (Cohen 2007; Cunningham 1989; Decker 1992; Gaston-Johansson 2000) and additional videotapes (Classen 2001).

\section{Duration}

The number of sessions was described in 22 studies, but there was a lot of variation. Among these studies the number of sessions varied from two to 12, with a median of six sessions. In two studies the number of sessions was not fixed for participants (Moadel 2007; Oh 2008). In the remaining three studies the intervention consisted of weekly 90 minute sessions, for the duration of at least one year, but the actual number of sessions was not given. The number of sessions could be estimated to be around 50 (Classen 2001; Goodwin 2001; Spiegel 1981).

Four studies failed to describe the duration of each session (Edelman 1999; Gaston-Johansson 2000; Godino 2006; Ream 2006). Among the remaining 23 studies the duration of the sessions varied from ten minutes to three hours. The most common duration was 30 minutes for individual sessions and 90 minutes for group sessions.

The duration of the full intervention was described in 20 studies or could be estimated. The total duration of the interventions varied from two weeks (Yates 2005) to 20 weeks (Edelman 1999; Given 2002), with three exceptions having a duration of at least one year (Classen 2001; Goodwin 2001; Spiegel 1981). From six studies the actual length of the intervention was not clear, but depended on the cancer treatment participants had received. For example the sessions took place on specific points in patients' treatment regimes (Faithfull 2001; Gaston-Johansson 2000; Godino 2006; Ream 2006), took place during patients' clinic visits (Fawzy 1995), or depended on the duration of the hospital admission (de Wit 1997). One study did not describe the total length of the intervention (Decker 1992).

\section{Content}

In only five studies the intervention was specifically focused on fatigue (Armes 2007; Barsevick 2004; Godino 2006; Ream 2006; Yates 2005). All the other interventions focused on other aspects. Eight interventions aimed to influence depression (Savard 2006), depression and anxiety (Berglund 2007), or mood states in general (Classen 2001; Cunningham 1989; de Moor 2002; Decker 1992; Edelman 1999; Spiegel 1981). Some interventions focused on symptoms, such as pain (de Wit 1997), or on symptoms and side-effects in general (Cohen 2007; Faithfull 2001; Forester 1985; Gaston-Johansson 2000; Given 2002; Rawl 2002). Interventions also focused on distress (Classen 2001; Cohen 2007; Cunningham 1989; de Moor 2002; Fawzy 1995; Forester 1985; Sandgren 2000; Sandgren 2003) and quality of life (Berglund 2007; Brown 2006; Faithfull 2001; Goodwin 2001; Moadel 2007; Oh 2008; Sandgren 2000).
The elements of the intervention varied among the studies. Some interventions were based on one or two elements, while others used multiple techniques. Four studies focused on the expression of emotions (de Moor 2002; Sandgren 2003), on providing social support (Spiegel 1981), or a combination of these two (Goodwin 2001). Yoga was evaluated in two studies, with elements such as meditation, and physical stretching. Yoga also falls within complementary medicine, but as general discussion and relaxation were also parts of the intervention, it was decided to include these studies (Moadel 2007; Oh 2008). All other studies used a combination of several elements in the intervention. Teaching, giving patients information and education on cancer and treatment is often used as one of the elements. In two studies exercise was actually performed (Berglund 2007; Brown 2006), but activities were more often one of the topics, for example activity management, or energy conservation. Relaxation or guided imagery were sometimes used as techniques to manage stress. Problem solving or teaching patients coping strategies were also elements of several interventions. In four studies cognitive (behavioural) therapy was the intervention (Cohen 2007; Edelman 1999; Savard 2006), or psychotherapy (Forester 1985).

\section{Control group}

In 18 studies participants in the control group did not receive the intervention, but received standard care and standard information (Armes 2007; Berglund 2007; Brown 2006; Cohen 2007; de Wit 1997; Decker 1992; Edelman 1999; Fawzy 1995; Forester 1985; GastonJohansson 2000; Given 2002; Godino 2006; Goodwin 2001; Oh 2008; Rawl 2002; Ream 2006; Sandgren 2000; Sandgren 2003). In the studies of Savard 2006 and Moadel 2007 participants in the control group were assigned to a waiting list. One study did not specify the control group (Spiegel 1981). In six studies the control condition involved more than standard care. In the study of Classen 2001 participants were provided with selfdirected education materials. In four studies participants in the control group received an intervention with the same number and duration of sessions, but received different information. In the first study the control condition comprised supportive discussion alone (Cunningham 1989). In the second study participants in the control group received information on nutrition (Barsevick 2004). In the third study the control condition was a 'neutral writing' condition (de Moor 2002). In the fourth study participants received general information on living with cancer (Yates 2005). In one study participants in the control group had more moments of contact than in the intervention group (Faithfull 2001). Participants in the control group received routine ten minute weekly appointments for patients with bladder cancer, or ten minute two-weekly appointments for patients with prostate cancer, led by physicians.

\section{Outcomes}

Studies were only included when they were RCTs. Thus, all the studies had a baseline assessment and a post-intervention assessment. However, the total number of assessments varied between two and six assessments, with a median of three. Studies with more than two measurements, also assessed participants during the intervention, or had a follow-up measurement. Twelve studies had one or more follow-up measurements (Armes 2007; Barsevick 2004; Cohen 2007; Cunningham 1989; de Moor 2002; de Wit 1997; Edelman 1999; Fawzy 1995; Forester 1985; Sandgren 2000; Sandgren 2003; Yates 2005), and ten studies assessed participants once or more during the intervention (Berglund 2007; Classen 2001; 
Edelman 1999; Forester 1985; Gaston-Johansson 2000; Given 2002; Godino 2006; Goodwin 2001; Rawl 2002; Spiegel 1981).

The timing of the measurements varied a lot across the studies. In most studies participants were assessed immediately or within a few days after the intervention was completed. In two studies the time between the end of the intervention and the assessment of participants was longer; one month (Rawl 2002) and six weeks (Fawzy 1995) after the intervention. The actual time between the end of the intervention and the assessment was not obvious in five studies (Armes 2007; Barsevick 2004; Faithfull 2001; Sandgren 2003; Yates 2005). In two of these studies the actual time between the end of the intervention and the follow-up assessment was also unclear (Barsevick 2004; Faithfull 2001). In Barsevick 2004 and Yates 2005 the post- and follow-up assessment depended on the treatment regimes, radiotherapy or chemotherapy. Five studies had a short period between the post-intervention assessment and the followup, of four weeks or less (Armes 2007; Cunningham 1989; de Moor 2002; de Wit 1997; Forester 1985). Three of these five studies had additional follow-up measurements at eight weeks (de Wit 1997), at six, eight, and ten weeks (de Moor 2002), and nine months after recruitment (Armes 2007). In five other studies the time between post-intervention and follow-up was longer varying between three to eight months (Cohen 2007; Edelman 1999; Fawzy 1995; Sandgren 2000; Sandgren 2003).

Five studies explicitly described that the post-intervention assessment took place after participants finished their cancer treatments (Armes 2007; de Wit 1997; Forester 1985; GastonJohansson 2000; Godino 2006), and three of these studies also had a follow-up assessment (Armes 2007; de Wit 1997; Forester 1985). In two studies it was described that part of the participants finished cancer treatment at the time of follow-up measurement (Barsevick 2004; Yates 2005).

Most studies used one instrument to measure fatigue, but six studies used two to four instruments (Armes 2007; Barsevick 2004; Brown 2006; Faithfull 2001; Goodwin 2001; Yates 2005) (see Table 1 'Outcomes'). Five instruments were used in multiple trials. The most frequently used instrument was the POMS sub-scale fatigue/ inertia, and was used in 12 studies to measure fatigue (Barsevick 2004; Brown 2006; Classen 2001; Cunningham 1989; de Moor 2002; Decker 1992; Edelman 1999; Fawzy 1995; Goodwin 2001; Sandgren 2000; Sandgren 2003; Spiegel 1981). The VAS was used in five studies (Armes 2007; Brown 2006; Faithfull 2001; Gaston-Johansson 2000; Ream 2006) and the EORTC QLQ-C30 (Armes 2007; Berglund 2007; de Wit 1997; Faithfull 2001; Goodwin 2001; Oh 2008) was used in six studies. The FACT-F (Godino 2006; Yates 2005) and the MFI (Armes 2007; Savard 2006) were used in two studies. All other instruments were only used in a single study.

A minority of the studies, only five, used specific questionnaires designed to measure fatigue, such as the MFI, SCFS, GFS, FSI, PFS. The most frequently used instruments were used to measure mood states, or quality of life. Fatigue in these instruments was measured with a sub-scale, or with only one item.

\section{Other study characteristics}

The sample size of the 27 included studies varied between 30 and 396 , with a total of 3324 participants. Most studies described the sample at randomisation. Five studies described the number of participants at baseline (Edelman 1999; Yates 2005), or used for analysis (Cohen 2007; Decker 1992; Gaston-Johansson 2000). The mean sample size was 123 (standard deviation (s.d.) 87). Twelve studies had a sample size smaller than 100 (Armes 2007; Cohen 2007; Cunningham 1989; de Moor 2002; Decker 1992; Edelman 1999; Fawzy 1995; Godino 2006; Oh 2008; Sandgren 2000; Savard 2006; Spiegel 1981), and ten studies between 100 and 200 (Brown 2006; Classen 2001; Faithfull 2001; Forester 1985; Gaston-Johansson 2000; Given 2002; Moadel 2007; Rawl 2002; Ream 2006; Yates 2005). Five studies had a larger sample than 200 (Barsevick 2004; Berglund 2007; de Wit 1997; Goodwin 2001; Sandgren 2003).

\section{Methodological Quality}

The results of the methodological quality assessment are described in the Tables of Quality Assessment (Table 2; Table 3; Table 4). A majority of the studies scored one or two on the Oxford Quality Scale (Jadad 1996) within the range of one to five. Only three studies scored three (Rawl 2002; Ream 2006; Yates 2005). On the Delphi List (Verhagen 1998) seven studies scored above three (Barsevick 2004; Cohen 2007; Gaston-Johansson 2000; Goodwin 2001; Ream 2006; Sandgren 2003; Yates 2005) and none of these were published before the year 2000. Looking at the scores on internal validity as suggested by van Tulder 1997, only one study had a good evaluation with a score of five (Yates 2005). All other studies scored lower than five.

The majority of the studies had a moderate methodological quality, varying between ten and 17 . In three studies the quality was graded a nine, being regarded as poor (Berglund 2007; Faithfull 2001; Spiegel 1981). The methodological quality of the study of Barsevick 2004 was rated as 18 , being good.

One of the items of the Quality Rating Scale was concealment of allocation and the evaluation is described in the 'Characteristics of included studies' table. Eight studies suggested that concealed allocation was used (Godino 2006; Goodwin 2001; Savard 2006) and in five studies the allocation was concealed adequately (Faithfull 2001; Rawl 2002; Ream 2006; Yates 2005), with one study changing the procedure during recruitment. In the remaining studies it was not described which procedure was used to conceal allocation.

Barsevick 2004 was the only study in which an intention-to-treat analysis was used. Two other studies described that intention-totreat analysis was used, however, this remained unclear from the described analysis and results (Berglund 2007; Goodwin 2001). In most studies the analysis was performed with participants who completed all assessments.

Three studies explicitly described that actions were taken to prevent contamination. In the study of Sandgren 2003 nurses gave both interventions, but the authors attempted to avoid contamination by informing the nurses about the risks of contamination. In two other studies it was explicitly mentioned that the persons administering the intervention were different from the persons in contact with participants in the control condition (Ream 2006; Yates 2005). In the study that evaluated medical qigong, patients in the control group were asked to refrain from joining an outside qigong class (Oh 2008).

An important aspect when evaluating the effectiveness of psychosocial interventions is the adherence of patients, however, in only 12 studies this was described. In eight studies the attendance of participants joining the sessions was described 
(Armes 2007; Brown 2006; Classen 2001; de Moor 2002; de Wit 1997; Goodwin 2001; Moadel 2007; Yates 2005) and in four studies adherence was assessed in other ways. Two studies measured if participants used the behaviours learned during the intervention (Barsevick 2004; Yates 2005). Two studies asked participants if they read the provided brochures (de Wit 1997), or practiced at home (Cohen 2007).

\section{Risk of bias in included studies}

The possibility of bias could be found in the characteristics of the sample. The exclusion criteria varied a lot between the included studies, for example some studies excluded patients with other comorbidities, while some studies did not describe additional exclusion criteria. The methodological quality might also cause a bias, however, this is described in the discussion in more detail.

\section{Effects of interventions}

See: Summary of findings for the main comparison Effective studies

Seven of the included studies reported a significant effect of the interventions on fatigue at a 0.05 level. The seven studies and their results are briefly described in the Summary of findings for the main comparison: Effective studies. The effect sizes varied between 0.17 (Barsevick 2004) and 1.07 (Cohen 2007). The smallest effect size was found in the study of Barsevick 2004, but this could be due to the use of intention-to-treat analysis not applied in other studies. In two studies it was not possible to obtain all relevant data to calculate effect sizes (Forester 1985; Spiegel 1981).

Of the seven studies which found a significant effect of the interventions on fatigue, three found significant time-by-group interaction effects at follow-up (Armes 2007; Barsevick 2004; Cohen 2007) on at least one instrument that measured fatigue. In the studies of Armes 2007 and Barsevick 2004 the follow-up period was short, up to one month. The follow-up period in the study of Cohen 2007 was longer, lasting four months. In the study of Armes 2007 participants were measured additionally at nine months after recruitment. Of these seven studies two studies found a significant effect immediately post-intervention, but these results were not maintained at follow-up (Forester 1985; Yates 2005). In the study of Spiegel 1981 significant results were found post-intervention, but no follow-up assessment was described. The study of Ream 2006 found a significant effect on fatigue comparing the postintervention scores with a t-test without controlling for baseline differences. No follow-up measurement was carried out. The use of a t-test was justified in this study as baseline fatigue scores of the control and the intervention group were not significantly different. These seven studies (Armes 2007; Barsevick 2004; Cohen 2007; Forester 1985; Ream 2006; Spiegel 1981; Yates 2005) are further referred to as the 'effective' studies.

The remaining 20 included studies were regarded as not effective. In 17 studies no significant effects of the intervention on fatigue were found, although in four of these 17 studies the authors concluded that the results were in the expected direction (Given 2002; Goodwin 2001; Oh 2008) or significant on a 0.1 level (Cunningham 1989). Three of the 20 studies found a significant effect of the intervention when measured with a t-test, immediately postintervention (Decker 1992; Gaston-Johansson 2000) or at follow-up (Fawzy 1995). In the first study, Gaston-Johansson 2000 reported that the difference between the intervention group and control group disappeared after controlling for demographic variables and fatigue at baseline. In the second study of Decker 1992 a statistically significant difference in the pre- versus post-test scores was found, where control patients became more fatigued. However, no significant results on treatment by repeated measures interaction were found on fatigue. In addition, when looking at the results fatigue scores were higher in the experimental group compared to the control group, at baseline and post-intervention. In the third study, Fawzy 1995 found significant results on fatigue on the within-group analysis and the between-group analysis, but reported no significant result of the analysis of covariance on fatigue. Thus, using a t-test to evaluate the intervention was not justified in the last three studies and therefore we concluded that in 20 studies the intervention was not effective for fatigue.

\section{Comparing effective and non-effective interventions for fatigue}

The quality of the seven effective studies did not differ from the non-effective studies $(P=0.231)$. The mean quality score of the effective studies was 14.0 (s.d. 3.6) compared to 12.2 (s.d. 2.0) of the non-effective studies. No difference was found in the mean number of participants $(P=0.598)$. The mean number of participants of the effective studies was 138 (s.d. 115) compared to 118 (s.d. 78) of the non-effective studies.

The psychosocial interventions could be distinguished into interventions specific for fatigue and interventions not specific for fatigue. The effectiveness of interventions specific for fatigue was significantly higher at $80 \%$ (four out of five) compared to interventions not specific for fatigue at $14 \%$ (three out of 22$)(P<$ 0.01). Two studies were specific interventions for pain (de Wit 1997), and depression (Savard 2006), but were not effective for fatigue. The other interventions not specific for fatigue had a more general approach and focused on distress, mood states, quality of life, or symptoms or side effects in general. Of these 20 studies, three studies were effective in reducing fatigue (Cohen 2007; Forester 1985; Spiegel 1981).

The five specific interventions for fatigue were short interventions, consisting of three individual sessions with a duration varying between ten and 60 minutes. These interventions were to a large extent based on the same elements. In all interventions participants were; 1 ) educated about fatigue; 2 ) taught in self-care or coping techniques; 3 ) taught activity management, learning to balance between activities and rest. In addition to these elements Ream 2006 emphasised emotional support. In these five studies (oncology) nurses administered the interventions and were trained. All studies included participants with various malignancies and stages of cancer. In the study described by Armes 2007, the first author was also the nurse administering the intervention. The study of Godino 2006 was the only intervention specific for fatigue, that was not effective. The most obvious difference between this study and the effective studies is the smaller number of participants. Godino 2006 randomised 40 participants, while the sample size of the effective studies was between 60 and nearly 400 participants.

The three effective studies not specific for fatigue were longer interventions compared to the interventions specific for fatigue. The study of Cohen 2007 consisted of nine weekly sessions of 90 minutes. The study of Forester 1985 consisted of ten weekly 30 minute sessions. The intervention in the study of Spiegel 1981 
lasted at least a year, in which participants met weekly for 90 minutes. The duration of these three interventions fall within the range of all other interventions that were not specific for fatigue, varying between four weeks and a year. The content of these three interventions varied among each other. The intervention groups in the study of Spiegel 1981 was primarily supportive and aimed to benefit patients psychologically. The intervention of Forester 1985 was individual unstructured supportive psychotherapy designed to reduce patients emotional distress and physical symptoms, regarding treatment. Cohen 2007 studied the effects of two group interventions on psychological distress and physical symptoms. The first was a cognitive behaviour group intervention and the second consisted of relaxation and guided imagery. Only the relaxation and guided imagery intervention appeared to be effective on fatigue. In the studies of Cohen 2007 and Forester 1985 the first authors were also the only care provider giving the intervention. The effectiveness of the three studies probably couldn't be explained by a larger sample size or by a better quality. The quality scores of the studies by Cohen 2007, Forester 1985, and Spiegel 1981 ranged between nine and 13 , while the quality score of the non-effective studies not specific for fatigue ranged from nine to 17 . Thus the quality scores were within the range of the effective studies not specific for fatigue, and even a bit lower. The number of participants of the three effective studies ranged between 86 and 114 , and was within the range of 30 to 313 of the non-effective studies not specific for fatigue.

\section{DISCUSSION}

The aim of this review was to provide an overview of psychosocial interventions for fatigue during cancer treatment, and to evaluate the effectiveness of these interventions. In our search 27 psychosocial interventions were found, in which the effect on fatigue was tested in a RCT. The sample size of the 27 included studies varied between 30 and 396, with a total of 3324 participants. The quality was generally evaluated as moderate.

In general, there is limited evidence that psychosocial interventions during treatment are effective in reducing fatigue in cancer patients. In only seven studies were the psychosocial interventions effective in reducing fatigue. In only three studies was the effect of the intervention on fatigue maintained during the follow-up period (Armes 2007; Barsevick 2004; Cohen 2007). The quality and the mean number of participants of the effective studies did not differ from the non-effective studies. The effect sizes of the effective studies were generally medium (Field 2005). In the studies with a large effect size, the intervention was provided by only one care provider, also being the first author (Armes 2007; Cohen 2007).

Overall the 27 studies were very heterogeneous on most aspects of the studies, on patient and treatment characteristics, types of interventions, and outcome measures. This made it difficult to establish if certain types of intervention or elements could be essential for reducing fatigue. Attempts were made to draw additional conclusions about certain types of interventions or subgroups of patients. For example a lot of studies were carried out with only breast cancer patients, but these studies were also too heterogeneous to draw additional conclusions about interventions for this specific group. Psychosocial interventions for patients with prostate cancer or other common types of cancer, are less often tested in RCTs, as also previously established (Jacobsen 2007). However, it was possible to distinguish interventions that were specifically designed to treat fatigue during cancer treatment, and interventions not specific for fatigue.

This review showed that the effectiveness of interventions specific for fatigue was significantly higher than interventions not specific for fatigue. To conclude, at present psychosocial interventions specifically for fatigue is the more promising type of intervention for reducing fatigue during cancer treatment. However, there is currently no solid evidence for the effectiveness of interventions not specific for fatigue.

Of the five interventions specific for fatigue, four were effective in reducing fatigue during cancer treatment (Armes 2007; Barsevick 2004; Ream 2006; Yates 2005). In two studies the effects were maintained in the follow-up period that lasted up to a month (Armes 2007; Barsevick 2004). One study was not effective (Godino 2006), but the small sample size might be an explanation why no significant result was found.

It seems promising that four out of five interventions specifically designed for fatigue were effective, but the stability of the evidence is questionable for three reasons. First, in two studies there was only an immediate effect on fatigue after the intervention, but the effect disappeared at follow-up (Yates 2005), or no follow-up assessment was performed (Ream 2006). Second, when more than one instrument was used to assess fatigue, the effects were not visible on all instruments. Third, in the study of Armes 2007 the intervention was provided by only one care giver, also being the first author.

Looking at the characteristics of the five studies that evaluated interventions specifically designed to treat fatigue, revealed two obvious features. Firstly, these studies included patients with various malignancies and stages of cancer. Secondly, these interventions were brief, consisting of three sessions lasting up to 60 minutes each, and containing to a large extent the same elements. In all interventions participants were; 1 ) educated about fatigue; 2) taught in self-care or coping techniques; 3) taught about activity management, learning to balance between activities and rest. Based on this limited number of five studies it could not be established which format or elements of an intervention were essential for reducing fatigue. For example, it could not be established if sessions should be based on face-to-face contact, or if telephone sessions might be an alternative.

Three out of 22 psychosocial interventions not specially designed to manage fatigue were effective in reducing fatigue during cancer treatment (Cohen 2007; Forester 1985; Spiegel 1981). In one study the effect on fatigue was maintained during the four month followup period. These three interventions had a more general approach aimed at psychological distress, mood and physical symptoms. There is no obvious reason why these three interventions were effective, while 19 other studies were not. No explanation could be found in the sample size, the quality of the studies or characteristics of the interventions.

There are several reasons that support the conclusion that interventions with a general approach are rarely effective. First, in the studies of Cohen 2007 and Forester 1985 the first author was also the care provider administering the intervention. Second, in only one study the effect was maintained at follow-up. In addition, one of these three studies was an early study of Spiegel 1981 and was replicated in later studies (Classen 2001; Goodwin 2001). 
However, the effect on fatigue demonstrated by Spiegel 1981, was not confirmed in the later two studies.

Interventions that did not focus on fatigue, for example interventions that aimed to reduce depression or pain, showed that fatigue did not decrease with depression or pain, and therefore we can conclude that these interventions are not effective for reducing fatigue.

\section{Limitation of the studies}

During the evaluation of the included studies several shortcomings were noticed. In most studies it was difficult to get a clear picture of the complete cancer treatment participants received, such as types of treatments and total duration. As a result it also remained unclear when during cancer treatment the assessments and the sessions took place. Often it was uncertain if participants continued with cancer treatment after the intervention.

The evaluation of the quality of the included studies revealed additional limitations. In the majority of the studies it was not described if a procedure was used to conceal allocation, not even in the most recent publications. In addition, only one study applied an intention-to-treat analysis. Recommendations for improving the quality of RCTs are provided in the CONSORT guidelines (Boutron 2008).

Several methodological elements of the psychosocial intervention studies could be improved. For example, avoiding the risk of contamination, and testing the adherence of participants. Training the care providers, supervising them, and applying an integrity check would help improve an intervention study.

In some studies the intervention was provided by only one care provider also being the author, but there might be a conflict of interest in performing the intervention at the one hand, and publishing the results at the other. The care provider might work hard to get positive outcomes, resulting in a large effect size. Despite the good intentions of realising a good intervention, with only one practising care provider it could be difficult to transfer the intervention to others, and to replicate the study. Thus it is recommended that the intervention should be given to participants by more than one person.

\section{Limitation of the review}

A limitation of this review is that RCTs were excluded when it was unclear if cancer patients were receiving treatment at the time of the intervention. To clarify this issue we contacted the experts and researchers who performed the studies. In addition the possibility remains that trials with negative results might not have been published at all, and therefore are missed during our search. Although we are unaware that relevant studies were missed, the possibility that a relevant study exists cannot be ruled out.

\section{AUTHORS' CONCLUSIONS}

\section{Implications for practice}

When cancer patients experience fatigue during cancer treatment there are several options to treat fatigue. In clinical practice an intervention with a general approach is usually chosen when intervening for fatigue, although at present there is no solid evidence for the effectiveness of psychosocial interventions not specific for fatigue. This review showed that interventions with a general approach were rarely effective in reducing fatigue, and these interventions focused on psychological distress, mood and physical symptoms. When other types of psychosocial intervention are offered to cancer patients, for example with the aim of reducing depression or pain, it is not likely that symptoms of fatigue automatically decrease with depression or pain.

The effectiveness of psychosocial interventions specifically designed to treat fatigue was significantly higher than interventions not specific for fatigue, and is currently the more promising type of intervention for reducing fatigue during cancer treatment. The interventions specific for fatigue contained, to a large extent, the same elements. In all interventions patients were: 1) educated about fatigue; 2) taught in self-care or coping techniques; 3 ) taught activity management, learning to balance between activities and rest. However, currently with only a limited number of studies it could not be established which format or elements are essential to reduce fatigue during cancer treatment.

It is important to note that psychosocial interventions during active cancer treatment were the focus of this review. Our results are therefore not applicable to cancer patients who have completed their cancer treatment.

\section{Implications for research}

This review showed that there is limited support for psychosocial interventions for fatigue during cancer treatment. At present the effectiveness of psychosocial interventions specifically designed to treat fatigue is high, but there is no solid evidence for the effectiveness of psychosocial interventions not specific for fatigue.

As the RCTs were very heterogeneous in nature, and the number of psychosocial interventions specific for fatigue were limited, there are still some questions that need to be answered. First, it is important to know why some psychosocial interventions work, and therefore interventions should preferably be based on a theory or model. To find essential components that are necessary to reduce fatigue it is advisable to assess if factors that are expected to reduce fatigue also change during the intervention. In addition, the optimal duration of the intervention needs to be established, and the best method to provide the intervention. For example, it is unclear if telephone or face-to-face sessions are equally effective. Also there are no RCTs that evaluated the effectiveness of group interventions specific for fatigue.

As the included studies were very heterogeneous it was not possible to identify high risk groups. Thus, the question remains whether patients with specific malignancies, or patients receiving specific types of treatments are at risk of becoming more fatigued, although some studies point in that direction (Jereczek-Fossa 2002). Some studies found that the prevalence of fatigue depended on the diagnosis. For example, patients with prostate carcinoma reported the least severe fatigue during radiotherapy and patients with lung, alimentary, and head and neck carcinoma reported the most severe fatigue (Hickok 2005a). Levels of fatigue also depended on diagnosis in patients receiving chemotherapy. In a group of cancer patients receiving cytotoxic treatment, lung and breast cancer patients experienced the highest degree of fatigue (Hartvig 2006). 
There are also indications that the prevalence of fatigue depends on the type of treatment cancer patients receive. For example, breast cancer patients who had a mastectomy operation were more fatigued than women who underwent a lumpectomy. Receiving radiotherapy supplementary to chemotherapy led to an increase in fatigue in women with breast cancer (de Jong 2004).

In addition the course of fatigue appears to depend on the type of treatment cancer patients receive. For example, the course of fatigue in patients receiving chemotherapy seems to be different from the course of fatigue in patients receiving radiotherapy. After the start of chemotherapy the prevalence of fatigue increases, remaining stable during chemotherapy treatment (de Jong 2004;
Jacobsen 1999). During radiotherapy the occurrence of fatigue increases with the number of weeks patients are treated with radiotherapy (Hickok 2005; Hickok 2005a).

If high risk groups can be identified it is important to know if these groups need adapted psychosocial interventions. In current guidelines for CRF, interventions for patients on active treatment are distinguished from interventions for patients at the end of life (NCCN 2008) although, the effectiveness of interventions specific for fatigue in this sample still needs to be demonstrated.

\section{ACK N OWLEDGEMENTS}

We are grateful to the Dutch Cancer Society for funding this study. 


\section{R E F E R E N C E S}

\section{References to studies included in this review}

Armes 2007 \{published data only\}

Armes J, Chalder T, Addington-Hall J, Richardson A, Hotopf M. A randomized controlled trial to evaluate the effectiveness of a brief, behaviorally oriented intervention for cancer-related fatigue. Cancer 2007;110(6):1385-95.

\section{Barsevick 2004 \{published data only\}}

Barsevick AM, Dudley W, Beck S, Sweeney C, Whitmer K, Nail L. A randomized clinical trial of energy conservation for patients with cancer-related fatigue. Cancer 2004;100(6):1302-10.

\section{Berglund 2007 \{published data only\}}

Berglund G, Petersson LM, Eriksson KC, Wallenius I, Roshanai A, Nordin KM, et al. "Between Men": a psychosocial rehabilitation programme for men with prostate cancer. Acta oncologica 2007;46(1):83-9.

\section{Brown 2006 \{published data only\}}

Brown P, Clark MM, Atherton P, Huschka M, Sloan JA, Gamble G, et al. Will improvement in quality of life (QOL) impact fatigue in patients receiving radiation therapy for advanced cancer?. American Journal of Clinical Oncology 2006;29(1):52-8

\section{Classen 2001 \{published data only\}}

Classen C, Butler LD, Koopman C, Miller E, DiMiceli S, GieseDavis J, et al. Supportive-expressive group therapy and distress in patients with metastatic breast cancer - A randomized clinical intervention trial. Archives of General Psychiatry 2001;58(5):494-501.

\section{Cohen 2007 \{published data only\}}

Cohen M, Fried G. Comparing relaxation training and cognitivebehavioral group therapy for women with breast cancer. Research on Social Work Practice 2007;17(3):313-23.

\section{Cunningham 1989 \{published data only\}}

Cunningham AJ, Tocco EK. A Randomized Trial of Group Psychoeducational Therapy for Cancer-Patients. Patient Education and Counseling 1989;14(2):101-14.

\section{Decker 1992 \{published data only\}}

Decker TW. Relaxation therapy as an adjunct in radiation oncology. Journal of Clinical Psychology 1992;48(3):388-93.

\section{de Moor 2002 \{published data only\}}

de Moor C, Sterner J, Hall M, Warneke C, Gilani Z, Amato R, et al. A pilot study of the effects of expressive writing on psychological and behavioral adjustment in patients enrolled in a Phase II trial of vaccine therapy for metastatic renal cell carcinoma. Health Psychology 2002;21(6):615-9.

\section{de Wit 1997 \{published data only\}}

de Wit $R$, van Dam F, Zandbelt $L$, van Buuren $A$, van der Heijden K, Leenhouts G, et al. A Pain Education Program for chronic cancer pain patients: follow-up results from a randomized controlled trial. Pain 1997;73(1):55-69.
Edelman 1999 \{published data only\}

Edelman S, Bell DR, Kidman AD. A group Cognitive Behaviour Therapy programme with metastatic breast cancer patients. Psycho Oncology 1999;8(4):295-305.

Faithfull 2001 \{published data only\}

Faithfull S, Corner J, Meyer L, Huddart R, Dearnaley D. Evaluation of nurse-led follow up for patients undergoing pelvic radiotherapy. British Journal of Cancer 2001;85(12):1853-64.

\section{Fawzy 1995 \{published data only\}}

Fawzy NW. A psychoeducational nursing intervention to enhance coping and affective state in newly diagnosed malignant melanoma patients. Cancer Nursing 1995;18(6):427-38.

\section{Forester 1985 \{published data only\}}

Forester B, Kornfeld DS, Fleiss JL. Psychotherapy during radiotherapy: effects on emotional and physical distress. American Journal of Psychiatry 1985;142(1):22-7.

\section{Gaston-Johansson 2000 \{published data only\}}

Gaston-Johansson F, Fall-Dickson JM, Nanda J, Ohly KV, Stillman S, Krumm S, et al. The effectiveness of the comprehensive coping strategy program on clinical outcomes in breast cancer autologous bone marrow transplantation. Cancer Nursing 2000;23(4):277-285.

\section{Given 2002 \{published data only\}}

Given B, Given CW, McCorkle R, Kozachik S, Cimprich B, Rahbar $\mathrm{MH}$, et al. Pain and fatigue management: results of a nursing randomized clinical trial. Oncology Nursing Forum 2002;29(6):949-56

\section{Godino 2006 \{published data only\}}

Godino C, Jodar L, Duran A, Martinez I, Schiaffino A. Nursing education as an intervention to decrease fatigue perception in oncology patients. European Journal of Oncology Nursing 2006;10(2):150-5.

\section{Goodwin 2001 \{published data only\}}

Bordeleau L, Szalai JP, Ennis M, Leszcz M, Speca M, Sela R, et al. Quality of life in a randomized trial of group psychosocial support in metastatic breast cancer: overall effects of the intervention and an exploration of missing data. Journal of Clinical Oncology 2003;21(10):1944-51.

* Goodwin PJ, Leszcz M, Ennis M, Koopmans J, Vincent L, Guther $\mathrm{H}$, et al. The effect of group psychosocial support on survival in metastatic breast cancer. New England Journal of Medicine 2001;345(24):1719-26.

\section{Moadel 2007 \{published data only\}}

Moadel AB, Shah C, Wylie-Rosett J, Harris MS, Patel SR, Hall CB, et al. Randomized controlled trial of yoga among a multiethnic sample of breast cancer patients: effects on quality of life. Journal of Clinical Oncology 2007;25(28):4387-95. 
Oh 2008 \{published data only\}

Oh B, Butow P, Mullan B, Clarke S. Medical qigong for cancer patients: pilot study of impact on quality of life, side effects of treatment and inflammation. The American Journal of Chinese Medicine 2008;36(3):459-72.

Rawl 2002 \{published data only\}

Rawl SM, Given BA, Given CW, Champion VL, Kozachik SL, Kozachik SL, et al. Intervention to improve psychological functioning for newly diagnosed patients with cancer. Oncology Nursing Forum 2002;29(6):967-75.

Ream 2006 \{published data only\}

Ream E, Richardson A, Alexander-Dann C. Supportive intervention for fatigue in patients undergoing chemotherapy: a randomized controlled trial. Journal of Pain and Symptom Management 2006;31(2):148-61.

\section{Sandgren 2000 \{published data only\}}

Sandgren AK, Mccaul KD, King B, O'Donnell S, Foreman G. Telephone therapy for patients with breast cancer. Oncology Nursing Forum 2000;27(4):683-8.

Sandgren 2003 \{published data only\}

* Sandgren AK. Short-term effects of telephone therapy for breast cancer patients. Health Psychology 2003;22(3):310-5.

Sandgren AK, McCaul KD. Long-term telephone therapy outcomes for breast cancer patients. Psycho Oncology 2007;16(1):38-47.

\section{Savard 2006 \{published data only\}}

Savard J, Simard S, Giguère I, Ivers H, Morin CM, Maunsell E, et al. Randomized clinical trial on cognitive therapy for depression in women with metastatic breast cancer: psychological and immunological effects. Palliative and Supportive Care 2006;4(3):219-37.

\section{Spiegel 1981 \{published data only\}}

Spiegel D, Bloom JR, Yalom I. Group Support for Patients with Metastatic Cancer. Archives of General Psychiatry 1981;38(5):527-33.

\section{Yates 2005 \{published data only\}}

Yates P, Aranda S, Hargraves M, Mirolo B, Clavarino A, McLachlan S, et al. Randomized controlled trial of an educational intervention for managing fatigue in women receiving adjuvant chemotherapy for early-stage breast cancer. Journal of Clinical Oncology 2005;23(25):6027-36.

\section{References to studies excluded from this review}

Badger 2005 \{published data only\}

Badger T, Segrin C, Meek P, Lopez AM, Bonham E, Sieger A. Telephone interpersonal counseling with women with breast cancer: symptom management and quality of life. Oncology Nursing Forum 2005;32(2):273-9.

\section{Bennet 2007 \{published data only\}}

Bennett JA, Lyons KS, Winters-Stone K, Nail LM, Scherer J. Motivational interviewing to increase physical activity in longterm cancer survivors: a randomized controlled trial. Nursing Research 2007;56(1):18-27.

\section{Berglund 1994 \{published data only\}}

Berglund G. A randomized study of a rehabilitation program for cancer patients: The 'Starting again' group. Psycho-Oncology 1994;3(2):109-20.

\section{Boesen 2005 \{published data only\}}

Boesen EH, Ross L, Frederiksen K, Thomsen BL, Dahlstrøm K, Schmidt $G$, et al. Psychoeducational intervention for patients with cutaneous malignant melanoma: a replication study. Journal of Clinical Oncology 2005;23(6):1270-7.

\section{Burns 2008 \{published data only}

Burns DS, Azzouz F, Sledge R, Rutledge C, Hincher K, Monahan PO, Cripe LD. Music imagery for adults with acute leukemia in protective environments: A feasibility study. Supportive Care in Cancer 2008;16(5):507-13.

\section{Campbell 2005 \{published data only\}}

Campbell A, Mutrie N, White F, McGuire F, Kearney N. A pilot study of a supervised group exercise programme as a rehabilitation treatment for women with breast cancer receiving adjuvant treatment. European Journal of Oncology Nursing 2005;9(1):56-63.

\section{Campbell 2007 \{published data only\}}

Campbell LC, Keefe FJ, Scipio C, McKee DC, Edwards CL, Herman $\mathrm{SH}$, et al. Facilitating research participation and improving quality of life for African American prostate cancer survivors and their intimate partners: A pilot study of telephone-based coping skills training. Cancer 2007;109 (2 Suppl):414-24

\section{Carlson 2005 \{published data only\}}

Carlson LE. Impact of mindfulness-based stress reduction (MBSR) on sleep, mood, stress and fatigue symptoms in cancer outpatients. International Journal of Behavioral Medicine 2005;12(4):278-85

\section{Cimprich 1993 \{published data only\}}

Cimprich B. Development of an intervention to restore attention in cancer patients. Cancer Nursing 1993;16(2):83-92.

\section{Cimprich 2003 \{published data only\}}

Cimprich B, Ronis DL. An environmental intervention to restore attention in women with newly diagnosed breast cancer. Cancer Nursing 2003;26(4):284-92.

\section{Clark 2006 \{published data only\}}

Clark M, Isaacks-Downton G, Wells N, Redlin-Frazier S, Eck C, Hepworth JT, et al. Use of preferred music to reduce emotional distress and symptom activity during radiation therapy. Journal of Music Therapy 2006;43(3):247-65. 
Cohen 2004 \{published data only\}

Cohen L, Warneke C, Fouladi RT, Rodriguez MA, Chaoul-Reich A. Psychological adjustment and sleep quality in a randomized trial of the effects of a Tibetan yoga intervention in patients with lymphoma. Cancer 2004;100(10):2253-60.

\section{Courneya 2003 \{published data only\}}

Courneya KS, Friedenreich CM, Sela RA, Quinney HA, Rhodes RE, Handman M. The group psychotherapy and home-based physical exercise (group-hope) trial in cancer survivors: physical fitness and quality of life outcomes. Psycho Oncology 2003;12(4):357-74.

\section{Crooks 2004 \{published data only\}}

Crooks DL, Whelan TJ, Reyno L, Willan A, Tozer R, Mings D, et al. The Initial Health Assessment: An intervention to identify the supportive care needs of cancer patients. Supportive Care in Cancer 2004;12(1):19-24.

\section{Culos-Reed 2006 \{published data only\}}

Culos-Reed SN, Carlson LE, Daroux LM, Hately-Aldous S. A pilot study of yoga for breast cancer survivors: physical and psychological benefits. Psycho Oncology 2006;15(10):891-7.

\section{Daley 2004 \{published data only\}}

Daley AJ. Exercise therapy in women who have had breast cancer: design of the Sheffield women's exercise and well-being project. Health Education Research 2004;19(6):686-97.

\section{Dalton 2004 \{published data only\}}

Dalton JA, Keefe FJ, Carlson J, Youngblood R. Tailoring cognitive-behavioral treatment for cancer pain. Pain Management Nursing 2004;5(1):3-18.

\section{Dimeo 1999 \{published data only\}}

Dimeo FC, Stieglitz RD, Novelli-Fischer U, Fetscher S, Keul J. Effects of physical activity on the fatigue and psychologic status of cancer patients during chemotherapy. Cancer 1999;85(10):2273-7.

\section{Dimeo 2004 \{published data only\}}

Dimeo FC, Thomas F, Raabe-Menssen C, Propper F, Mathias M. Effect of aerobic exercise and relaxation training on fatigue and physical performance of cancer patients after surgery. A randomised controlled trial. Supportive Care in Cancer 2004;12(11):774-9.

\section{Doorenbos 2005 \{published data only\}}

Doorenbos A. A cognitive behavioral intervention randomized trial. Psycho Oncology 2005;14(7):574-84.

\section{Fawzy 1990 \{published data only\}}

Fawzy Fl, Cousins N, Fawzy NW, Kemeny ME, Elashoff R, Morton D. A structured psychiatric intervention for cancer patients I. Changes over time in methods of coping and affective disturbance. Archives of General Psychiatry 1990;47(8):720-5.

\section{Gielissen 2006 \{published data only\}}

Gielissen MFM, Verhagen S, Witjes F, Bleijenberg G. Effects of cognitive behavior therapy in severely fatigued disease-free cancer patients compared with patients waiting for cognitive behavior therapy: A randomized controlled trial. Journal of Clinical Oncology 2006;24(30):4882-7.

Given 2004 \{published data only\}

Given C, Given B, Rahbar M, Jeon S, McCorkle R, Cimprich B, et al. Effect of a cognitive behavioral intervention on reducing symptom severity during chemotherapy. Journal of Clinical Oncology 2004;22(3):507-16.

Given 2005 \{published data only\}

Given BA, Given CW, Jeon S, Sikorskii A. Effect of neutropenia on the impact of a cognitive-behavioral intervention for symptom management. Cancer 2005;104(4):869-78.

\section{Haase 2005 \{published data only\}}

Haase O, Schwenk W, Hermann C, Muller JM. Guided imagery and relaxation in conventional colorectal resections: a randomized, controlled, partially blinded trial. Diseases of the Colon and Rectum 2005;48(10):1955-63.

Hack 2003 \{published data only\}

Hack TF, Pickles T, Bultz BD, Ruether JD, Weir LM, Degner LF, et al. Impact of providing audiotapes of primary adjuvant treatment consultations to women with breast cancer: A multisite, randomized, controlled trial. Journal of Clinical Oncology 2003;21(22):4138-44.

\section{Hanna 2008 \{published data only\}}

Hanna LR, Avila PF, Meteer JD, Nicholas DR, Kaminsky LA. The effects of a comprehensive exercise program on physical function, fatigue, and mood in patients with various types of cancer. Oncology Nursing Forum 2008;35(3):461-9.

\section{Hoekstra 2006 \{published data only\}}

Hoekstra J, de VR, van Duijn NP, Schade E, Bindels PJ. Using the symptom monitor in a randomized controlled trial: the effect on symptom prevalence and severity. Journal of Pain and Symptom Management 2006;31(1):22-30.

\section{Houborg 2006 \{published data only\}}

Houborg KB, Jensen MB, Rasmussen P, Gandrup P, Schroll M, Laurberg S. Postoperative physical training following colorectal surgery: a randomised, placebo-controlled study. Scandinavian Journal of Surgery 2006;95(1):17-22.

\section{Jacobsen 2002 \{published data only\}}

Jacobsen PB, Meade CD, Stein KD, Chirikos TN, Small BJ, Ruckdeschel JC. Efficacy and costs of two forms of stress management training for cancer patients undergoing chemotherapy. Journal of Clinical Oncology 2002;20(12):2851-62.

\section{Kim 2002 \{published data only\}}

Kim Y, Roscoe JA, Morrow GR. The effects of information and negative affect on severity of side effects from radiation therapy for prostate cancer. Supportive Care in Cancer 2002;10(5):416-21. 
Kim 2005 \{published data only\}

Kim SD, Kim HS. Effects of a relaxation breathing exercise on fatigue in haemopoietic stem cell transplantation patients. Journal of Clinical Nursing 2005;14(1):51-5.

\section{Korstjens 2008 \{published data only\}}

Korstjens I, May AM, van Weert E, Mesters I, Tan F, Ros WJ, et al. Quality of life after self-management cancer rehabilitation: a randomized controlled trial comparing physical and cognitivebehavioral training versus physical training. Psychosomatic Medicine 2008;70(4):422-9.

\section{Laidlaw 2005 \{published data only\}}

Laidlaw T. Quality of life and mood changes in metastatic breast cancer after training in self-hypnosis or Johrei: A short report. Contemporary Hypnosis 2005;22(2):84-93.

\section{Lindemalm 2008 \{published data only\}}

Lindemalm C, Mozaffari F, Choudhury A, GranstamBjörneklett $\mathrm{H}$, Lekander M, Nilsson B, et al. Immune response, depression and fatigue in relation to support intervention in mammary cancer patients. Supportive Care in Cancer 2008;16(1):57-65.

\section{Mock 1994 \{published data only\}}

Mock V, Burke MB, Sheehan P, Creaton EM, Winningham ML, McKenney-Tedder S, et al. A nursing rehabilitation program for women with breast cancer receiving adjuvant chemotherapy. Oncology Nursing Forum 1994;21(5):899-907.

\section{Ollenschlager 1992 \{published data only\}}

Ollenschlager G, Thomas W, Konkol K, Diehl V, Roth E. Nutritional behaviour and quality of life during oncological polychemotherapy: results of a prospective study on the efficacy of oral nutrition therapy in patients with acute leukaemia. European Journal of Clinical Investigation 1992;22(8):546-53.

\section{Ovesen 1993 \{published data only\}}

Ovesen L, Allingstrup L, Hannibal J, Mortensen EL, Hansen OP. Effect of dietary counseling on food intake, body weight, response rate, survival, and quality of life in cancer patients undergoing chemotherapy: a prospective, randomized study. Journal of Clinical Oncology 1993;11(10):2043-9.

\section{Oyama 2000 \{published data only\}}

Oyama H, Kaneda M, Katsumata N, Akechi T, Ohsuga M. Using the bedside wellness system during chemotherapy decreases fatigue and emesis in cancer patients. Journal of Medical Systems 2000;24(3):173-82.

\section{Persson 2002 \{published data only\}}

Persson CR, Johansson BB, Sjoden PO, Glimelius BL. $A$ randomized study of nutritional support in patients with colorectal and gastric cancer. Nutrition and Cancer 2002;42(1):48-58.

\section{Post-White 2003 \{published data only\}}

Post-White J, Kinney ME, Savik K, Gau JB, Wilcox C, Lerner I. Therapeutic massage and healing touch improve symptoms in cancer. Integrative Cancer Therapies 2003;2(4):332-44.

\section{Ravasco 2005 \{published data only\}}

Ravasco P, Monteiro-Grillo I, Vidal PM, Camilo ME. Dietary counseling improves patient outcomes: a prospective, randomized, controlled trial in colorectal cancer patients undergoing radiotherapy. Journal of Clinical Oncology 2005;23(7):1431-8

\section{Ravasco 2005a \{published data only\}}

Ravasco P, Monteiro-Grillo I, Marques VP, Camilo ME. Impact of nutrition on outcome: a prospective randomized controlled trial in patients with head and neck cancer undergoing radiotherapy. Head and Neck 2005;27(8):659-68.

Roscoe 2005 \{published data only\}

Roscoe JA, Matteson SE, Mustian KM, Padmanaban D, Morrow GR. Treatment of radiotherapy-induced fatigue through a nonpharmacological approach. Integrative Cancer Therapies 2005;4:8-13.

\section{Savard 2005 \{published data only\}}

Savard J. Randomized study on the efficacy of cognitivebehavioral therapy for insomnia secondary to breast cancer, part I: Sleep and psychological effects. Journal of Clinical Oncology 2005;23(25):6083-96.

\section{Sherwood 2005 \{published data only\}}

Sherwood P, Given BA, Given CW, Champion VL, Doorenbos AZ, Azzouz $F$, et al. A cognitive behavioral intervention for symptom management in patients with advanced cancer. Oncology Nursing Forum 2005;32(8):1190-8.

\section{Speca 2000 \{published data only\}}

Speca M, Carlson LE, Goodey E, Angen M. A randomized, wait-list controlled clinical trial: The effect of a mindfulness meditation-based stress reduction program on mood and symptoms of stress in cancer outpatients. Psychosomatic Medicine 2000;62(5):613-22.

\section{Stanton 2005 \{published data only\}}

Stanton AL, Ganz PA, Kwan L, Meyerowitz BE, Bower JE, Krupnick JL, et al. Outcomes from the Moving Beyond Cancer psychoeducational, randomized, controlled trial with breast cancer patients. Journal of Clinical Oncology 2005;23(25):6009-18.

\section{Stiegelis 2004 \{published data only\}}

Stiegelis HE, Hagedoorn M, Sanderman R, Bennenbroek FT, Buunk BP, van den Bergh AC, et al. The impact of an informational self-management intervention on the association between control and illness uncertainty before and psychological distress after radiotherapy. Psycho Oncology 2004;13(4):248-59.

\section{Strong 2008 \{published data only\}}

Strong V, Waters R, Hibberd C, Murray G, Wall L, Walker J, et al. Management of depression for people with cancer (SMaRT oncology 1): a randomised trial. Lancet 2008;372(9632):40-8.

Telch 1986 \{published data only\}

Telch CF, Telch MJ. Group coping skills instruction and supportive group therapy for cancer patients: A comparison 
of strategies. Journal of Consulting and Clinical Psychology 1986;54:802-8.

\section{Vos 2004 \{published data only\}}

Vos PJ, Garssen B, Visser AP, Duivenvoorden HJ. Psychosocial intervention for women with primary, non-metastatic breast cancer: A comparison between participants and non-participants. Psychotherapy and Psychosomatics 2004;73(5):276-85

\section{Wenzel 1995 \{published data only\}}

Wenzel LB, Robinson SE, Blake DD. The effects of problemfocused group counseling for early-stage gynecologic cancer patients. Journal of Mental Health Counseling 1995;17(1):81-93.

\section{Williams 2004 \{published data only\}}

Williams SA, Schreier AM. The effect of education in managing side effects in women receiving chemotherapy for treatment of breast cancer. Oncology Nursing Forum 2004;31(1):E16-E23.

\section{Williams 2005 \{published data only\}}

Williams SA, Schreier AM. The role of education in managing fatigue, anxiety, and sleep disorders in women undergoing chemotherapy for breast cancer. Applied Nursing Research 2005;18(3):138-47.

\section{Wydra 2001 \{published data only\}}

Wydra EW. The effectiveness of a self-care management interactive multimedia module. Oncology Nursing Forum 2001;28(9):1399-407.

\section{References to ongoing studies}

Cohen 2004a \{unpublished data only\}

Mindfulness relaxation compared with relaxing music and standard symptom management education in treating patients who are undergoing chemotherapy for newly diagnosed solid tumors.. Ongoing study March 2006

\section{Cohen 2006 \{unpublished data only\}}

Evaluation of the effect of cognitive behavior intervention on psychological distress of cancer patients and their family members.. Ongoing study July 2006.

\section{Cohen 2007a \{unpublished data only\}}

Effects of Tibetan yoga on fatigue and sleep in cancer.. Ongoing study November 2006.

\section{Cohen 2007b \{unpublished data only\}}

Effects of yoga in breast cancer patients.. Ongoing study March 2006.

\section{Goedendorp 2005 \{unpublished data only\}}

Evaluation of intervention strategies to manage fatigue during active treatment and to prevent persistent fatigue after curative treatment for cancer.. Ongoing study 1-11-2005.

\section{Oh 2008b \{unpublished data only\}}

Randomized Clinical Trial: The impact of medical qigong (traditional Chinese medicine) on fatigue, quality of life, side effects, mood status and inflammation of cancer patients.. Ongoing study Unclear. In September 2008 almost 162 participants were recruited..

Purcell 2008 \{unpublished data only\}

A randomised control trial investigating the effects of group education and support in reducing cancer-related fatigue and improving quality of life in patients undergoing radiotherapy.. Ongoing study 01-04-2008.

Savard 2008 \{published data only\}

Self-Help treatment for insomnia in breast cancer patients. Ongoing study April 2008

\section{Additional references}

\section{Ahlberg 2003}

Ahlberg K, Gaston-Johansson F, Mock V. Assessment and management of cancer related fatigue in adults. The Lancet 2003;362:640-50.

\section{Barnes 2002}

Barnes EA, Bruera E. Fatigue in patients with advanced cancer: a review. International Journal of Gynaecology Cancer 2002;12:424-8.

\section{Bennett 2008}

Bennett CL, Silver SM, Djulbegovic B, et al. Venous thromboembolism and mortality associated with recombinant erythropoietin and darbepoetin administration for the treatment of cancer-associated anemia. The Journal of the American Medical Association 2008;299:914-24.

\section{Boutron 2008}

Boutron I, Moher D, Altman DG, Schulz KF, Ravaud P. Extending the CONSORT statement to randomized trials of nonpharmacologic treatment: Explanation and elaboration. Annals of Internal Medicine 2008;148(4):295-309.

\section{CBO 2002}

CBO. Form II for evaluating randomised controlled trials (RCT), October 2002 valid until December 2006: Evidence based guideline development (EBRO) [Formulier II voor het beoordelen van randomised controlled trial (RCT), versie Oktober 2002 geldig t/m December 2006: Evidence-based richtlijn ontwikkeling (EBRO)]. www.cbo.nl (accessed 12 July 2007).

\section{Cella 1998}

Cella D, Peterman A, Passik S, Jacobsen P, Breitbart W. Progress towards guidelines for the management of fatigue. Oncology 1998;12:369-77.

\section{Conn 2006}

Conn VS, Hafdahl AR, Porock DC, McDaniel R, Nielsen PJ. A metaanalysis of exercise interventions among people treated for cancer. Supportive Care in Cancer 2006;14(7):699-712. 


\section{Cramp 2008}

Cramp F, Daniel J. Exercise for the management of cancerrelated fatigue in adults. Cochrane Database of Systematic Reviews 2008, Issue 2. [DOI: 10.1002/14651858.CD006145.pub2]

\section{de Jong 2004}

De Jong N, Candel MJJM, Schouten HC, Abu-Saad HH, Courtens AM. Prevalence and course of fatigue in breast cancer patients receiving adjuvant chemotherapy. Annals of Oncology 2004;15(6):896-905.

\section{Edwards 2004}

Edwards AGK, Hailey S, Maxwell M. Psychological interventions for women with metastatic breast cancer. Cochrane Database of Systematic Reviews 2004, Issue 2. [DOI: 10.1002/14651858.CD004253.pub2]

\section{Field 2005}

Field A. Effect sizes. In: Wright DB editor(s). Discovering Statistics using SPSS. Second Edition. London: Sage Publications, 2005:32.

\section{Hartvig 2006}

Hartvig P, Aulin J, Hugerth M, Wallenberg S, Wagenius G. Fatigue in cancer patients treated with cytotoxic drugs. Journal of Oncology Pharmacy Practice 2006;12:155-64.

\section{Hickok 2005}

Hickok JT, Roscoe JA, Morrow GR, Mustian K, Okunieff P, Bole CW. Frequency, severity, clinical course, and correlates of fatigue in 372 patients during 5 weeks of radiotherapy for cancer. Cancer 2005;104(8):1772-78.

\section{Hickok 2005a}

Hickok JT, Morrow GR, Roscoe JA, Mustian K, Okunieff P. Occurrence, severity, and longitudinal course of twelve common symptoms in 1129 consecutive patients during radiotherapy for cancer. Journal of Pain and Symptom Management 2005;30(5):433-42.

\section{Higgins 2008}

Higgins JPT, Green S (editors). Cochrane Handbook for Systematic Reviews of Interventions. Version 5.0.0 [updated February 2008]. The Cochrane Collaboration 2008; Vol. Accessed 1 October 2008 from www.cochrane-handbook.org.

\section{Jacobsen 1999}

Jacobsen PB, Hann DM, Azzarello LM, Horton J, Balducci L, Lyman $\mathrm{GH}$. Fatigue in women receiving adjuvant chemotherapy for breast cancer: Characteristics, course, and correlates. Journal of Pain and Symptom Management 1999;18(4):233-42.

\section{Jacobsen 2003}

Jacobsen PB, Thors CL. Fatigue in the radiation therapy patient: Current management and investigations. Seminars in Radiation Oncology 2003;13:372-80.

\section{Jacobsen 2007}

Jacobsen PB, Donovan KA, Vadaparampil ST, Small BJ.

Systematic review and meta-analysis of psychological and activity-based interventions for cancer-related fatigue. Health Psychology 2007;26:660-67.

\section{Jadad 1996}

Jadad AR, Moore RA, Carroll D, Jenkinson C, Reynolds DJ, Gavaghan DJ, et al. Assessing the quality of reports of randomized clinical trials: is blinding necessary?. Controlled Clinical Trials 1996;17:1-12.

\section{Jereczek-Fossa 2002}

Jereczek-Fossa BA, Marsiglia HR, Orecchia R. Radiotherapyrelated fatigue. Critical Reviews in Oncology/Haematology 2002;41:317-25.

\section{Khuri 2007}

Khuri FR. Weighing the hazards of erythropoiesis stimulation in patients with cancer. The New England Journal of Medicine 2007;356:2445-8.

\section{Knols 2005}

Knols R, Aaronson NK, Uebelhart D, Fransen J, Aufdemkampe G. Physical exercise in cancer patients during and after medical treatment: A systematic review of randomized and controlled clinical trials. Journal of Clinical Oncology 2005;23(16):3830-42.

\section{Lawrence 2004}

Lawrence DP, Kupelnick B, Miller K, Devine D, Lau J. Evidence report on the occurrence, assessment, and treatment of fatigue in cancer patients. Journal of the National Cancer Institute Monographs 2004;32:40-50.

\section{Markes 2006}

Markes M, Brockow T, Resch KL. Exercise for women receiving adjuvant therapy for breast cancer (Review). Cochrane Database of Systematic Reviews 2006, Issue 4. [Art. No.: CD005001. DOI: 10.1002/14651858.CD005001]

\section{McNeely 2006}

McNeely ML, Campbell KL, Rowe BH, Klassen TP, Mackey JR, Courneya KS. Effects of exercise on breast cancer patients and survivors: a systematic review and meta-analysis. Canadian Medical Association Journal 2006;175(1):34-41.

\section{Minton 2008}

Minton O, Stone P, Richardson A, Sharpe M, Hotopf M. Drug therapy for the management of cancer related fatigue. Cochrane Database of Systematic Reviews 2008, Issue 1. [Art. No.: CD006704. DOI: 10.1002/14651858.CD006704]

\section{Mock 2004}

Mock V. Evidence-based treatment for cancer-related fatigue. Journal of the National Cancer Institute Monographs 2004;32:112-8.

\section{NCCN 2008}

National Comprehensive Cancer Network. Clinical Practice Guidelines in Oncology. Cancer-related fatigue version VI.2008. www.nccn.org (accessed March 2008) 


\section{Portenoy 1999}

Portenoy RK, Itri L. Cancer-related fatigue: guidelines for evaluation and management. Oncologist 1999;4:1-10.

\section{Radbruch 2007}

Radbruch L, Elsner F, Krumm N, Peuckmann V, Trottenberg P. Drugs for the treatment of fatigue in palliative care. Cochrane Database of Systematic Reviews 2007, Issue 4. [Art. No.: CD006788. DOI: 10.1002/14651858.CD006788]

\section{Servaes 2002}

Servaes P, Verhagen C, Bleijenberg G. Fatigue in cancer patients during and after treatment: prevalence, correlates and interventions. European Journal of Cancer 2002;38:27-43.

\section{Servaes 2002a}

Servaes P, Verhagen C, Bleijenberg G. Determinants of chronic fatigue in disease-free breast cancer patients: a cross-sectional study. Annals of Oncology 2002;13:589-98.

\section{Stevinson 2004}

Stevinson C, Lawlor DA, Fox KR. Exercise interventions for cancer patients: systematic review of controlled trials. Cancer Causes and Control 2004;15:1035-56.

\section{Stone 2008}

Stone PC, Minton O. Cancer-related fatigue. European Journal of Cancer Accepted 25 February 2008.

\section{van Tulder 1997}

van Tulder MW, Assendelft WJ, Koes BW, Bouter LM. Method guidelines for systematic reviews in the Cochrane Collaboration Back Review Group for spinal disorders. Spine 1997;22:2323-30.

\section{Verhagen 1998}

Verhagen AP, de Vet HC, de Bie RA, Kessels AG, Boers M, Knipschild PG. The Delphi list: a criteria list for quality assessment of randomized clinical trials for conducting systematic reviews developed by Delphi consensus. Journal of Clinical Epidemiology 1998;51:1235-41.

* Indicates the major publication for the study

\section{CHARACTERISTICS OF STUDIES}

Characteristics of included studies [ordered by study ID]

Armes 2007

Methods

RCT. Originally starting with minimization on basis of age, sex, site, and stage of cancer, and HADS scores. After 10 patients were allocated, simple random permuted block randomization was implemented. Sixty participants were randomized, 30 to both groups, the final sample size was 55 . Of the experimental group (EG) 28 completed baseline questionnaires ( $\mathrm{T} 0=$ cycle 3 of $\mathrm{CT}$ ), 21 participants completed T1 assessment (end of cytotoxic treatment), 22 participants completed T2 assessment (4 weeks after the end of cytotoxic treatment), and 17 participants completed T3 assessment ( 9 months after recruitment). Of the control group (CG) 27 participants completed T0, 16 completed T1, 22 completed T2, 19 completed T3. Non response rate varied across assessment from 16 to 5 . At T3 14 participants died and 5 were non-responders (EG 7 died, 4 non response; CG 7 died, 1 non response).

Participants

Patients who were attending for chemotherapy treatment were screened for eligibility at 2 cancer centres in South London. Patients were excluded who 1 ) were aged $<18$ years; 2 ) did not have histologically proven cancer or were not aware of their cancer diagnosis; 3 ) were receiving the last half of the planned course of cytotoxic treatment; 4) were unable to speak and understand English; 5) did not report significant fatigue; 6 ) had a poor Eastern Cooperative Oncology Group performance status (>3); 7) had a previous history of psychotic disorder; 8) had evidence of cognitive impairment or central nervous system metastases; 9) were receiving psychotherapy or CBT; 10) were receiving cytokine treatment; or 11) had an uncontrolled infection at the time of recruitment. The mean age of the 55 participants was 59 years. A majority were women $(n=33)$ and were white British $(n=46)$. Of these, 27 had a diagnosis of colorectal cancer, 44 had stage III or IV, and 42 had at least 1 metastasis.

Interventions

One trained research fellow (nurse) (first author) provided the intervention, consisting of 3 individual, face-to-face, 60 minute sessions at 3 to 4 weekly intervals (coinciding with chemotherapy). The components of the intervention were education of CRF, written information on CRF, discussing effectiveness of coping strategies; goal setting, activity scheduling, graded task management, self monitoring and modification; distraction, cognitive restructuring, praise and encouragement. The control group received standard care.

Outcomes

Three primary outcomes were measured. Fatigue was assessed using a VAS of global fatigue, physical functioning (sub-scale of EORTC-QLQ-C30), fatigue-related distress was measured with a Fatigue 
Armes 2007 (Continued)

Outcome Measure designed specifically for the study. Secondary outcomes were MFI, HADS, and the EORTC-QLQ-C30.

Notes

The duration of the cytostatic treatment is not described.

\section{Risk of bias}

\begin{tabular}{lll}
\hline Bias & Authors' judgement & Support for judgement \\
\hline $\begin{array}{l}\text { Allocation concealment } \\
\text { (selection bias) }\end{array}$ & Low risk & Not concealed at the start of the study (see methods) \\
\hline
\end{tabular}

\section{Barsevick 2004}

Methods

RCT. Participants were stratified by job status (working vs. Nonworking), type of treatment (CTX vs. RT vs. concurrent therapy), and diagnosis (breast vs. non-breast cancer). Questionnaires were administered at three points. Baseline assessment occurred before the start of cancer treatment. For participants receiving CTX or concurrent therapies assessment occurred 48 hours after the second and third CTX. For participants receiving RT assessment occurred during the last week of treatment and one month after completion of treatment. 396 participants were included in the study.

Participants

Individuals were eligible if they were currently beginning treatment intended for cure of local control, for breast, lung, colorectal, advanced prostate, gynaecologic, or testicular cancer or lymphoma and if they planned to receive $>3$ cycles of high-dose chemotherapy (CTX), 6 weeks of radiotherapy (RT) or current RT and CTX. Other treatment other than surgery had to be completed one month previously. Exclusion criteria were if the treatment plan included stem cell transplantation, interleukins, interferons, or tumour necrosis factor, patients with chronic fatigue syndrome, patients who enrolled on to other studies involving psycho-educational interventions, patients with a psychiatric disorder, and patients receiving treatment for anaemia or depression. The mean age of the 396 participants was 56.3 years, the majority were female (85\%), Caucasian (91\%) and college educated (65\%). The study was conducted at a university health science centre and a comprehensive cancer centre.

Interventions Participants allocated to the energy conservation and activity management (ECAM) condition received three telephone sessions from a trained oncology nurse. Participants were given information on cancer-related fatigue and learned energy conservation skills. An energy conservation plan was created (coping stage), evaluated and revised (appraisal stage). The control group received three telephone sessions with information on nutrition, informing and discussing maintenance of a healthy diet, use of vitamins and minerals. Planned duration for both conditions of the first two sessions was 30 minutes and the third session 15 minutes. For participants receiving CTX or concurrent therapy the intervention was administered during the first 3 weeks of treatment. For participants receiving RT the intervention occurred during week 3 to 5 of treatment.

Outcomes Fatigue was measured with three scales (POMS-sf, SCFS and GFS). An other outcome was functional performance (FPI).

Notes

How many patients were randomised to the two conditions and how many were lost to follow up is not described. In addition a description what was done with missing values is lacking. domised to Physical training (Phys) ( $n=53$ ), Information (Info) ( $n=55)$, information plus physical training (PhysInfo) ( $n=52$ ) or a control group (C) ( $n=51)$. Questionnaires were completed by 194 participants at baseline, 166 participants at 6 months follow-up, and 158 participants at 12 months follow-up. Some participants $(n=23)$ dropped-out after randomisation, others in a later stage for the following reasons; 
Berglund 2007 (Continued)

dissatisfied with group assignment, could not arrange transportation. In addition some questionnaires were not returned, at 6 months follow-up or at 12 months follow-up.

Participants

Within six months after diagnosis prostate cancer were included at the university hospital in Uppsala, Sweden. Participants were excluded if they had another cancer diagnosis, participated in other studies, were patients in other care programmes, had severe hearing or vision impairment, were not Swedish speaking, or were physically or mentally disabled. Overall $20 \%$ of the participants had metastasis, the most frequent curative treatment was radical prostatectomy (24\%), and $36 \%$ did not had active treatment (watchful waiting). The average age was 69 years, $80 \%$ was married and $24 \%$ had a university degree.

Interventions

Each intervention program included 7 weekly sessions, with group sizes varying from 3 to 10 participants. Phys: A physiotherapist led 60-minute physical training session followed by a 15 minute coffee break. The programme included light physical training with movement and fitness training, relaxation and breathing exercises. A booster session was held 2 months after the conclusion of the training exercises. Info: A nurse led 60 minute information sessions followed by a 15 minute coffee break. Emphasis was laid on giving the information about prostate cancer, its treatment (lecture given by an urologist) and potential side effects and how to deal with side effects. PhysInfo: combination of Phys and Info programs. Participants were given physical training and then information in the same session, consisting of seven 135-minute sessions. The control group received standard care, i.e. the information and care that was available at that time.

Outcomes The HADS and EORTC-QLQ-C30 were used. Fatigue was assessed with the fatigue sub-scale of the EORTC QLQ-C30.

Notes Unclear how many patients completed questionnaires at 12 months follow-up as numbers in the figure are different from the tables. experimental condition 58 to the control condition. Before assessment 3 participants cancelled due to illness. 55 participants in the experimental condition completed baseline assessment, 57 in the control condition. Of the experimental condition 46 completed the assessment at week 4, 6 were found ineligible due to lack of session attendance. Of the control condition 54 completed the assessment at week 4 .

Participants

Eligible participants were adult advanced cancer patients scheduled to undergo radiation therapy, recruited at the division of radiation oncology mayo clinic Rochester. Participants had to be diagnosed with cancer in the past 12 months, have an expected survival of at least 6 months, but a 5-year survival probability of no more than $50 \%$, and recommended radiotherapy for at least two weeks. Exclusion criteria was a MMSE-score less than 20, an ECOG performance score of 3 or more, active alcohol or substance dependence, active thought disorder, suicidal plans, or participation in a psychosocial trial. The mean age of the 115 participants was 59.6 and 66 of the participants were male.

Interventions

In the structured multidisciplinary intervention participants attended eight 90 -minute sessions over the first 4 weeks after enrolment. A psychiatrist or a psychologist led each session; depending on the theme (mental, emotional, physical, social, spatial), an advanced practice nurse, a chaplain, or a social worker co-facilitated each session. Sessions began with 20 minutes of exercise conducted by a physical therapist followed by educational information, cognitive-behavioral strategies, discussion, and support. Sessions concluded with a 10 to 20 minute guided relaxation exercise. Participants received a manual and specific education brochures. The control group received standard medical care.

Outcomes Fatigue was assessed as a secondary outcome, measured with LASA, POMS, and SDS at baseline and at week 4, 8, 27 and STAI at baseline. In addition raw scores were transformed to a 0 to 100 point scale as fatigue QOL. 
Classen 2001

Methods

On completion of baseline testing, participants were randomised to intervention or control conditions using the adaptive randomisation biased coin-design method. The adaptive randomisation method used the following variables: 1 dominant site of metastasis at study entry, 2 estrogen receptor status, 3 disease-free interval, metastasis or recurrence, 4 age at study entry, 5 systemic treatment received since metastasis, 6 institution. 102 women were included in the data analysis, with patients who completed a pre-randomisation baseline measure and at least 1 post baseline assessment. 23 of the 125 women randomised into the study did not complete any post-baseline assessments: 15 of these 23 participants were too ill to complete questionnaires ( 4 treatment and 11 control participants), 2 were too busy (both control participants), 4 withdrew from the study because they were not assigned to a support group, 1 withdrew because she did not like the support group, and 1 assigned to the treatment condition withdrew for no stated reason. 64 women were randomised to the intervention arm of the study and 61 to the control arm. Post-baseline assessments were conducted every 4 months during the first year and every 6 months thereafter.

Participants

Women with confirmed metastatic or locally recurrent breast cancer were recruited through the Oncology Day Care Center at Stanford University Medical Center. Patients were eligible if they had a Karnofsky score of at least 70\%, were proficient enough in English to be able to respond to questionnaires and participate in a support group. Women were not included with positive supraclavicular lymph nodes as the only metastatic lesion at the time of initial diagnosis; active cancers within the past 10 years other than breast cancer, basal cell or squamous cell carcinomas of the skin, in situ cancer of the cervix, or melanoma with a Breslow depth less than $0.76 \mathrm{~mm}$; or concurrent medical conditions likely to affect short-term survival. At study entry $41 \%$ of the control group received chemotherapy and $84 \%$ hormone therapy. Of the treatment group $43 \%$ received chemotherapy and $81 \%$ received hormone therapy. The mean age of the control group was 54 , the mean education was 19 years, and $80 \%$ was white. The mean age of the treatment group was 53 , the mean education was 16 years, and $91 \%$ was white.

Interventions

Participants in the treatment group, the size ranging from 3 to 15 , met weekly for 90 -minute sessions. The intended duration of treatment was 1 year. The therapy sessions were facilitated by 2 therapists. Therapists included a psychiatrist, psychologists, and social workers. The supportive-expressive therapy model involved the creation of a supportive environment in which participants were encouraged to confront their problems, strengthen their relationships, and find enhanced meaning in their lives. Psycho education was provided in a similar fashion, with group members sharing knowledge they gathered about the illness and related issues. The intervention was unstructured, neither coping strategies nor psycho education was taught in a didactic manner. Each session ended with a self-hypnosis exercise to help participants manage stress and deal with pain. Participants were encouraged to use this exercise at home. All participants (also from the control group) were offered self-directed education materials. They were given a list of materials to select from and to take home on loan. The selection of 30 books, 15 pamphlets, 5 videotapes, and 7 audiotapes covered a wide range of topics related to breast cancer.

Outcomes The Profile of Mood States (POMS) was used to assess mood disturbance, including the sub-scale fatigue. The Impact of Event Scale (IES) was used to assess trauma symptoms.

Notes Results of the six months follow-up measurements after the intervention are not described.

Cohen 2007

Methods

RCT. The number of participants was 38 in the cognitive-behavior (CB) group, 39 in the relaxation and guided imagery (RGI) group, and 37 in the control group (CG). Participants completed questionnaires at three time point: pre-intervention, post-intervention, and at the end of a 4-month follow-up after the $\mathrm{CB}$ and RGI groups concluded. Several women did not complete the post-intervention or follow-up questionnaires: 3 from the RGI group, 1 from the CB group, and 6 from the CG.

Participants

Breast cancer patients, stages I and II, who were 2 to 12 months since surgery and receiving treatment (chemotherapy or radiotherapy) were invited to participate in the outpatient unit of the oncology cen- 
Cohen 2007 (Continued)

tre. Inclusion criteria were fluent spoken Hebrew and absence of a psychiatric illness known to the oncology staff. The mean age of the women was 55.9 (CB), 51.8 (RGI), and 52.9 (CG). The mean education in years was 13.5 (CB), 13.2 (RGI) and 12.8 (CG). The majority were married $76.3 \%$ (CB), $64.1 \%(\mathrm{RGI})$, and $81.1 \%$ (CG). The time since diagnosis was 6.9 (CB), 7.2 (RGI), 6.5 (CG) months. A majority received chemotherapy 60.5 (CB), 64.1 (RGI), 56.8 (CG).

Interventions

The interventions were conducted by the first author, a senior social worker and expert in psycho-oncology, with training and experience in CB techniques. Each group of 6 to 8 participants met weekly, for nine 90-minute sessions. CB: Cognitive components focused on learning to elicit negative thinking patterns and restructure them into adaptive patterns and stress-reducing thoughts. In addition mental distraction, problem-solving, and decision-making strategies were taught. Behavioral components focused on activity scheduling, graded task assignment and behavioral distraction. Practicing at home was emphasized, with homework exercises, and written material was provided. RGI: Systematic learning of deep RGI, practicing deep breathing and autogenic relaxation. Experience of practice at home was discussed to give reassurance and work on problems in the relaxation process. Participants also practiced anxiety, pain, and nausea reduction, and strategies to overcome sleep problems. Participants were provided with RGI audio cassettes or compact disks for activity at home. Patients in the control group received standard care in the oncology unit.

Outcomes The Fatigue Symptom Inventory (FSI) was used to measure fatigue. Other instruments used were the Brief Symptom Inventory, the Perceived Stress Scale, the Mini Sleep Questionnaire, and the Multidimensional Health Locus of Control.

Notes

The two interventions could overlap in the use of a behavioral strategy such as distraction. Group processes, such as mutual support, exchange of information, and expression of feelings, took place in both groups. They were stratified by the authors according to age, sex and apparent seriousness of disease. Seven dropped out of the therapy (three dying during the program, three being too ill to attend, and one for unknown reasons), leaving 53, 28 in the psycho educational therapy plus supportive discussion, 25 in supportive discussion only. All assessments were being administered, by the authors, at the beginning of the first weekly session of each intervention, at the end of the last weekly session, and for a third time 2 to 3 weeks later.

Participants

The participants were consecutive admissions to an ongoing coping skills training program at a large metropolitan cancer centre. They were referred by a variety of health professionals, or self-referred. The group was heterogeneous in demographic and disease characteristics, about half having recurrent disease, and half being on some form of medical treatment (chemotherapy, radiotherapy or hormone treatment) at the time the interventions began. Of the psycho educations group ( $n=28)$, 20 were female, the mean age was 48,13 had breast cancer, and 16 did not receive treatment at start of the groups. Of the discussion control group ( $n=25), 19$ were female, the mean age was 49, 12 had breast cancer, and 12 did not receive treatment at start of the groups.

Interventions

Both interventions occupied 6 weekly, 2-hour sessions with groups from 7 to 10 participants and a single leader. The psycho educational intervention included in addition to supportive discussions, education in coping skills. The training comprised two sessions of relaxation, two sessions on the use of positive mental imagery and one session each centred around goal-setting and on general lifestyle management. Where coping techniques were taught, they were practised first in the group after which participants were asked to continue the practice at home with the aid of a workbook and two audiotapes. These groups were conducted by the first author, at that time a graduate student in clinical psychology. The control intervention consisted of supportive discussion, ventilation of feelings, general problem solving and information sharing. The leader was the second author, a senior nurse. 
Participants Patients with newly diagnosed stage IV renal cell carcinoma were recruited from a Phase II trial. Inclusion criteria for the Phase II trial were that all participants had a life expectancy of $>4$ months, a Zubrod performance status of 2, no serious intercurrent illnesses, and no brain metastases. Prior to enrolment participants could not have received any chemotherapy, or immunotherapy. Participants underwent a nephrectomy and vaccine treatment. In both groups, the average age was 56 years, $86 \%$ were male, and $76 \%$ had two or more metastases. Participants with non-lung involvement was $76 \%$ in the EW group and $71 \%$ in the NW group. the participants waited to receive their vaccine treatment. Participants were given verbal and written instructions. Participants in the EW group were instructed to write for 15 minutes about their deepest thoughts and feelings about their cancer. The instructions remained essentially the same for each assignment. The participants in the NW group were instructed to write about a different health behaviour at each session, which comprised diet, physical activity, substance use and sleep.

Outcomes The outcome measures were symptoms of distress (IES), perceived stress (PSS), mood disturbance (POMS), and sleep disturbances (PSQI). Fatigue was measured with a sub-scale of the POMS.

Notes The results represented the overall group means averaged across the five follow-up measures, for both groups. In addition it was not described how many participants the statistical analysis was performed upon.

\section{de Wit 1997}

\section{Methods} Cancer patients who would receive district nursing at home and patients who would not receive district nursing were studied separately. Both patient groups were randomly assigned to a control or an intervention group, after stratifying for three variables: gender, age, and metastatic sites. Summarizing, four study groups were distinguished: 1 ) a control group without district nursing ( $n=103) ; 2$ ) an intervention group without district nursing $(n=106) ; 3)$ a control group with district nursing ( $n=51)$; and 4 ) an intervention group with district nursing $(n=53)$. Patients were approached to participate after admission to the hospital. All participants were followed up by telephone at 2 (T1), 4 (T2), and 8 weeks postdischarge (T3). (Group (1) T1: N=94, T2: N=86, T3: N=78. Group (2) T1: N=100, T2: N=97, T3: N=85. Group (3) T1: $N=44, T 2: \mathrm{N}=43, \mathrm{T3}: \mathrm{N}=41$. Group (4) T1: $\mathrm{N}=39, \mathrm{~T} 2: \mathrm{N}=33, \mathrm{T3}: \mathrm{N}=31$ ).

Participants

The study was carried out in the Antoni van Leeuwenhoek Hospital, Amsterdam, the Netherlands. The following inclusion and exclusion criteria were used: 1) pain related to cancer, cancer therapy, or illness; 2) pain duration of at least 1 month; 3 ) life expectancy of at least 3 months; (4) able to read and speak Dutch; (5) accessible by telephone; and (6) not residing in a nursing home or retirement home. Participants had various types of primary tumours and extent of the disease. At baseline $22.4 \%$ of the participants did not receive cancer treatment, $62.6 \%$ were female, $25.9 \%$ had a higher education and the mean age was 55.5 years. 
de Wit 1997 (Continued)

Interventions

Three nurses gave the Pain Education Program (PEP). The PEP consists of three components:

1) Enhancing patients' knowledge about pain and pain treatment. A patient was instructed about a specific pain topic only when that topic was assessed as applicable to the patient, and only when the patient's knowledge about pain and pain treatment was assessed as insufficient. This tailored information was provided on a one-to-one setting lasting between 30 and 60 minutes. The verbal instruction was accompanied by a pain brochure consisted of two parts: $(A)$ a section with general information aimed at all cancer pain patients, and (B) a loose-leaf part given to patients when applicable, including supplementary sheets with information about different cancer pain treatments.

2) Participants were instructed on how to register their Present Pain Intensity twice daily in a pain diary for a period of 2 months. In addition, participants were instructed to document changes on type of pain and use of (non-)pharmacological pain treatment.

3) Stimulating patients' help-seeking behavior. Participants were instructed on how to use simple nonpharmacological pain management techniques, such as cold, heat, relaxation, and massage, at home when pain relief was insufficient. They were encouraged to contact health care providers if necessary. Besides the instruction provided in the hospital, participants were called at home at 3 and 7 days postdischarge by the same nurse to determine whether the instruction was fully understood, and to offer the opportunity to ask questions. These phone calls took 5 to 15 minutes each.

Outcomes Pain experience was measured with the MCGill Pain Questionnaire Dutch Language Version (MPQ-DLV). Present and Average Pain Intensity was measured with a numeric rating scale. Pain knowledge was measured with PKQ-DLV. Quality of life was measured with the EORTC-QLQ. Fatigue was measured with the symptom list of the EORTC-QLQ.

Notes Drop out rate in the intervention group with district nursing was much higher compared to the other three groups, thus possible selective drop-out.

\section{Decker 1992}

Methods

RCT. Baseline assessment took place prior to radiation therapy. The post intervention assessment took place at the sixth session, for both groups. 34 participants of the relaxation group completed the postintervention assessment, 29 of the control group.

Participants

Eligible participants were recently diagnosed cancer patients scheduled to receive external beam radiation. Patients with prior cancer were excluded, those who received prior radiation therapy, in-patients, or those with suicidal ideas. 74 were treated with curative intent, 8 with palliative intent. Of the 82 patients randomised 30 were males, the mean age was 61 years.

Interventions

Participants receiving relaxation treatment met individually for six 1-hour sessions with a graduate student supervised by the first author. In addition to relaxation training, support focused on concerns related to cancer radiation treatment and its effects on physical and emotional sensations. Participants were instructed to perform relaxation each day at home and were provided with a relaxation tape and written instructions. The control group completed the assessment and received standard education and support along with the radiation therapy. All participants received the usual services during radiation therapy.

Outcomes

Fatigue was measured with the POMS sub-scale fatigue.

Notes

Methods

RCT. For every 20 participants that were recruited a block randomisation procedure took place, with ten to each condition. Of the 124 participants recruited 32 were classified as dropouts ( 16 died, 10 due to illness, 3 were found not have metastatic disease, 3 other reasons. Ninety-two completed baseline 
Edelman 1999 (Continued)

questionnaires, 43 in the CBT group and 49 in the control group (CG). The 3 month assessments was completed by 36 CBT and 37 CG. The 6 month assessment was completed by 31 CBT and 32 CG.

Participants

This study focused on metastatic breast cancer patients recruited from the Royal North Shore Hospital Sydney. Eligibility criteria included: ability to attend group sessions; no concurrent psychiatric disorder, organic brain disorder or drug/alcohol dependency; ability to speak and read English; and aged between 30 and 65 years. Of the recruited participants $47 \%$ were between 41 and 50 years old, $63 \%$ was married. It was not described whether participants received treatment during the intervention.

Interventions

Therapy recipients attended eight weekly sessions of group CBT, followed by a family night, and three further monthly sessions. The programme was led by two therapists and incorporated the use of cognitive and behavioural techniques, encouraging the expression of feelings and building of group support. Participants received a manual, handouts and homework exercises at every session. In the first few sessions participants were taught basic cognitive skills, including how to identify and challenge maladaptive thoughts and beliefs. Behavioural techniques were introduced in the second sessions, with a discussion on deep relaxation/meditation as a tool for managing anxiety. Participants received a relaxation tape and were encouraged to practise. The no-therapy control group received standard oncological care.

Outcomes The POMS was used to measure mood, including the sub-scale fatigue. The Coopersmith Self-esteem Inventory-Adult form was also used to measure self-esteem.

Notes

Faithfull 2001

$\begin{array}{ll}\text { Methods } & \text { RCT. } 115 \text { men were randomised and stratified to provide a balanced representation of men with } \\ \text { prostate and bladder cancer. Both groups were assessed within the first week of starting RT, week 3, } 6, \\ \text { and at } 12 \text { weeks following start of RT. There was a decrease in completion of questionnaires over time } \\ \text { (88\% at week 6). 81\% of the EORTC QLQ was returned at week } 12 .\end{array}$

Participants Men included in the study were those undergoing radical (greater than $60 \mathrm{~Gy}$ ) radiotherapy for prostate $(83 \%)$ or bladder cancer $(17 \%)$. The mean age of the men was 70 in both groups.

Interventions

The nurse-led care (intervention) was organised for within the first week and last week of RT. Appointments were for 20 minutes and further appointments could be negotiated as required. The nurse explored the individual's understanding of their diagnosis, symptoms and the meaning of the illness. The intervention provided participants with information and practical advice on how to recognise early symptoms, what to expect from treatment and how to manage existing problems. The nurse also provided men and their families with leaflets on healthy eating, RT and how to manage urinary symptoms during RT. The control group received conventional care consisting of routine medical appointments lasting 10 minutes. These were arranged at the start of RT, continuing weekly for patients with bladder cancer, or 2-weekly for patients with prostate cancer, throughout the duration of RT, and led with a group of 6 physicians.

Outcomes

Data collected were observer-rated toxicity scores (RTOG/EORTC), self-assessment of symptoms (VAS), quality of life (EORTC QLQ-C30), satisfaction with clinical care (based on Newcastle satisfaction with nursing scale), costs. Fatigue was measured with a VAS and a sub-scale of EORTC QLQ-C30.

Notes

Missing data were removed from analysis. Therefore the number of participants varies from 56 at week 1 to 25 at week 12 , in the intervention group (SES)

\section{Risk of bias}


Faithfull 2001 (Continued)

\begin{tabular}{l}
$\begin{array}{l}\text { Allocation concealment Low risk } \\
\text { (selection bias) }\end{array}$ \\
\hline
\end{tabular}

Fawzy 1995

Methods

RCT. Stage I patients were recruited at time of their postoperative checkup and stage II patients when they began immunotherapy protocols. At recruitment participants were asked to fill in the baseline questionnaires. At baseline (t0) 31 participants were randomised to the intervention group and 32 to the control group. Follow-up Questionnaires were mailed to all participants, six weeks (t1) and 3 months (t2) after completion of the intervention. At $t 2$ three participants were lost to follow-up, leaving 28 participants in the intervention group and 32 in the control group.

Participants

This study focused on patients with malignant melanoma, stage I or II. Any Breslow depth and Clark levels I-V were acceptable. Participants had to be at least 18 and no older than 70 , able to speak and read English and have no previous history of cancer or psychiatric treatment. The mean age of the experimental condition ( $n=29$ ) was 42 , all were white, 15 were males, and 24 had a college degree or higher. The mean age of the control group ( $n=33$ ) was 46,30 were white, 19 were males, and 19 had a college degree or higher.

\begin{abstract}
Interventions Participants randomised to the psycho educational nursing intervention received an educational manual and 3 hours of individualized teaching on two separate occasions from an oncology nurse. The first session was after baseline testing, the second was made coinciding with the patients' next clinic visit. The intervention consisted of three specific nursing goals and strategies. Health education, stress management, including teaching about stress, stress monitoring and relaxation exercises, and enhancement of coping skills. Participants were called by the nurse prior to the second appointment to remind them of the appointment and to do the reading and relaxation exercises. The control group did not receive the intervention but completed the questionnaires.
\end{abstract}

Outcomes Affective state was measured with the BSI and POMS, which includes the sub-scale fatigue/inertia. The Dealing with Illness Inventory was used to asses health seeking and coping behaviours.

Notes The numbers of patients participating is not clear. Different numbers are described at baseline, and the numbers at $\mathrm{t} 1$ are not described.

\title{
Forester 1985
}

Methods

RCT. 48 participants were randomly selected from the 100 patients to receive psychotherapy, the other 52 participants served as control subjects. Assessments were made at five points, at baseline (week 0 ), midpoint in radiotherapy (RT) (week 3), end of RT (week 6), 4 weeks after RT (week 10), 8 weeks after RT (week 14).

Participants

Participants were randomly selected before they received 6 weeks of radiotherapy for cancer. Patients with abdominal cancer were excluded. The mean age of the participants given psychotherapy was 62.4 years ( $n=52), 54 \%$ were men and $71 \%$ was married; of the control group $(n=48)$ the mean age was 61.5 years, $46 \%$ were men and $67 \%$ were married.

Interventions

Participants given the intervention were given weekly supportive psychotherapy for 10 weeks (4 weeks beyond completion of RT). The sessions were provided by the first author and lasted 30 minutes. The content was unstructured and focused on perceived patients needs, helping them deal with their emotions regarding treatment. For the majority the sessions were composed of supportive psychotherapy with explanatory, educational, interpretive, and cathartic components. The control group received only RT. 
Forester 1985 (Continued)

Outcomes

The outcome measure was a SADS interview measuring emotional symptoms, physical symptoms, including a anorexia, nausea and vomiting, and a fatigue scale.

Notes

It seems that of the 100 participants all assessment were available. Nothing is mentioned on missing data or loss to follow up. group (CG). The participants completed the questionnaires at baseline, 2 days before autologous bone marrow/peripheral blood stem cell transplantation (ABMT), and 7 days after the ABMT provided by the BMT clinical nurse specialist.

Participants

Eligibility criteria for the participants required a diagnosis of stage II, III or IV breast cancer; a scheduled ABMT at an urban National Cancer Institute-designated comprehensive cancer centre; age of 18 years or older; and ability to read and write English. Most participants were between 41 and 50 years old (50\% in the IG and 56\% in the CG). Most participants had a college or graduate degree (65\% in the IG and $51 \%$ in the CG) and were white ( $89 \%$ in the IG and $83 \%$ in the CG).

Interventions

The comprehensive coping strategy program (CCSP) was taught to participants by a clinical social worker at least 2 weeks before hospital admission for treatment with high-dose chemotherapy and ABMT. During the intervention preparatory information was presented explaining that adequate control of pain can lead to decreased psychological distress and a decrease in physical symptoms such as fatigue. Several handouts were given explaining theoretical considerations and the use of relaxation exercise with guided imagery, and coping self-statements. Cognitive restructuring information focused on the avoidance of catastrophising distorted thinking. Relaxation with guided imagery was presented via live model and participants were given an audiotape and recorder with earphones to guide them through the relaxation exercise. Participants were instructed to use it every day and before stressful events. The CCSP was reinforced by an ABMT oncology nurse, the principal investigator or the project director, on the day patients were admitted to hospital, 2 days after completing of chemotherapy, and 7-9 days after ABMT. The control group did not receive CCSP.

Outcomes The outcome measures were pain (POM), nausea (VAS), fatigue (VAS), psychological distress (anxiety (STAI) and depression (BDI)).

Notes (CG), and were interviewed for baseline assessment, within eight weeks of the participants initiating chemotherapy. The second interview, 10 weeks following baseline was completed by 42 participants of the $E G$ and 48 of the CG. The third interview, 20 weeks following baseline was completed by 35 participants of the EG and 43 of the CG.

Participants Participants were eligible when they were within 56 days of the first cycle of chemotherapy, after a new cancer diagnosis, for colon, breast, lung cancer, non-Hodgkin lymphoma or other solid tumours. Participants had to be at least 40 years of age, and had to report both pain and fatigue at baseline. In addition participants had to be cognitive intact and able to read English. Patients were excluded when they were not expected to survive the duration of the study. Four out-patient cancer treatment sites were used for this study. Two sites were affiliated with comprehensive cancer centres, and two were community cancer treatment clinics. The mean age of the sample was 58 years, $28 \%$ was male, and $73 \%$ had some college education. About $70 \%$ had advanced cancer (stages III of IV). 
Given 2002 (Continued)

Interventions
The intervention given by nurses with a certification in oncology, was a 20-week during intervention with 10 sessions at two weeks interval. Six sessions were in person, lasting one hour, and four were via telephone, lasting 20 minutes. With the use of a computer assisted protocol, symptoms were assessed, including fatigue. For each problematic symptom an intervention strategy was created and in later sessions modified, changed or deleted depending on the result. Intervention strategies were categorized as teaching, counselling and support, coordination and communication. The control group did not receive the intervention, but did completed the interview assessments.
Symptoms, the primary outcomes, were measured with the SES, with fatigue as one of the symptoms. Functioning was measured with the SF-36 (short-form) as secondary outcome.

Notes

RCT. Participants were stratified based on diagnosis and treatment with mono-chemo therapy or multi-chemotherapy schedule. 40 participants were randomised, 23 to the intervention, 17 to the control condition. A second assessment was available from 16 participants, from the experimental condition only. The third assessment was available from 13 participants who received the intervention and 7 participants from the control condition. Part of the participants were lost to follow-up because they declined in health. The three assessment were carried out at the same time as the sessions of the intervention.

Participants
chemotherapy at time of the study. Other inclusion criteria were Karnofsky Index $>70$ and willing to
sign the consent form. Exclusion criteria were previous cancer treatment, including surgery, radiother-
apy or chemotherapy; presence of respiratory; cardiac or hepatic dysfunctions; learning disability and
central nervous system metastasis. The mean age of the experimental group was 58.5 years (30 to 75 ),
of the 23 participants 12 were men and 11 had primary school as education. The mean age of the con-
trol group was 62.7 years, of the 17 participants were 9 men and 8 had primary school as education.
The study was carried out in a comprehensive cancer centre in Barcelona.

Interventions

The experimental group received an individualised intervention over three sessions given by an experienced nurse. The first session during the first cycle of chemotherapy, the second session during the second cycle of chemotherapy, the third session one month after finishing treatment. The issues discussed during the sessions included nutrition, stress management, rest and sleep, activity to maintain energy, lifestyle changes and adjustment. Family members could attend and written information was provided to participants. Control group received the usual information provided to patients by cancer nurses and data were collected during the first and the third session.

Outcomes Fatigue was measured with the FACT-F as primary outcome. Satisfaction with the nursing intervention was assessed with a self-completed questionnaire consisting of 10 items.

Notes

The differences in fatigue scores were not significant, but results are not described.

\section{Risk of bias}

\begin{tabular}{lll}
\hline Bias & Authors' judgement & Support for judgement \\
\hline $\begin{array}{l}\text { Allocation concealment } \\
\text { (selection bias) }\end{array}$ & Low risk & Not adequate \\
\hline
\end{tabular}


Goodwin 2001

\section{Methods}

Randomisation was performed centrally with the use of sealed envelopes containing allocations form a computer generated table of random numbers, was stratified according to the centre ( 7 sites) and the presence or absence of visceral metastases. A 2:1 ratio (intervention/control) was used. Of the 237 women randomly assigned. Two of them were found ineligible - one woman (control group) did not have metastases, and one woman (intervention group) had a carcinoid tumour. These women were excluded from the analysis. The analyses included the 218 women who completed baseline questionnaires during the four months before randomisation (146 in the intervention group and 72 in the control group). After one year, 102 completed the POMS in the intervention group, and 45 in the control group.

Participants

Inclusion criteria: histologic confirmation of breast cancer at the time of diagnosis, presence of metastatic disease outside of the breast and ipsilateral axilla, consent of the most responsible treating physician. Exclusion criteria: central nervous system metastases, life expectancy of less than 3 months as assessed by the treating oncologist; active psychosis, untreated major depression, or severe character disorder; inability to speak and read English; planned participation in a therapist-led support group for patients with metastatic breast cancer outside of the study centre; and residence of more than 1 hour from the study centre. At randomisation $73.9 \%$ of the women in the intervention group were currently married, and the mean age was 49.5 . Currently $41.1 \%$ received chemotherapy, $43.0 \%$ hormone therapy, and $3.2 \%$ radiotherapy. In the control group $69.3 \%$ of the women were currently married, and the mean age was 51.5 . and $14.3 \%$ did not had active treatment. Currently $39.0 \%$ received chemotherapy, $46.8 \%$ hormone therapy, and $6.5 \%$ radiotherapy.

Interventions Women in the intervention group participated in a weekly 90-minute therapist-led group of supportive-expressive therapy. Each group consisted of 8 to 12 women and two leaders. The leaders were psychiatrists, psychologists, social workers, or nurse clinicians who were experienced in leading group therapy. The supportive-expressive therapy was intended to foster support among group members and to encourage the expression of emotions about cancer and its broad ranging effects on their lives. Women were encouraged to interact with each other and to support each other outside of the group sessions. Participants were given the opportunity and support to speak about the effects of the illness, its treatment, and changes in their self-image, roles, and relationships with family members, friends, coworkers, health care providers, and others. The women also discussed the life-altering nature of the illness and strategies for coping and communicating. They were asked to attend the group sessions for at least one year. A monthly 90-minute session was provided for family and friends. Women in the control arm did not participate in a support group. Every 6 months, all women received educational materials about breast cancer and its treatment, relaxation, and nutrition.

Outcomes The primary outcome for this trial was survival. Psychosocial function was assessed by self-reported questionnaires including the POMS fatigue-inertia sub-scale. Pain and suffering was measured with a VAS.

Notes

\section{Risk of bias}

Bias Authors' judgement Support for judgement

Allocation concealment Low risk

(selection bias)

not adequate

Moadel 2007

Methods

RCT: After baseline assessment, participants were randomly assigned to start classes either immediately or in 3 months. The baseline assessment was conducted in person, the follow-up assessment by telephone on a day when participants did not attend a yoga class previous to the assessment. 164 women consented to participate. Random assignment was in a 2:1 ratio to intervention ( $n=108)$ or control $(n=56)$ after stratification by treatment (chemotherapy or antiestrogen therapy). 128 (78\%) completed the baseline and follow-up assessment (yoga=84, control=44). In the yoga group 24 participants were 
Moadel 2007 (Continued)

study drop-out, 16 were lost to follow-up, 5 refused, and 3 had a change in health status. In the control group 12 participants were study drop-out, 8 were lost to follow-up, 3 refused, and 1 had a change in health status.

Participants

Eligibility included age $\geq 18$ years, new/recurrent (stage I to III) breast cancer diagnosis within previous 5 years, high performance status (Eastern Cooperative Oncology Group performance status of $<3$ ), ability to speak English or Spanish, and not actively practicing yoga. Throughout the study $48 \%$ of the participants were receiving medical treatment. Of the sample $(n=128) 27$ received CT, 30 received antiestrogen therapy and 10 received radiation treatment at baseline. Participants were $42 \%$ African American, $31 \%$ Hispanic, and $23 \%$ white; mean age was 54,8 years, and $69 \%$ of patients were not currently married. Three quarters of the sample earned up to, but no greater than, a high school degree.

Interventions

The yoga intervention consisted of 121,5 -hour weekly classes. Participants were permitted to attend more than one class per week. The yoga intervention was developed for use with breast cancer patients by one of the co-authors (C.S.), an oncologist and certified yoga instructor, in consultation with experts in India and the USA. Based on Hatha yoga techniques, the intervention incorporated the following three major yoga components: physical stretches and poses; breathing exercises; and meditation. Participants were asked to practice yoga at home daily and given an audiotape/compact disk for guidance. The control group started classed after 3 months.

Outcomes

QOL was measured with FACT. The FACIT-fatigue was used to assess limitations in daily activity and energy level. The FACIT-spiritual was used to assess spiritual and existential well-being. A Distressed Mood Index was developed using 19 feelings-state descriptive adjectives from the Profile of Mood States.

Notes

\section{Oh 2008}

Methods

$\mathrm{RCT}: 30$ participants were randomly assigned into the intervention group $(n=15)$, and the control group $(n=15)$. The randomization was stratified by treatment at baseline (currently ongoing chemotherapy or completed the cancer treatment). Randomization was done by a computer program. 18 participants completed the study, 8 from the intervention group (MQ) and 10 from the control group. Reasons were the time schedule was not suitable $(n=3)$, family holiday $(n=2)$ and sickness $(n=2)$. Five participants of the control group did not respond to the questionnaires and were not reachable to provide reasons. At the end of the program all participants were assessed.

Participants Inclusion criteria were: a confirmed diagnosis of cancer at any stage, 18 years of age or older, an Eastern Cooperative Oncology Group (ECOG) performance status of 0-3, an expected survival length of more than 12 months, and ability to complete all questionnaires. Exclusion criteria were: diagnosis of other major medical or psychiatric disorders, a history of epilepsy, brain metastasis, delirium or dementia, medical contraindication for exercise and already practicing Qigong. Participants ranged in age from 35 to 75 years old (mean 54, s.d. 9). Most were females (75\%), living with a partner (67\%), and of Caucasian ethnicity (84\%). Of the participants $53 \%$ were on active treatment.

Interventions

The intervention was a Medical Qigong (MQ) group therapy program, modified to specifically target the needs of cancer patients to control emotion and stress as well as improve physical function. The MQ group was lead by an experienced MQ instructor. Participants attended class once or twice a week for eight weeks that lasted totally 90 minutes, and it was recommended that they carried out practice at home every day for at least an hour. Each session consisted of 15 minutes of general discussion, including the philosophy and principle behind the intervention, patients' feelings and experiences of treatment; 30 minutes of stretching and body movements; 15 minutes movement in seated posture; and 30 minutes of breathing exercise, meditation and visualization. The control group received usual care and were asked to refrain from joining an outside Qigong class.

Outcomes

Participants completed the EORTC QLQ-C30, including the symptom scales (fatigue, pain, and nausea and vomiting). 
Oh 2008 (Continued)

Notes Change scores of side effects were only tested within groups. Not between groups. Change scores for the MQ group and the control group were not significant for fatigue.

\section{Risk of bias}

\begin{tabular}{lll}
\hline Bias & Authors' judgement & Support for judgement \\
\hline $\begin{array}{l}\text { Allocation concealment } \\
\text { (selection bias) }\end{array}$ & Unclear risk & Randomization was done by a computer program. \\
\hline
\end{tabular}

Rawl 2002

Methods $\quad$ RCT. 120 participants were randomised, 31 did not continue in the study (21 in the intervention group (IG), 10 in the standard care group (CG)). 109 patients provided data for analysis, at baseline, 94 (55 IG, 54 CG), 94 at time 2, which was midway through the intervention (9 weeks), and 77 at time 3 which was one month post intervention ( 24 weeks). Group assignment was generated via computer and stratified according to, site of recruitment, site of the patients' cancer, and care givers' employment status.

Patients newly diagnosed with breast, colorectal, or lung cancer who were undergoing chemotherapy
were approached within 56 days of initiating chemotherapy, in a tertiary-cancer centre or a commu-
nity-based cancer centre. Participants were eligible if they were 18 or older and spoke English. Of the
109 participants $91 \%$ were Caucasian, $77 \%$ were female. $51 \%$ had breast cancer, $23 \%$ colorectal cancer,
and $27 \%$ lung cancer. The average age was 55.7 years. The sample was distributed evenly between ear-
ly (stage I or II) and late (stage III or IV) cancers. Education levels were fairly heterogeneous.

Interventions The intervention was a computer-based nursing intervention and occurred over 18 weeks consisting of nine visits (five in person ( 1 hour) and four via telephone (20 minutes) with a masters'-prepared oncology nurse specialist. It was a menu-driven computer program that guided clinical assessment, problem identification, selection of interventions, and measurement of outcomes. Symptom experience was assessed for 38 symptoms, including frequency, severity, limitations, and level of distress. Interventions were tailored individually to address up to four symptoms that were prioritised as problems by the participant. The nurse provided objective information about the management and monitoring of the symptom, but also provided emotional support and counselling during each session. Control group participants received any education normally delivered during chemotherapy.

Outcomes

The Medical Outcomes Study Short Form (SF-36) was used. The sub-scale vitality was used to measure fatigue. Other instruments were also used. The Center for Epidemiological Studies Depression-20 scale and the State-Trait Anxiety Inventory.

Notes

\section{Risk of bias}

\begin{tabular}{lll}
\hline Bias & Authors' judgement & Support for judgement \\
\hline $\begin{array}{l}\text { Allocation concealment } \\
\text { (selection bias) }\end{array}$ & Low risk & adequate \\
\hline
\end{tabular}

Ream 2006

Methods

RCT. Participants were stratified according to the centre they were treated and the chemotherapy regimen they were given. 103 participants were randomised, 48 allocated to the intervention, 55 to the control condition. In the intervention condition 5 participants were lost to follow-up ( 1 withdrew, 4 declined in health). In the control condition 12 participants were lost to follow-up (3 withdrew, 9 declined 
Ream 2006 (Continued)

in health). In both conditions 43 participants were available for analysis. Pre-intervention measurement took place prior to the chemotherapy. The post-intervention measurement took place prior to the fourth treatment cycle.

Participants

Eligible participants had been diagnosed with, non-Hodgkin's lymphoma or gastrointestinal, non-small cell, lung, colorectal, breast, or unknown primary cancer, and were chemotherapy-naive. They had to understand, speak, read, and write English. Patients were excluded when treated for psychiatric illness. The mean age of the sample was 56.5 years ( 18 to 70 ) and 55\% was male. Participants were recruited from the inpatient or outpatient service prior to commencing their first cycle of treatment.

Interventions

The intervention program was provided by an experienced cancer nurse visiting participants at home, over the first three treatment cycles (3 sessions). The intervention comprised: assessment/monitoring of fatigue; education on fatigue including an investigator-designed information pack; coaching in selfcare; and provision of emotional support. Control group received usual care and fatigue assessments.

Outcomes Fatigue (four VAS'), as primary outcome. Other outcomes were Emotional well-being (HADS), General
health status (SF-36) and coping (VAS and COPE).

Notes

\section{Risk of bias}

\begin{tabular}{lll}
\hline Bias & Authors' judgement & Support for judgement \\
\hline $\begin{array}{l}\text { Allocation concealment } \\
\text { (selection bias) }\end{array}$ & Low risk & adequate \\
\hline
\end{tabular}

Sandgren 2000

\section{Methods}

RCT. Participants first completed baseline questionnaires. For women in the experimental group, telephone therapy began the week following the return of the questionnaires. Questionnaires were mailed at 1 month (not presented), 4 and 10 month intervals. Data presented came from 53 of the original 62 participants, 24 therapy participants and 29 control participants. Four women failed to complete measures at some intervals, and five dropped out of the study (one died, others unknown).

Participants Women with stage I or II breast cancer initially were recruited through a tertiary cancer treatment centre serving rural eastern North Dakota and western Minnesota. Women diagnosed within the prior three to four months were eligible. All but five women underwent adjuvant treatment, and were in the midst of such treatment during the study. All had completed chemotherapy and radiation before the 10-month follow-up. Ages ranged from 30 to 82 (mean 51). Nearly all (92\%) of the sample had completed high school, and 30\% completed a college education (mean 13.5 years). All participants were Caucasian except for one Native American.

Interventions

Treatment participants received up to 10 telephone calls (mean=9). Therapy was administered once a week for four weeks and then every other week for six more sessions (4 months). Phone sessions lasted up to 30 minutes, averaging 20 to 25 minutes. Therapy included providing support, teaching coping skills, managing anxiety and stress, and helping to solve patients-generated problems. Cognitive restructuring was used, a technique that involves identifying erroneous beliefs, over-generalization, or catastrophic thinking. Therapists also encouraged emotional expression, and relaxation techniques. Three female clinical psychology master's candidates conducted the therapy. The control group had assessments only.

Outcomes The POMS was used to measure distress. It assesses six moods, including fatigue. The Coping Response Indices-Revised scale was used to measure coping, and the Medical Outcome Scale (MOS) short-form was used to measure quality of life. 
Methods RCT. Of the 235 participants who began the study 13 dropped out. A total of 222 participants completed the study. Random assignment to a condition was based on a 2:2:1 ratio. 55 participants in the standard care completed the study, 78 of the health education intervention, and 89 of the emotional expression intervention. Participants were blocked by cancer stage. Measures were collected immediately before the intervention, which was typically after surgery, but during adjuvant treatment. Follow-up took place approximately 5 months later.

Participants

Eligibility criteria included diagnosis of stages I-III breast cancer, ability to speak English and to talk by phone, absence of serious comorbid conditions, and undergoing adjuvant treatment. Adjuvant treatment included any combination of chemotherapy, radiotherapy, and hormone therapy. Patients were recruited from two cancer treatment clinics, 1-3 months after diagnosis. The average age of the sample was 54.5 years, most participants (78\%) were married and Caucasian $(97 \%)$.

Both interventions included 5 weekly 30 min phone calls, with a sixth follow-up 3 months later, about the time adjuvant chemotherapy typically ended. Participants in the health education intervention received a structured curriculum. The topics included understanding breast cancer and treatment (chemotherapy, radiation therapy, and hormone therapy), managing post-surgical changes and treatment side effects and fatigue, and maintaining a healthy lifestyle. Participants in the emotional expression were asked to talk about thoughts, feelings and emotional issues and stressful experiences. Trained nurses participated in both treatment conditions. Participants in the control group received standard care in which the usual nurse help line would be available.

\begin{tabular}{ll}
\hline Outcomes & $\begin{array}{l}\text { Outcome measures included quality of life (FACT-B) and additionally POMS. Fatigue was measured as } \\
\text { the fatigue/inertia sub-scale of the POMS. }\end{array}$ \\
\hline Notes & Not described how many participants were randomised and what was done with any missing values. \\
\hline
\end{tabular}

\section{Savard 2006}

\section{Methods}

Participants were first stratified according to the cancer clinic they were recruited to. 45 participants were then randomly assigned either to the CT (25) or WLC (20) condition. Pre-treatment measures were completed by 21 participants of the CT and 16 of the WLC. Post-treatment measures were completed by 15 (CT) and 13 (WLC). 3-month follow-up measures were completed by 14 (CT) and 10 (WLC). 6-month follow-up measures were completed by 12 (CT) and 9 (WLC). Reasons for lost to follow-up were, study or therapy too burdensome, lost interest, due to chemotherapy side effects, terminal stage or death.

Participants

Inclusion criteria: 1) a diagnosis of metastatic breast cancer (stage IV) and 2) a score of 7 or more on the HADS-D or 15 or more on the BDI.

Exclusion criteria: 1) life expectancy of less than 2 months, 2) meeting DSM-IV criteria for a severe psychiatric disorder other than major depression, 3) presenting severe suicidal ideas with a risk of acting out, 4) having recently started an antidepressant medication or recently altered the dosage, 5) currently receiving a psychological intervention targeting depression. Participants were recruited in three cancer clinics. All participants were Caucasian. In the experimental condition 57\% was married, $48 \%$ completed university and the mean age was 51 . In the waiting-list control condition $50 \%$ were married, $31 \%$ completed university and the mean age was 52. (not described how many participants received treatment).

Interventions Cognitive therapy (CT) was administered individually and involved eight weekly sessions of 60 to 90 minutes, with three booster sessions of CT every 3 weeks following treatment. Two psychologists with experience in the application of CT conducted the sessions. The ultimate goal was to develop an opti- 
Savard 2006 (Continued)

mistic but realistic attitude towards their situation. CT began with the presentation of a cognitive theory of emotions. Then participants were encouraged to increase their level of daily activities. Participants were then trained to identify their negative thoughts and to use cognitive restructuring to modify dysfunctional or irrational cognitions. Participants were then encouraged to redefine their life goals. Finally, future high-risk situations were identified, as well as strategies to cope with them. Patients in the waiting-list control (WLC) condition were scheduled 10 weeks later for CT.

Outcomes

Fatigue was measured with the MFI. Other instruments used were Hospital Anxiety and Depression Scale, Beck Depression Inventory, Insomnia Severity Index, Quality of life questionnaires: QLQ-C33, QLQ BR-23, and List of Life Events.

Notes

Risk of bias

\begin{tabular}{lll}
\hline Bias & Authors' judgement & Support for judgement \\
\hline $\begin{array}{l}\text { Allocation concealment } \\
\text { (selection bias) }\end{array}$ & Low risk & not adequate \\
\hline
\end{tabular}

\section{Spiegel 1981}

Methods $\quad$ RCT. 109 women were referred to the study by their oncologists, and 86 completed the first questionnaire. More participants were randomised to the experimental group $(E G=50)$ than to the control group (CG=36). Of the EG 14 were too weak or too ill to participate and 2 moved away. Of the CG 12 participants were lost; 4 were too ill, 2 died, 4 refused, 2 were out of contact. The final EG consisted of 34 women, and the final CG of 24 women. Follow-up testing was done at four-month intervals for a total of a year. The analysis considered 16 (EG) and 14 (CG) that completed all four assessments.

Participants

Participants with documented metastatic carcinoma of the breast were included. The average age of the treatment group was 54 years, and the control group 55 years. $75 \%$ of the treatment group and $70 \%$ of the control group were married. Two members of the treatment group and three of the control group lived alone. The average length of time since diagnosis of recurrence was 54 months for the treatment group and 68 months for the control group. Members of the treatment and control group received equivalent amounts of chemotherapy during the period of study. At onset of the study it was noted that the members of the treatment group were of significantly higher social status than were members of the control group.

Interventions

The psychological support groups met weekly in outpatient settings for $11 / 2$ hours and were composed of seven to ten women. Although the period of measurement was one year, no termination time was set for the groups. Three groups were formed; each group had two leaders, a psychiatrist or a social worker and a counsellor who had had breast cancer. The groups were designed primarily to be supportive. There was a high degree of cohesion and relatively little confrontation and here-and-now interpersonal exploration. Interaction in the group often contained a considerable amount of self disclosure and sharing of mutual fears and concerns. Unlike a therapy group, there were few process interpretations; the focus was more on content, which included discussion of death and dying, related daily problems, difficulties in obtaining treatment, issues of communication with physicians, and living as richly as possible in the face of a terminal illness.

\section{Outcomes}

Fatigue was measured with the POMS sub-scale fatigue. In addition Health Locus of control, Maladaptive coping response and denial was measured. Self-esteem was assessed with the Janis-Field Scale and Phobias with a checklist. 
Yates 2005

RCT: Baseline assessments were completed at the first treatment visit (week1) (53 of the intervention
group (IG) and 57 of the control group (CG)). The first follow-up assessment (t2) was conducted at the
third course of chemotherapy (CT) (week 7-9) (50 of IG and 54 of CG). The second follow-up (t3) was
conducted at the fourth course of CT or for participants receiving radiotherapy (RT) assessment was
conducted on the first day of RT (week10-13) ( 50 of IG and 50 of CG). The third follow-up ( $t 4$ ) was con-
ducted at the fifth course of CT or for participants receiving radiotherapy (RT) assessment was conduct-
ed on the first day of RT. Participants receiving RT at t3, assessment was conducted two weeks after RT
(week 13-21) (49 of IG and 48 of CG).

Participants

Women more than 18 years of age with stage I or II breast cancer who were commencing adjuvant chemotherapy at one of 5 day-treatment units were approached and admitted if they had an ECOG performance rating of one or two and their haemoglobin level was at least $11.6 \mathrm{~g} / \mathrm{mL}$ at recruitment. The mean age of the participants was 49.4 , and approximately $65 \%$ of the sample had post-high school qualifications. Most of the women were married ( $77 \%$ in the IG and $73 \%$ in the CG).

Interventions

The psycho educational intervention, given by an oncology nurse (2), aimed to improve patients knowledge and skills in performing self-care behaviours to minimize fatigue, based on Green's PRECEDE model of health behaviours. Effective strategies to reduce fatigue included promoting: sleep and rest, a balance between activity and exercise, conserving energy, and restorative activities. The first session, a face to face contact of 20 minutes, focused on the participants specific needs and to target influencing these factors. The second and third session, a telephone call of 10 minutes, were aimed to review the patients' fatigue management plan, and reinforcement. The intervention was given at the start of the second cycle of chemotherapy with one week between each session. In addition patients received a booklet with specific information. Participants in the control group received general cancer education sessions equivalent in number and timing and also given by the same oncology nurses. The education focused on talking about general issues associated with living with cancer. Participants also received a booklet with general information.

Outcomes

The primary end points for the study included use of fatigue-management behaviours, confidence with managing fatigue, and fatigue experiences (levels of fatigue at worst, best, average in the past week and currently, PFS, and FACT-F).

Notes Not described what was done with missing values.

\section{Risk of bias}

\begin{tabular}{lll}
\hline Bias & Authors' judgement & Support for judgement \\
\hline $\begin{array}{l}\text { Allocation concealment } \\
\text { (selection bias) }\end{array}$ & Low risk & adequate \\
\hline
\end{tabular}

RT: Radiotherapy

vs: versus

CBT: cognitive behavioural therapy

CRF: cancer related fatigue

FOM: fatigue outcome measure

ECAM: energy conservation and activity management

Characteristics of excluded studies [ordered by study ID]

\begin{tabular}{ll}
\hline Study & Reason for exclusion \\
\hline Badger 2005 & $\begin{array}{l}\text { In a previous study of Badger 2001, participants were randomised between six conditions, five ex- } \\
\text { perimental groups and a control group. In this study participants of the five experimental groups }\end{array}$
\end{tabular}




\begin{tabular}{|c|c|}
\hline Study & Reason for exclusion \\
\hline & $\begin{array}{l}\text { were taken together as one, and compared with the control group on fatigue. This was not consid- } \\
\text { ered to be a RCT. }\end{array}$ \\
\hline Bennet 2007 & Intervention was conducted after cancer treatment was completed. \\
\hline Berglund 1994 & Intervention was conducted after cancer treatment was completed. \\
\hline Boesen 2005 & Intervention was conducted after cancer treatment was completed. \\
\hline Burns 2008 & $\begin{array}{l}\text { No psychosocial intervention. Participants were educated about the use of music imagery and re- } \\
\text { laxation. Thus no feedback was given on their behaviour. }\end{array}$ \\
\hline Campbell 2005 & No psychosocial intervention. The emphasis was placed on exercise. \\
\hline Campbell 2007 & Intervention was conducted after cancer treatment was completed. \\
\hline Carlson 2005 & In this study there was no control or normal care group. \\
\hline Cimprich 1993 & Fatigue was not measured. \\
\hline Cimprich 2003 & Fatigue was not measured. \\
\hline Clark 2006 & $\begin{array}{l}\text { No psychosocial intervention. During the intervention participants listened to music, but no feed- } \\
\text { back was received on their behaviour. }\end{array}$ \\
\hline Cohen 2004 & Most participants $(71 \%)$ did not receive cancer treatment during the intervention. \\
\hline Courneya 2003 & Unclear if participants received cancer treatment during the intervention. \\
\hline Crooks 2004 & Participants were not randomised between the conditions. \\
\hline Culos-Reed 2006 & Intervention was conducted after cancer treatment was completed. \\
\hline Daley 2004 & Intervention was conducted after cancer treatment was completed. \\
\hline Dalton 2004 & Fatigue was not measured. \\
\hline Dimeo 1999 & No psychosocial intervention. The emphasis was placed on exercise. \\
\hline Dimeo 2004 & Intervention was conducted after cancer treatment was completed. \\
\hline Doorenbos 2005 & $\begin{array}{l}\text { Fatigue was mentioned as one of the symptoms. Results on the total number of symptoms were } \\
\text { described, and not separated for fatigue. }\end{array}$ \\
\hline Fawzy 1990 & Cancer participants undergoing treatment were excluded. \\
\hline Gielissen 2006 & The intervention was conducted after cancer treatment was completed. \\
\hline Given 2004 & $\begin{array}{l}\text { Fatigue was mentioned as one of the symptoms. Results on the total number of symptoms were } \\
\text { described, and not separated for fatigue. }\end{array}$ \\
\hline
\end{tabular}




\begin{tabular}{|c|c|}
\hline Study & Reason for exclusion \\
\hline Hack 2003 & Consultation was recorded and participants received an audiotape. \\
\hline Hanna 2008 & In this study there was no control or usual care group. \\
\hline Hoekstra 2006 & $\begin{array}{l}\text { No psychosocial intervention. This study evaluated a symptom monitor. Participants monitored } \\
\text { their symptoms, but no additional feedback on their behaviour was provided. }\end{array}$ \\
\hline Houborg 2006 & $\begin{array}{l}\text { Not only cancer participants were included (participants undergoing colorectal surgery also includ- } \\
\text { ed). }\end{array}$ \\
\hline Jacobsen 2002 & $\begin{array}{l}\text { No psychosocial intervention. This study evaluated two types of stress management consisting of } \\
\text { only one session. This intervention is not a systematic process. }\end{array}$ \\
\hline Kim 2002 & $\begin{array}{l}\text { No psychosocial intervention. In this intervention participants received tapes with information on } \\
\text { self-help. Thus feedback was lacking }\end{array}$ \\
\hline Kim 2005 & $\begin{array}{l}\text { No psychosocial intervention. In this intervention participants received tapes for exercise in bed } \\
\text { and relaxation breathing exercise, but there was no additional feedback. }\end{array}$ \\
\hline Korstjens 2008 & Intervention was conducted after cancer treatment was finished. \\
\hline Laidlaw 2005 & $\begin{array}{l}\text { Less than } 10 \text { participants for each condition ( } n=7 \text { self hypnosis group, } n=4 \text { Johrei group, } n=3 \text { con- } \\
\text { trol group). }\end{array}$ \\
\hline Lindemalm 2008 & Intervention was conducted after cancer treatment was finished. \\
\hline Mock 1994 & Less than 10 participants for each condition ( $n=9$ experimental group, $n=5$ control group). \\
\hline Ollenschlager 1992 & No psychosocial intervention. The emphasis was placed on changing nutritional behaviour. \\
\hline Ovesen 1993 & Fatigue was not measured. \\
\hline Oyama 2000 & $\begin{array}{l}\text { No psychosocial intervention. This study evaluated a Bedside wellness system, including aromatic } \\
\text { oil and virtual reality using sound systems. Thus feedback was lacking. }\end{array}$ \\
\hline Persson 2002 & $\begin{array}{l}\text { Four conditions were described, but participants were randomised between two of the four groups. } \\
\text { There was no control for these two groups.. }\end{array}$ \\
\hline Post-White 2003 & In this study there was no control or normal care group. \\
\hline Ravasco 2005 & No psychosocial intervention. The emphasis was placed on changing nutritional behaviour. \\
\hline Ravasco 2005a & No psychosocial intervention. The emphasis was placed on changing nutritional behaviour. \\
\hline Roscoe 2005 & $\begin{array}{l}\text { No psychosocial intervention. This study evaluated polarity, but feedback on their behaviour was } \\
\text { lacking. }\end{array}$ \\
\hline Savard 2005 & Intervention was conducted after cancer treatment was completed. \\
\hline Sherwood 2005 & $\begin{array}{l}\text { Fatigue was mentioned as one of the symptoms. Results on the total number of symptoms were } \\
\text { described, but was not separated for fatigue. }\end{array}$ \\
\hline Speca 2000 & Unclear if participants received cancer treatment during the intervention. \\
\hline Stanton 2005 & Intervention was conducted after cancer treatment was completed. \\
\hline
\end{tabular}




\begin{tabular}{ll}
\hline Study & Reason for exclusion \\
\hline Stiegelis 2004 & Intervention was conducted after cancer treatment was completed. \\
\hline Strong 2008 & Cancer patients with concurrent chemotherapy or radiotherapy were excluded. \\
\hline Telch 1986 & Unclear if participants received cancer treatment during the intervention. \\
\hline Vos 2004 & Unclear if participants received cancer treatment during the intervention. \\
\hline Wenzel 1995 & Unclear if participants received cancer treatment during the intervention. \\
\hline Williams 2004 & $\begin{array}{l}\text { No psychosocial intervention. In this intervention participants were educated using audiotapes. } \\
\text { Thus feedback was lacking. }\end{array}$ \\
\hline Williams 2005 & $\begin{array}{l}\text { No psychosocial intervention. In this intervention participants were educated using audiotapes. } \\
\text { Thus feedback was lacking. }\end{array}$ \\
\hline Wydra 2001 & $\begin{array}{l}\text { No psychosocial intervention. This intervention evaluated self-care management giving partici- } \\
\text { pants an interactive videodisc module, but received no feedback from a care provider. }\end{array}$ \\
\hline
\end{tabular}

Characteristics of ongoing studies [ordered by study ID]

\section{Cohen 2004a}

Trial name or title

Mindfulness relaxation compared with relaxing music and standard symptom management education in treating patients who are undergoing chemotherapy for newly diagnosed solid tumors.

Methods

Randomized phase: Patients are randomized to 1 of 3 treatment arms; Arm I: Patients undergo mindfulness relaxation therapy (MR); Arm II: Patients listen to relaxing music; Arm III: Patients receive standard symptom management education. Nausea and vomiting, mental health (anxiety, depression, and distress), and quality of life (cancer-related symptoms, fatigue, sleep, and pain) are assessed at baseline, in the middle of chemotherapy (course 2 of a 4-course chemotherapy protocol OR course 3 of a 6-course chemotherapy protocol), at the end of treatment, and then at 3 months.

Participants Patients who are undergoing chemotherapy for newly diagnosed solid tumors.

Interventions

Arm I: Patients undergo mindfulness relaxation (MR) therapy comprising listening to instructions on breathing techniques and other mind and body relaxation practices on compact disc for $30 \mathrm{~min}$ utes before and during each chemotherapy session and at least once daily for the entire duration of chemotherapy treatment.

Arm II: Patients listen to relaxing music (with no instructions on relaxation techniques) for $30 \mathrm{~min}$ utes before and during each chemotherapy session and at least once daily for the entire duration of chemotherapy treatment.

Arm III: Patients receive standard symptom management education.

\begin{tabular}{ll}
\hline Outcomes & Conditioned nausea and vomiting as measured by Morrow assessment of nausea and emesis \\
(MANE); Distress as measured by Impact of Event Scale (IES); Fatigue as measured by brief fatigue \\
inventory (BFI); Anxiety as measured by Spielberger State/Trait Anxiety Scale (STAI); Depression as \\
measured by Center for Epidemiology-Depression (CES-D); Sleep as measured by Pittsburgh Sleep \\
Quality Index (PSQI); Pain as measured by brief pain inventory (BPI); Quality of life as measured by \\
Functional Assessment of Cancer Therapy.
\end{tabular}


Cohen 2004a (Continued)

Contact information

Lorenzo Cohen: U.T.M.D. Anderson Cancer Center USA

\section{Notes}

\section{Cohen 2006}

Trial name or title

Evaluation of the effect of cognitive behavior intervention on psychological distress of cancer patients and their family members.

\section{Methods}

Study Design: Randomized, Active Control Study.

Questionnaires will be answered by the participants pre-, post-intervention and after four months.

\begin{tabular}{ll}
\hline Participants & Cancer patients. \\
\hline Interventions & Cognitive behavior group intervention. \\
\hline Outcomes & $\begin{array}{l}\text { Brief Symptom Inventory, Fatigue inventory, Mini Sleep Questionnaire and repression-sensitization } \\
\text { questionnaire. }\end{array}$ \\
\hline Starting date & July 2006 \\
\hline Contact information & cohenm@research.haifa.ac.il \\
\hline Notes & \\
\hline
\end{tabular}

\section{Cohen 2007 a}

\begin{tabular}{ll} 
Trial name or title & Effects of Tibetan yoga on fatigue and sleep in cancer. \\
\hline Methods & Participants are randomly assigned to three groups: a Tibetan Yoga (TY) group; stretching group \\
(SG); or a usual care group (UC). Measures will be obtained prior to randomization and 1 week, 1 \\
month, 6 months, and 12 months, after the last intervention session.
\end{tabular}

\begin{tabular}{ll}
\hline Participants & Women with breast cancer undergoing chemotherapy. \\
\hline Interventions & $\begin{array}{l}\text { Participants in the TY and SG groups will participate in seven weekly group sessions (60 minutes) or } \\
4 \text { sessions every } 3 \text { weeks ( } 90 \text { minutes). } \\
\text { TY: Deep breathing exercises and performing different stretching and movement exercises. } \\
\text { SG: Simple stretching exercises. }\end{array}$ \\
\hline Outcomes & Fatigue and sleep disturbances. \\
\hline Starting date & November 2006 \\
\hline Contact information & Lorenzo Cohen: U.T.M.D. Anderson Cancer Center USA \\
\hline
\end{tabular}

Notes 
Cohen 2007b

\begin{tabular}{ll} 
Trial name or title & Effects of yoga in breast cancer patients. \\
\hline Methods & $\begin{array}{l}\text { Participants are randomly assigned to three groups: a Yoga group (YG) group; stretching group } \\
\text { (ST); or a waitlist control group (WL). Measures will be obtained prior to randomization, a brief as- } \\
\text { sessment during the middle of radiation therapy, during the last week of radiation therapy and } 1 \\
\text { month, } 3 \text { months, and } 6 \text { months, after the last radiation session. }\end{array}$
\end{tabular}

\begin{tabular}{ll}
\hline Participants & Women with breast cancer undergoing radiotherapy. \\
\hline Interventions & $\begin{array}{l}\text { Participants in the YG and ST groups will attend three sessions (60 minutes) each week throughout } \\
\text { their 6-week radiotherapy schedule. TY: Deep breathing exercises and performing different move- } \\
\text { ments and meditation. }\end{array}$
\end{tabular}

SG: Simple stretching exercises.

\begin{tabular}{ll}
\hline Outcomes & Fatigue and sleep disturbances (self-report and actigraphy). \\
\hline Starting date & March 2006 \\
\hline Contact information & Lorenzo Cohen: U.T.M.D. Anderson Cancer Center USA \\
\hline Notes & \\
\hline
\end{tabular}

Goedendorp 2005

Trial name or title $\quad$ Evaluation of intervention strategies to manage fatigue during active treatment and to prevent per-
sistent fatigue after curative treatment for cancer.

Methods $\quad$ Participants are randomly assigned to three groups: the minimal intervention; the CBT intervention; and a usual care group. Patients will be assessed before cancer treatment (TO), shortly after cancer treatment (at least 6 months after baseline) (T1), and one year after T1.

Participants

Patients just have been diagnosed for breast cancer, colorectal cancer, cervix cancer, uterus cancer, testis cancer, Hodgkin and non-Hodgkin disease. Patients in preparation of receiving therapy with curative intention.

Interventions

1) The nursing intervention consists of a booklet with easily understood general information about two components. In two one hour session the research nurse will explain the booklet and help the patient to applicate this to their situation. General information about fatigue during active treatment will be given. The second component consists of physical activity instructions. In the second session also the adherence of the patients to the instructions will be discussed.

2) CBT condition will also get and discuss the booklet given in the minimal intervention condition. Additional they get individual treatment that consists of 10 sessions with a psychotherapist of the Expert Centre Chronic Fatigue in about six months. Patients will; learn to cope with emotions evoked by having a life-threatening disease; be thought how to get a more regular sleep/wake cycle; learn to regulate activities; learn to regulate support of others, emotionally or instrumentally; engaging in activities that give mental rest and relief; integrate the learned way of thinking and behaving in daily life.

\begin{tabular}{ll}
\hline Outcomes & Fatigue severity will be measured using the Checklist Individual Strength. \\
\hline Starting date & $1-11-2005$ \\
\hline Contact information & m.goedendorp@nkcv.umcn.nl; g.bleijenberg@nkcv.umcn.nl \\
\hline
\end{tabular}


Goedendorp 2005 (Continued)

Notes

Oh 2008b

Trial name or title Randomized Clinical Trial: The impact of medical qigong (traditional Chinese medicine) on fatigue, quality of life, side effects, mood status and inflammation of cancer patients.

Participants are randomly assigned to two groups: a control group that receive usual health care
and an intervention group who participate in a Medical Qigong (MQ) program in addition to receiv-
ing usual health care at the hospital. Randomisation was stratified by completion of cancer treat-
ment or under active cancer treatment. Patients completed measures before and after the pro-
gram.

Participants Patients diagnosed with a range of cancers.

\begin{tabular}{ll}
\hline Interventions & $\begin{array}{l}\text { The } 10 \text { week MQ program consists of, coordination of gentle exercise and relaxation through medi- } \\
\text { tation and breathing exercise based on the Chinese Medicine theory of energy channels. }\end{array}$ \\
\hline Outcomes & $\begin{array}{l}\text { Cancer related fatigue was measured by FACT-F, quality of life and symptoms were measured by } \\
\text { the FACT-G, mood status by POMS. The inflammatory marker serum C-reactive protein (CRP) was } \\
\text { also monitored serially. }\end{array}$ \\
\hline Starting date & Unclear. In September 2008 almost 162 participants were recruited. \\
\hline Contact information & byeongsangoh@health.usyd.edu.au \\
\hline Notes & An abstract can be found at the American Society of Clinical Oncology: 08-AB-32678-ASCOAM \\
\hline
\end{tabular}

\section{Purcell 2008} $\begin{array}{ll}\text { Trial name or title } & \begin{array}{l}\text { A randomised control trial investigating the effects of group education and support in reducing } \\ \text { cancer-related fatigue and improving quality of life in patients undergoing radiotherapy. }\end{array}\end{array}$

Methods

Patients will be randomised into one of four group using a $2 \times 2$ factorial design. These groups will attend a fatigue education and support (FES) group either once at the start of treatment, once at the end of treatment or twice at both the start and end of treatment. These three interventions will be compared to a control group who receive standard care (no FES group). Patients will be assessed at three time points; once at the start of treatment, once at the end of treatment, and once six weeks after the completion of treatment.

\begin{tabular}{ll}
\hline Participants & Patients diagnosed with a range of cancers. \\
\hline Interventions & $\begin{array}{l}\text { Participants receive education about radiotherapy process, what to expect from treatment, side ef- } \\
\text { fects and strategies to use to minimise side effects. }\end{array}$ \\
\hline Outcomes & Fatigue using the Multidimensional Fatigue Inventory. \\
\hline Starting date & 01-04-2008 \\
\hline Contact information & Amanda_purcell@health.qld.gov.au \\
\hline Notes & \\
\hline
\end{tabular}


Savard 2008

\begin{tabular}{ll} 
Trial name or title & Self-Help treatment for insomnia in breast cancer patients. \\
\hline Methods & $\begin{array}{l}\text { Study Design: Randomized, Active Control Study with three study arms: two forms of cognitive-be } \\
\text { havioral therapy (CBT) and a the control condition (i.e., usual care). Timeframe: pre-treatment, } \\
\text { post-treatment, } 4 \text { follow-up. }\end{array}$ \\
\hline Participants & Cancer patients. \\
\hline Interventions & $\begin{array}{l}\text { 1: professionally administered cognitive-behavioral therapy, consisting of six weekly sessions. } \\
\text { 2: self-administered form of cognitive behavioral therapy, consisting of six short booklets and } \\
\text { videotapes. }\end{array}$
\end{tabular}

Outcomes sleep diary indices, actigraphy, Insomnia Severity Index.

\begin{tabular}{ll}
\hline Starting date & April 2008 \\
\hline Contact information & josee.savard@psy.ulaval.ca; julie.villa@crhdq.ulaval.ca \\
\hline
\end{tabular}

Notes

\section{ADDITIONAL TABLES}

\section{Table 1. Outcomes}

\begin{tabular}{|c|c|c|}
\hline Author and year & Instruments used to measure fatigue & $\begin{array}{l}\text { number of instru- } \\
\text { ments used to } \\
\text { measure fatigue }\end{array}$ \\
\hline Armes 2007 & $\begin{array}{l}\text { Visual Analogue Scale (VAS-f) of global fatigue. European Organisation for Research and } \\
\text { Treatment of Cancer Quality of Life Questionnaire C30 (EORTC QLQ-C30), sub-scale fa- } \\
\text { tigue. Multidimensional Fatigue Inventory (MFI). }\end{array}$ & 3 \\
\hline Barsevick 2004 & $\begin{array}{l}\text { Short Form of the Profile of Mood States (POMS), sub-scale Fatigue. Schwartz Cancer Fa- } \\
\text { tigue Scale (SCFS). General Fatigue Scale (GFS). }\end{array}$ & 3 \\
\hline Berglund 2007 & $\begin{array}{l}\text { European Organisation for Research and Treatment of Cancer Quality of Life Question- } \\
\text { naire C30 (EORTC QLQ-C30), sub-scale fatigue. }\end{array}$ & 1 \\
\hline Brown 2006 & $\begin{array}{l}\text { Single item Linear Analogue Self Assessment (LASA). Profile of Mood States (POMS), Fa- } \\
\text { tigue-Inertia sub-scale. STAl question } 26 \text {, Symptom Distress Scale (SDS) fatigue question. }\end{array}$ & 4 \\
\hline Classen 2001 & Profile of Mood States (POMS), Fatigue-Inertia sub-scale. & 1 \\
\hline Cohen 2007 & Fatigue Symptom Inventory (FSI). & 1 \\
\hline Cunningham 1989 & Profile of Mood States (POMS), Fatigue-Inertia sub-scale. & 1 \\
\hline Decker 1992 & Profile of Mood States (POMS), Fatigue-Inertia sub-scale. & 1 \\
\hline de Moor 2002 & Profile of Mood States (POMS), Fatigue-Inertia sub-scale. & 1 \\
\hline
\end{tabular}




\section{Table 1. Outcomes (Continued)}
de Wit 1997
European Organisation for Research and Treatment of Cancer Quality of Life Question-
1 naire C30 (EORTC QLQ-C30), sub-scale fatigue.

\begin{tabular}{|c|c|c|}
\hline Edelman 1999 & Profile of Mood States (POMS), Fatigue-Inertia sub-scale. & 1 \\
\hline Faithfull 2001 & $\begin{array}{l}\text { Visual Analogue Scale (VAS). European Organisation for Research and Treatment of Can- } \\
\text { cer Quality of Life Questionnaire C30 (EORTC QLQ-C30), sub-scale fatigue. }\end{array}$ & 2 \\
\hline Fawzy 1995 & Profile of Mood States (POMS), Fatigue-Inertia sub-scale. & 1 \\
\hline Forester 1985 & Schedule of Affective Disorders and Schizophrenia (SADS), item Fatigue. & 1 \\
\hline $\begin{array}{l}\text { Gaston-Johans- } \\
\text { son } 2000\end{array}$ & Visual Analogue Scale (VAS). & 1 \\
\hline Given 2002 & Symptom Experience Scale (SES), item Fatigue. & 1 \\
\hline Godino 2006 & Functional Assessment of Cancer Therapy Fatigue (FACT-F). & 1 \\
\hline Goodwin 2001 & $\begin{array}{l}\text { Profile of Mood States (POMS), Fatigue-Inertia sub-scale. European Organisation for Re- } \\
\text { search and Treatment of Cancer Quality of Life Questionnaire C30 (EORTC QLQ-C30), sub- } \\
\text { scale fatigue. }\end{array}$ & 2 \\
\hline Moadel 2007 & Functional Assessment of Chronic Ilness Therapy - Fatigue (FACIT-F). & 1 \\
\hline Oh 2008 & $\begin{array}{l}\text { European Organisation for Research and Treatment of Cancer Quality of Life Question- } \\
\text { naire C30 (EORTC QLQ-C30), sub-scale fatigue. }\end{array}$ & 1 \\
\hline Rawl 2002 & SF-36 Vitality. & 1 \\
\hline Ream 2006 & Visual Analogue Scale (VAS), SF-36 sub-scale vitality. & 2 \\
\hline Sandgren 2000 & Profile of Mood States (POMS), Fatigue sub-scale. & 1 \\
\hline Sandgren 2003 & Profile of Mood States (POMS), Fatigue-Inertia sub-scale. & 1 \\
\hline Savard 2006 & Multidimensional Fatigue Inventory (MFI). & 1 \\
\hline Spiegel 1981 & Profile of Mood States (POMS), Fatigue sub-scale. & 1 \\
\hline Yates 2005 & $\begin{array}{l}\text { Revised Piper Fatigue Scale (PFS). Functional Assessment of Cancer Therapy Fatigue } \\
\text { (FACT-F). Four 11-point numeric fatigue rating scales (NFRS) assessing levels of fatigue at } \\
\text { worst, best, and average in the past week, and currently. }\end{array}$ & 6 \\
\hline
\end{tabular}




\begin{tabular}{|c|c|c|c|c|c|c|c|c|}
\hline Scales & $\begin{array}{l}\text { Armes } \\
2007\end{array}$ & $\begin{array}{l}\text { Barsevick } \\
2004\end{array}$ & $\begin{array}{l}\text { Berglund } \\
2007\end{array}$ & $\begin{array}{l}\text { Brown } \\
2006\end{array}$ & $\begin{array}{l}\text { Classen } \\
2001\end{array}$ & $\begin{array}{l}\text { Cohen } \\
2007\end{array}$ & $\begin{array}{l}\text { Cunning- } \\
\text { ham } 1989\end{array}$ & $\begin{array}{l}\text { Decker } \\
1992\end{array}$ \\
\hline randomisation & 1 & 1 & 1 & 1 & 1 & 1 & 1 & 1 \\
\hline concealment of allocation & 0 & 0 & 0 & 0 & 0 & 0 & 0 & 0 \\
\hline blinded outcome assessor & 0 & 0 & 0 & 0 & 0 & 1 & 0 & 1 \\
\hline power calculation & 1 & 0 & 0 & 0 & 0 & 0 & 0 & 0 \\
\hline intention to treat & 0 & 1 & 0 & 0 & 0 & 0 & 0 & 0 \\
\hline group similarity at baseline & 0 & 1 & 1 & 0 & 1 & 1 & 1 & 0 \\
\hline specified eligibility criteria & 1 & 1 & 1 & 1 & 1 & 1 & 0 & 1 \\
\hline drop-out & 1 & 0 & 1 & 0 & 1 & 0 & 1 & 0 \\
\hline selective lost to follow-up & 0 & 1 & 0 & 0 & 0 & 0 & 0 & 1 \\
\hline co-intervention avoided & 1 & 1 & 1 & 1 & 1 & 1 & 1 & 1 \\
\hline compliance & 1 & 1 & 0 & 1 & 1 & 1 & 0 & 0 \\
\hline relevant measures & 1 & 1 & 1 & 1 & 1 & 1 & 1 & 1 \\
\hline timing assessments & 1 & 1 & 0 & 1 & 1 & 0 & 0 & 1 \\
\hline equally treatment & 1 & 1 & 1 & 0 & 1 & 1 & 1 & 1 \\
\hline contamination & 0 & 0 & 0 & 0 & 0 & 0 & 1 & 0 \\
\hline protocol & 1 & 1 & 0 & 1 & 1 & 1 & 1 & 1 \\
\hline training & 1 & 1 & 0 & 1 & 0 & 0 & 0 & 0 \\
\hline integrity check & 1 & 1 & 0 & 0 & 0 & 0 & 0 & 0 \\
\hline adverse effects & 0 & 0 & 0 & 0 & 0 & 0 & 0 & 0 \\
\hline sample size & 1 & 0 & 0 & 0 & 1 & 1 & 1 & 0 \\
\hline
\end{tabular}




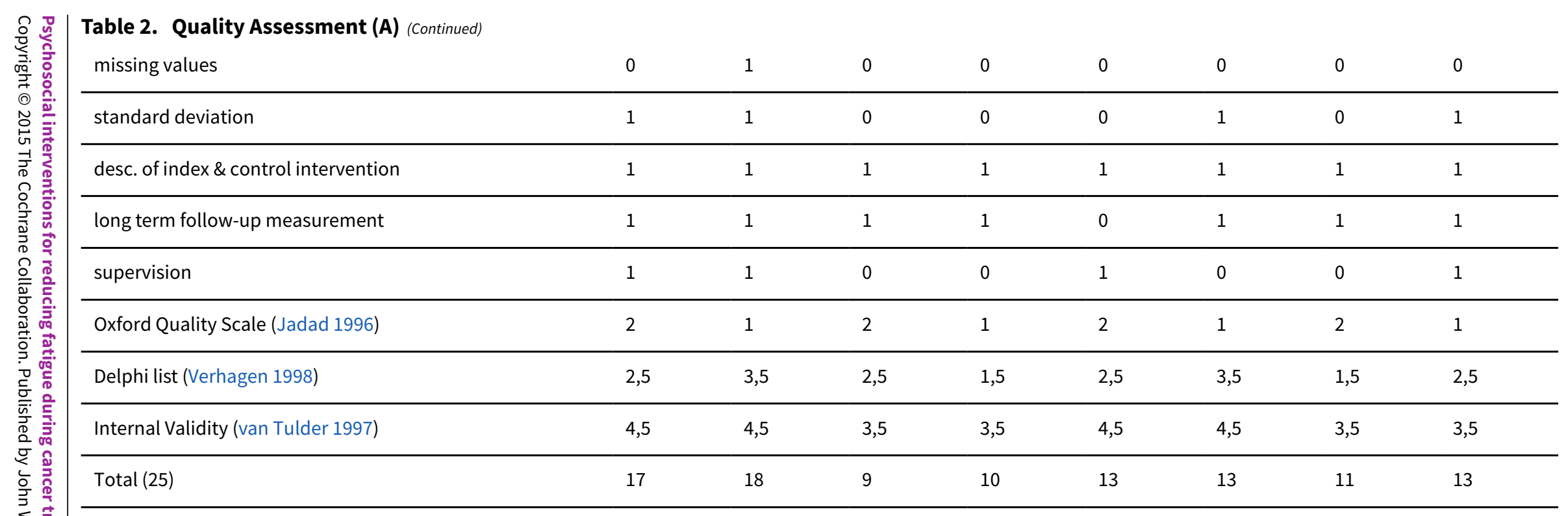

Oxford Quality Scale (Jadad 1996): randomisation, concealed allocation, drop-out (0-3).

Delphi list (Verhagen 1998): randomisation (0,5 points), concealed allocation (0,5 points), blinded outcome assessor, power calculation, intention to treat, group similarity at baseline, specified eligibility criteria (0-6).

Internal validity (van Tulder 1997): randomisation, concealed allocation, blinded outcome assessor, intention to treat, drop-out, co-intervention avoided, compliance, timing assessments. $(0-8)$

Yes $=1, \mathrm{No}=0$, Not enough information to answer this question $=0$

desc. $=$ description

\section{Table 3. Quality Assessment (B)}

\begin{tabular}{|c|c|c|c|c|c|c|c|c|c|}
\hline Scales & $\begin{array}{l}\text { de Moor } \\
2002\end{array}$ & $\begin{array}{l}\text { de Wit } \\
1997\end{array}$ & $\begin{array}{l}\text { Edelman } \\
1999\end{array}$ & $\begin{array}{l}\text { Faithfull } \\
2001\end{array}$ & $\begin{array}{l}\text { Fawzy } \\
1995\end{array}$ & $\begin{array}{l}\text { Forester } \\
1985\end{array}$ & $\begin{array}{l}\text { Gas- } \\
\text { ton-Jo- } \\
\text { hansson } \\
2000\end{array}$ & $\begin{array}{l}\text { Given } \\
2002\end{array}$ & $\begin{array}{l}\text { Godino } \\
2006\end{array}$ \\
\hline randomisation & 1 & 1 & 1 & 1 & 1 & 1 & 1 & 1 & 1 \\
\hline concealment of allocation & 0 & 0 & 0 & 0 & 0 & 0 & 0 & 0 & 0 \\
\hline power calculation & 0 & 0 & 0 & 1 & 0 & 0 & 1 & 0 & 0 \\
\hline
\end{tabular}




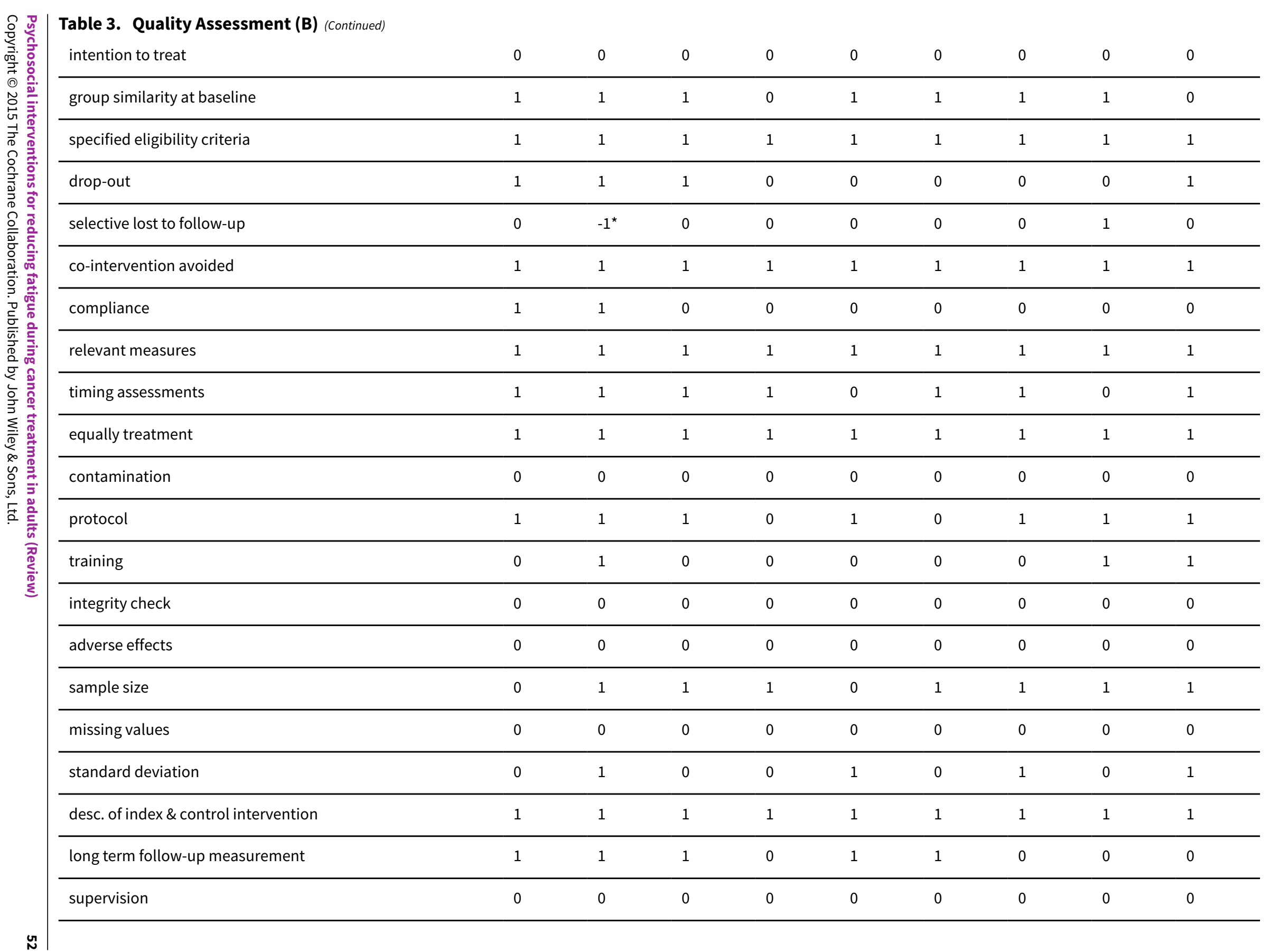




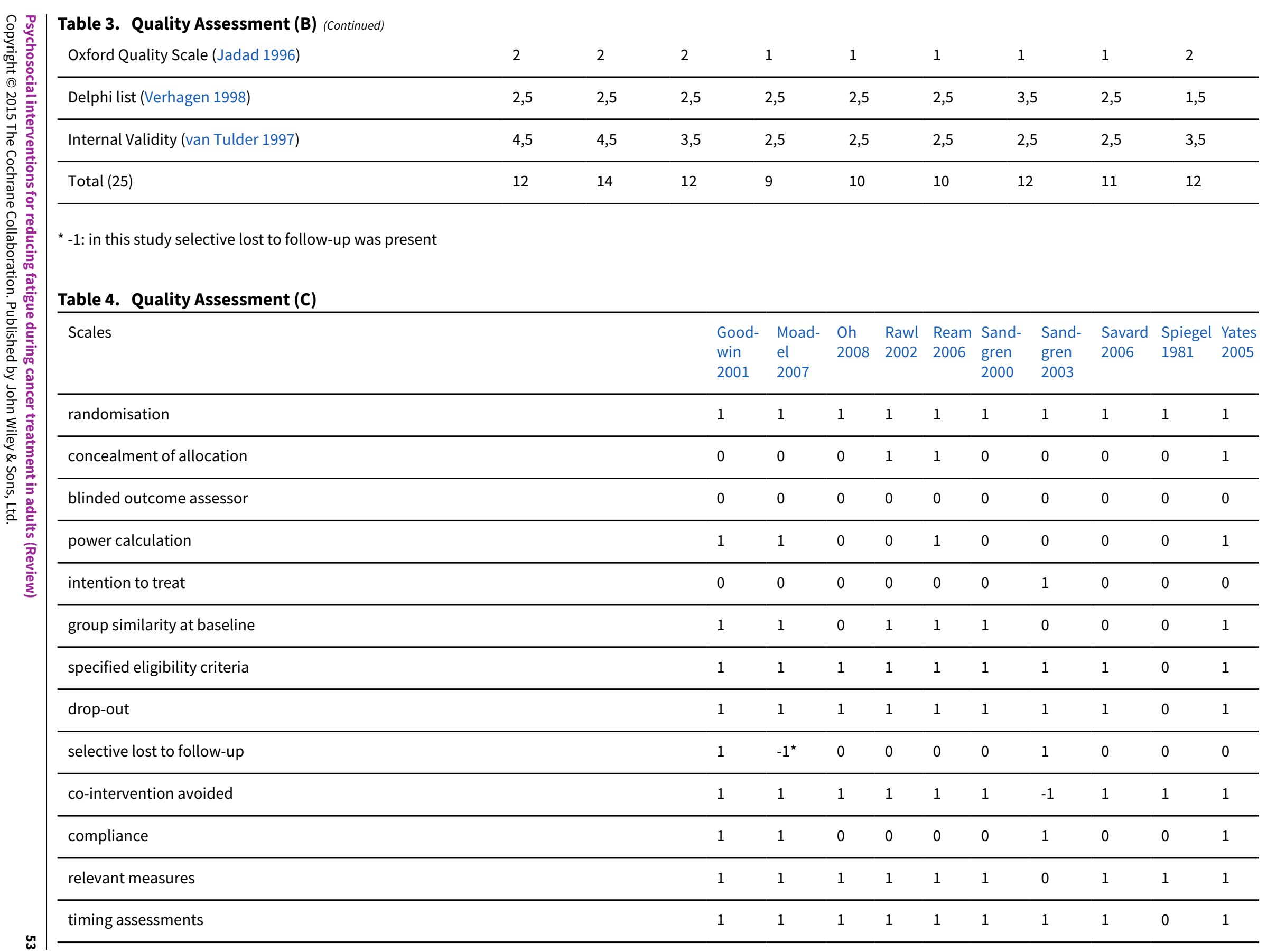




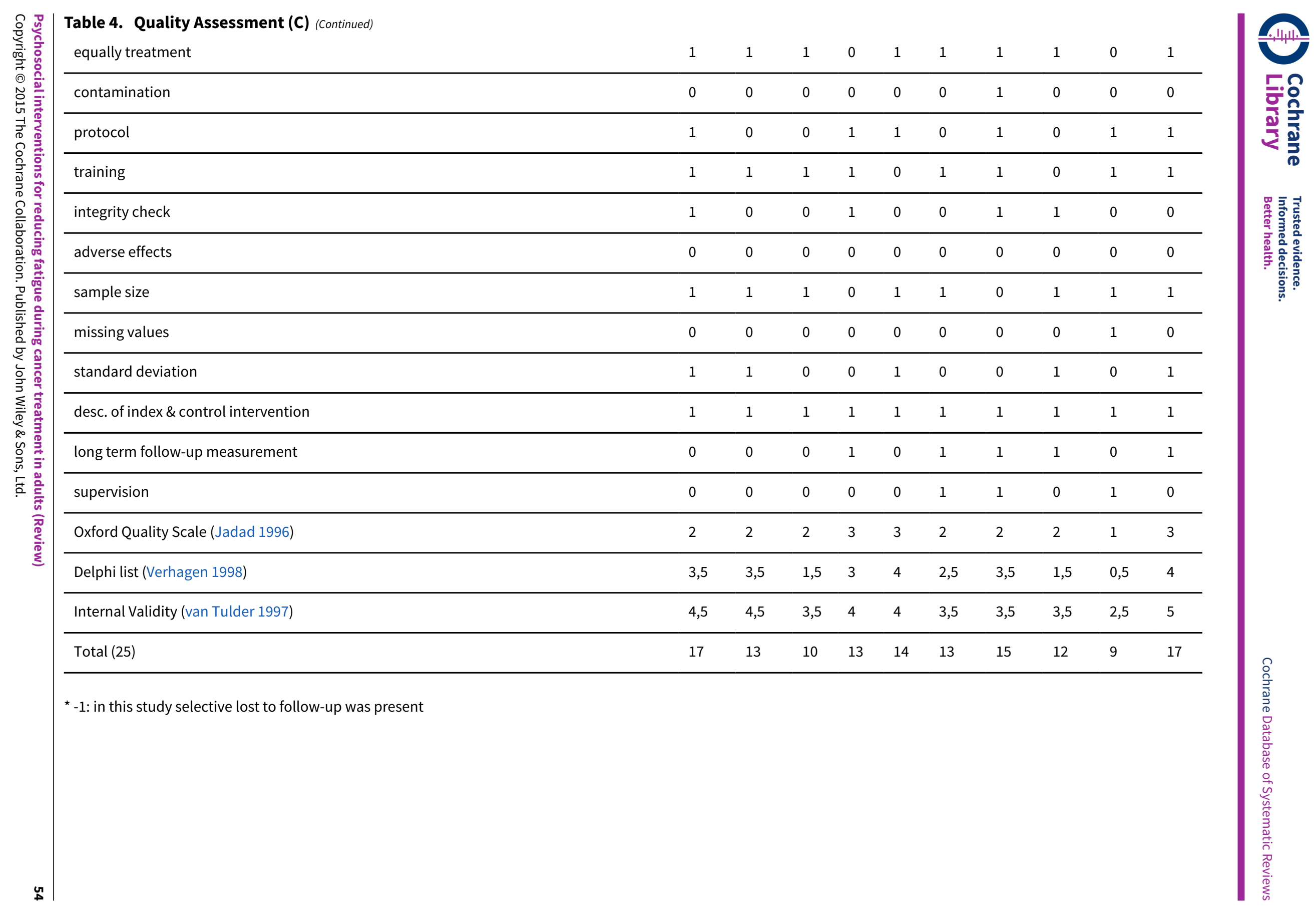




\section{APPENDICES}

\section{Appendix 1. MEDLINE search strategy}

MEDLINE (via OVID)

1. ExP NEOPLASMS

2. BONE MARROW TRANSPLANTATION

3. Exp STEM CELL TRANSPLANTATION

4. (neoplas\$ or cancer\$ or carcinoma\$ or tumour\$ or adenocarcinoma or leukemi\$ or leukaemia or lymphoma\$ or tumor\$ or malignan \$ or melanoma or sarcoma\$ or "bone marrow transplant\$" or "stem cell transplant\$")

5. OR/1-4

6. FATIGUE/

7. (fatigue\$ or asthenia or asthenic or astheni\$)

8. (exhaustion or exhausted)

9. ((loss adj4 energy) or (loss adj4 vitality))

10. (weary or weariness or weakness)

11. (apathy or apathetic or lassitude or lethargic or lethargy)

12. (sleepy or sleepiness or drowsy or drowsiness)

13. (tired or tiredness)

14. OR/6-13

15. EXP PSYCHOLOGY, SOCIAL/

16. Exp PSYCHOTHERAPY/

17. (psychosocial\$ or psycho-social\$)

18. (counsel\$ or (behaviour $\$$ adj4 therap\$) or "autogenic training" or (behavior $\$$ adj4 therap\$) or (relax\$ adj4 therap\$) or (relax\$ adj4 treatment\$) or (support\$ adj4 group\$) or imagery or "energy conservation" or "stress management" or psychotherapy\$ or "self care" or "self help" or biofeedback or educati\$ or psychoeducat\$ or relaxation therap\$ or "nursing intervention" or "nursing support")

19. OR/15-18

20. randomized controlled trial.pt.

21. controlled clinical trial.pt.

22. randomized controlled trials.sh.

23. random allocation.sh.

24. double blind method.sh.

25. single blind method.sh.

26. or/1-6

27. (ANIMALS not HUMANS).sh.

28. 7 not 8

29. clinical trial.pt.

30. Exp CLINICAL TRIALS

31. (clin\$ adj25 trial\$).ti,ab.

32. ((singl\$ or doubl\$ or trebl\$ or tripl\$) adj25 (blind\$ or mask\$)).ti,ab.

33. placebos.sh.

34. placebo\$.ti,ab.

35. random $\$ . t i, a b$.

36. research design.sh.

37. or $/ 10-17$

38. 18 not 8

39. 19 not 9

40.9 or 19

41. 5 AND 14 AND 19 AND 40

WHAT' S NEW

Date Event Description

31 March $2015 \quad$ Review declared as stable

This review will be superseded by a new protocol. Anticipated publication 2015. 


\section{CONTRIBUTIONS OF AUTHORS}

Draft the protocol, develop the search strategy, search for trials, obtain copies of trials: M Goedendorp, M Gielissen, G Bleijenberg Select which trials to include: M Goedendorp, G Bleijenberg, C Verhagen

Extract data from trials: M Goedendorp, M Gielissen

Enter data into RevMan: M Goedendorp, G Bleijenberg

Carry out the analysis: M Goedendorp

Interpret the analysis: M Goedendorp, M Gielissen, G Bleijenberg and researchers of the 'Expert Centre for Chronic Fatigue' Draft the final review: $M$ Goedendorp, $M$ Gielissen, $G$ Bleijenberg

Update the review: M Goedendorp, M Gielissen, G Bleijenberg

\section{DECLARATIONS OF INTEREST}

None known

\section{SOURCES OF SUPPORT}

\section{Internal sources}

- Nijmeegs Kenniscentrum Chronische Vermoeidheid (Expert Centre for Chronic Fatigue), Netherlands.

\section{External sources}

- The Dutch Cancer Society, Netherlands.

\section{N DEX TERMS}

\section{Medical Subject Headings (MeSH)}

Fatigue [etiology] [ ${ }^{\star}$ therapy]; Mind-Body Therapies [ ${ }^{\star}$ methods]; Neoplasms [complications] [*therapy]; Psychotherapy [ ${ }^{\star}$ methods]; Randomized Controlled Trials as Topic

\section{MeSH check words}

Female; Humans; Male 